\title{
DESENVOLVIMENTO DE UM SISTEMA DE MONITORAMENTO E SUPERVISÃO PARA O PROCESSO DE TORNEAMENTO
}

\author{
Eng. Fábio Ferraz Júnior
}

Dissertação apresentada à Escola de Engenharia de São Carlos da Universidade de São Paulo, como parte dos requisitos para a obtenção do título de Mestre em Engenharia Mecânica.

ORIENTADOR: Prof. Dr. Reginaldo Teixeira Coelho

São Carlos

2002 


\section{EPÍGRAFE}

\section{Exigência}

Não pense mal de mim.

A minha luta, o meu esforço...

Aquilo por que mais torço,

é uma batalha sem fim.

Não pense que idealizo

Para nós a perfeição.

Mas brigo por isso, antemão,

Sabendo que não realizo.

A vida é luta constante.

$E$ se o querer-subir não vem,

A decadência intervém,

E leva a todos rasante.

Por isso brado com gosto,

- Para ficarmos no meio -

Querendo, com todo anseio,

$\mathrm{O}$ idealismo proposto.

Fábio Ferraz

( "Exigência", pág. 23 do livro "Mente Corpo Coração" ) 
Aos meus pais, Fábio e Antonia, e irmãos, Fabrício, Lúcio e Jéssica, - fonte de inspiração e conforto, exemplo de dignidade e amor dedico este trabalho. 


\section{AGRADECIMENTOS}

À Deus - razão de toda a existência, fonte de esperança e amor -, por ter me guiado para alcançar mais esta graça.

Ao professor Reginaldo Teixeira Coelho, pela confiança, pela excelente orientação, pela amizade e paciência.

À Fundação de Amparo à Pesquisa do Estado de São Paulo (FAPESP), pelo apoio financeiro.

À "família" OPF (Laboratório de Otimização de Processsos de Fabricação), João Fernando (Muringa), Irene, Aldo (Fiotão), Alexandre (PE), Américo, Carlos Elias (Véio), Carlos Magno (Dinho Purga), Douglas, Eraldo, Giuliano (Zóio Maluco), Guilherme (46), Jalon, João Jorge, Leonardo (LP), Marcelo Biffi (Tora Biffi), Marcelo (Marcelinho), Milton (Miltinho), Otaviano (Baiano), Paulo (Paulinho), Ricardo (Bob), Roger (Guaraná), Ronaldo (Fiote), Vinicius, pelo apoio, convivência e momentos de descontração.

Aos amigos da turma de Eng. Mecânica (EESC/USP - 1995), em especial à Carlos Milhor (Carlão) e Evandro Fockink (Gargamel), pelo apoio e conselhos.

A todos os funcionários do Departamento de Engenharia Mecânica da EESC-USP, pela cooperação direta ou indireta.

À Elipse Softwares, pela doação do software SCADA Elipse 2.20.

Aos colegas engenheiros Rogério Frateschi (Magrão) e Ricardo Bambozzi Marchesan, da SIEMENS, pelo apoio técnico e amizade. 


\section{SUMÁRIO}

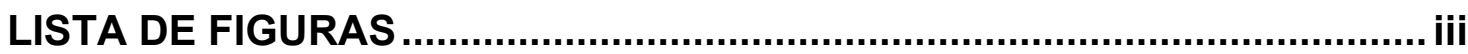

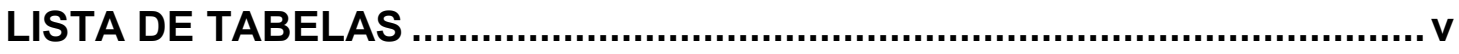

LISTA DE ABREVIATURAS E SIGLAS .................................................. vi

LISTA DE SÍMBOLOS ................................................................................ viii

RESUMO

ABSTRACT

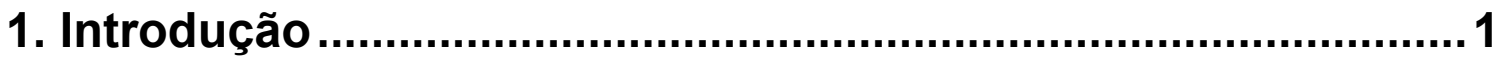

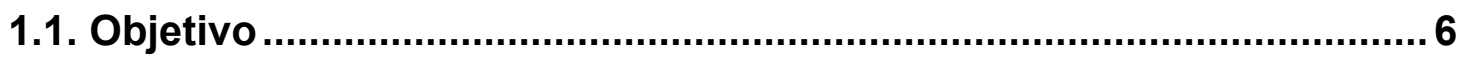

1.2. Estrutura da Dissertação .....................................................................

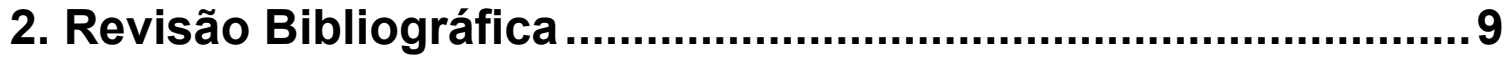

2.1. Logística e Gestão da Cadeia de Suprimentos...................................... 9

2.1.1.Supply Chain (Cadeia de Suprimentos) ............................................................

2.1.2.Supply Chain Management (Gestão da Cadeia de Suprimentos) ..........................10

2.1.3. Logística.............................................................................................................. 10

2.2. Processos de Usinagem e Monitoramento ……..................................11

2.2.1. Fenomenologia do Processo de Torneamento..................................................11

2.2.2. Principais Problemas....................................................................................... 14

2.2.3. Sistemas de Monitoramento e Controle do Processo de Usinagem.....................18

2.3. Sistemas de Supervisão e Controle de Processos .............................. 23

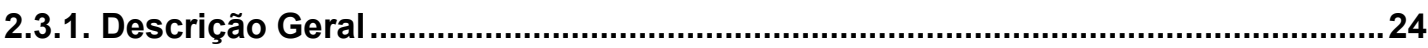

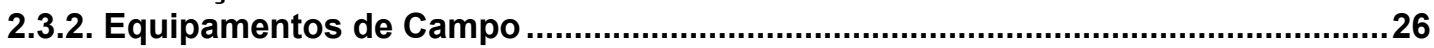

2.3.3. Redes de Comunicação.....................................................................................29

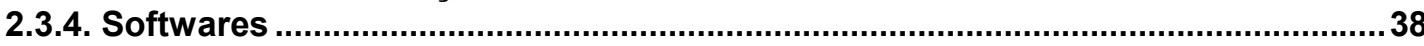

3. Sistema de Supervisão e Monitoramento Proposto..................42

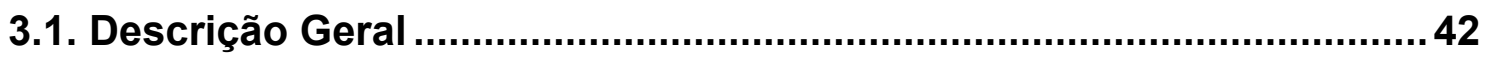

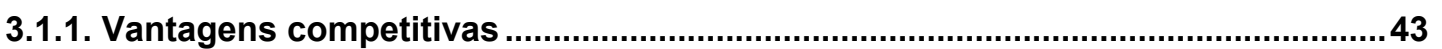

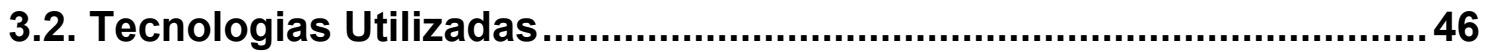

3.2.1. CNC de Arquitetura Aberta ........................................................................ 48

3.2.2. Rede Ethernet ................................................................................................. 48

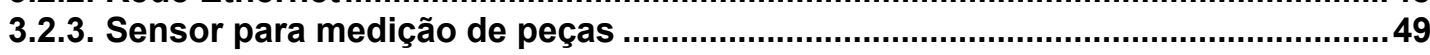




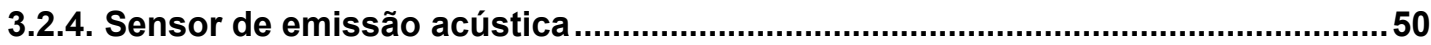

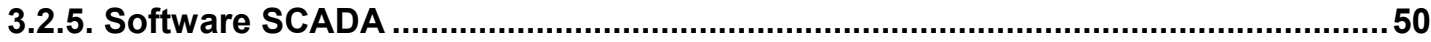

3.2.6. Software de Aquisição e Manipulação de Dados (LabView) ...............................52

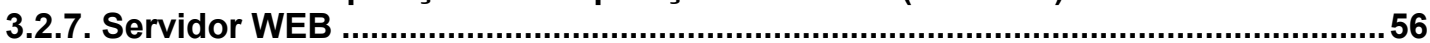

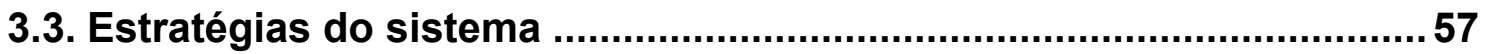

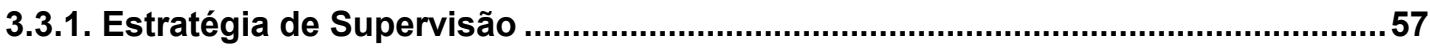

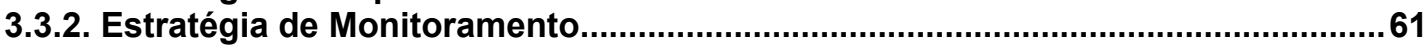

4. Avaliação do Sistema Proposto...............................................64

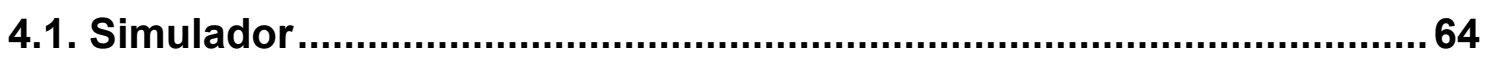

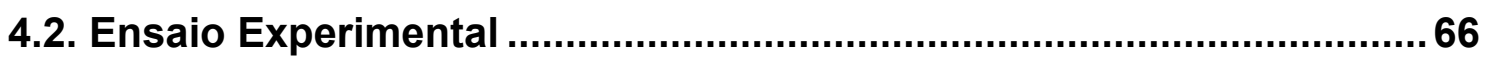

5. Resultados e discussões.......................................................69

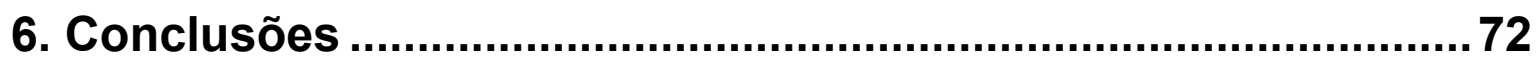

7. Sugestões para trabalhos futuros ...........................................73

ANEXO

REFERÊNCIAS BIBLIOGRÁFICAS .........................................75

Referências Citadas .......................................................................... 75

Referências Consultadas................................................................... 78 


\section{LISTA DE FIGURAS}

FIGURA 1.1 - Modelo de um sistema de manufatura. AGOSTINHO (1996)-modificado ….... 3

FIGURA 1.2 - Exemplo de integração de uma empresa com cadeia logística global ............. 5

FIGURA 2.1 - Esquema de um Supply Chain .............................................................. 9

FIGURA 2.2 - Esquema de cadeias logísticas internas e global...................................... 11

FIGURA 2.3 - Exemplo de um torneamento. DINIZ et al (1999) - modificado ....................... 11

FIGURA 2.4 - Torneamento Cilíndrico. FERRARESI (1990) ............................................ 13

FIGURA 2.5 - Torneamento Cônico. FERRARESI (1990) ……...................................... 13

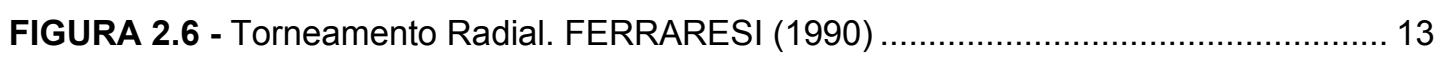

FIGURA 2.7 - Torneamento Curvelinio. FERRARESI (1990) …..................................... 14

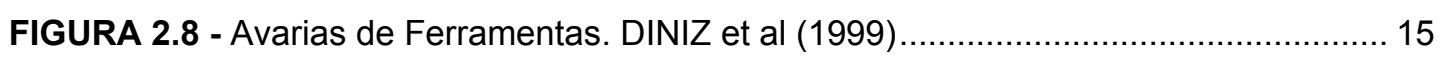

FIGURA 2.9 - Desgastes de Ferramentas. DINIZ et al (1999)......................................... 17

FIGURA 2.10 - Influência e Compensação de Desgastes ....................................................... 18

FIGURA 2.11 - Sistemas de Monitoramento. GRAHAM (1989) - modificado. ...................... 19

FIGURA 2.12 - Monitoramento de Processos de Manufatura.DU et al (1995)-modificado .. 20

FIGURA 2.13 - Estratégia de Monitoramento: Limites Fixos e Flutuantes........................... 22

FIGURA 2.14 - Estratégia de Monitoramento: Limites definidos pelo tempo........................ 22

FIGURA 2.15 - Estratégia de Monitoramento: "Assinatura da peça" ................................... 23

FIGURA 2.16 - Esquema geral de um sistema de supervisão e controle de processos. ..... 24

FIGURA 2.17 - Esquema geral de CNC de arquitetura aberta ............................................ 28

FIGURA 2.18 - Diferença entre redes de cabos paralelos e fieldbus ................................. 31

FIGURA 2.19 - Níveis de automação e tipos de redes ................................................... 32

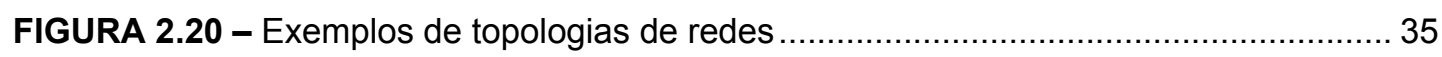

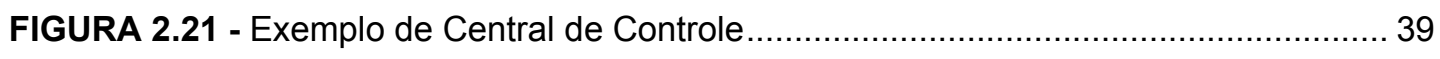

FIGURA 2.22 - Exemplos de telas de supervisão ......................................................... 40

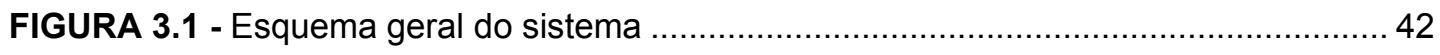

FIGURA 3.2 - Exemplo de aplicação do sistema como ferramenta de competitividade ...... 44

FIGURA 3.3 - Componentes do sistema de supervisão e monitoramento............................ 46

FIGURA 3.4 - Sensor LVDT e detalhe de sua fixação no suporte de ferramenta................. 49 


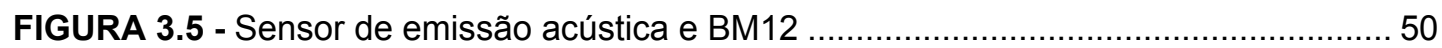

FIGURA 3.6 - Front end do sistema de supervisão......................................................... 51

FIGURA 3.7 - Front end do sistema de supervisão em formato HTML ............................... 52

FIGURA 3.8 - Front end do software de aquisição e manipulação de dados (LabView) ....... 53

FIGURA 3.9 - Exemplo de cabeçalho de registradores $R_{i}$ de um programa $C N$.................. 58

FIGURA 3.10 - Trecho do programa CN pra medição de peças.........................................60

FIGURA 3.11 - Esquema do sistema utilizando sensor LVDT .........................................61

FIGURA 3.12 - Trecho do programa CN para compensação do desgaste da ferramenta .. 62

FIGURA 3.13 - Algoritmo para cálculo do PCDD e classificação de peças............................ 63

FIGURA 4.1 - Front End do simulador do processo de torneamento ....................................65

FIGURA 4.2 - Corpo de prova preparado para a primeira etapa ........................................6. 67

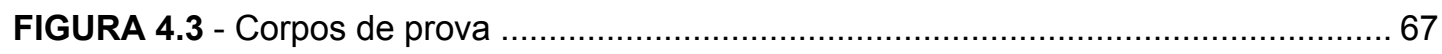

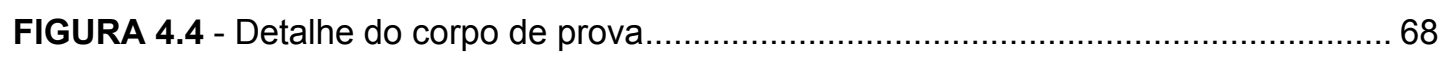

FIGURA 5.1 - Comparação entre torneamentos com compensação e sem.......................... 70 


\section{LISTA DE TABELAS}

TABELA 2.1 - Métodos para o monitoramento de estado de ferramentas de corte 21

TABELA 3.1- Dados e informações obtidos da Máquina, Programa CN e Sensores ........... 57

TABELA 3.2 - Algumas informações de processo e produção obtidos 58 


\section{LISTA DE ABREVIATURAS E SIGLAS}

ABNT - Associação Brasileira de Normas Técnicas

ARC - Automation Research Corporation

B2B - Business-to-Business

CAM - Computer Aided Manufacturing

CEP - Controle Estatístico de Processo

CLP - Controlador Lógico Programável

CNC - Comando Numérico Computadorizado

CN - Comando Numérico

COM - Component Object Model

CPU - Central Processing Unit

DCOM - Distributed Component Object Model

DDE - Dynamic Data Exchange

DLL - Dynamic Linking Libraries

DTL - Diodo-Transistor Logic

EA - Emissão Acústica

ERP - Enterprise Resource Planning

FDDI - Fiber Distributed Data Interface

FTP - File Transmission Protocol

HMI - Human Machine Interfacing

HTML - HyperText Markup Language

HTTP - HyperText Transfer Protocol

IEEE - Institute of Electrical and Electronics Engineers

IIS - Internet Information Server

I/O - Input/ Output

IP - Internet Protocol 
ISA - The Instrumentation, Systems and Automation Society

ISO - International Organization for Standardization

LVDT - Linear Variable Differential Transformer

MES - Manufacturing Execution System

MMI - Man Machine Interfacing

NetDDE - Network Dynamic Data Exchange

ODBC - Open Database Connectivity

OLE - Object Linking and Embedding

OPC - OLE for Process Control

PCDD - Parâmetro de Compensação devido ao Desgaste

PWS - Personal Web Server

RTU - Remote Terminal Unit

SCADA - Supervisory Control And Data Acquisition

SDCD - Sistemas Digitais de Controle Distribuídos

SQL - Structured Query Language

TCP - Transmission Control Protocol

TTL - Transistor-Transistor Logic

URL - Uniform Resource Locator 


\section{LISTA DE SÍMBOLOS}

$\mathbf{V}_{\mathbf{c}}$ - Velocidade de corte $(\mathrm{m} / \mathrm{min})$

$\mathbf{V}_{\mathbf{f}}$ - Velocidade de avanço $(\mathrm{mm} / \mathrm{min})$

$\mathbf{a}_{\mathbf{p}}$ - profundidade de usinagem $(\mathrm{mm})$

$\mathbf{f}$ - avanço $(\mathrm{mm} / \mathrm{rot})$

n - rotação $(\mathrm{rpm})$

$\mathbf{V}_{\mathbf{c c}}$ - tensão elétrica (Volts) , de corrente contínua

LSE - Limite Superior de Especificação

LIE - Limite Inferior de Especificação

$\mathbf{l}_{\mathbf{c}}-$ Comprimento de Corte $(\mathrm{mm})$

$\mathbf{R}_{\mathbf{i}}$ - Registradores temporários usados como variáveis globais nos programas $\mathrm{CN}$. 


\section{RESUMO}

FERRAZ JUNIOR, F. (2002). Sobre o desenvolvimento de um sistema de monitoramento e supervisão para o processo de torneamento. São Carlos, 2002. 90p. Dissertação (Mestrado) - Escola de Engenharia de São Carlos, Universidade de São Paulo.

Vários fatores, tais como custos, qualidade, flexibilidade e tempo de resposta, levam a vantagens competitivas. Nas indústrias do ramo metal mecânico, os fatores custos e qualidade estão intimamente ligados ao surgimento de novos materiais de difícil usinagem (cujos comportamentos ainda são desconhecidos), e como conseqüência o surgimento de novos e caros materiais de ferramentas juntamente com as exigências de alta produção, lotes variados, faixas de tolerâncias cada vez mais estreitas e baixos custos de produção, o que têm extrapolado os limites e habilidades de operadores de máquinas. Quanto aos fatores flexibilidade e tempo de resposta, as indústrias têm apontado uma grande necessidade de informações confiáveis sobre desempenho da produção e informações sobre parâmetros tecnológicos das máquinas-ferramenta. Sistemas de apontamentos manuais mostramse deficientes, quanto à confiabilidade, velocidade de atualização, detecção de não conformidades e outros fatores prejudiciais à produção, além de gerarem redundância de trabalho na coleta e alimentação de bancos de dados. O sistema proposto contribui para a satisfação dessas necessidades, utilizando-se de tecnologias de comunicação e de aquisição de dados, que propicia o monitoramento e supervisão de processos de torneamento. Permite o monitoramento da qualidade dimensional e indiretamente do desgaste de ferramentas, e ainda o compartilhamento de informações de chão de fábrica, em tempo real, para qualquer localidade via intranet e/ou internet, auxiliando na integração do sistema de manufatura. 
Palavras-chave: monitoramento; supervisão; usinagem; torneamento.

\begin{abstract}
FERRAZ JUNIOR, F. (2002). On the development of monitoring system and supervision for the turning process. São Carlos, 2002. 90p. Dissertação (Mestrado) - Escola de Engenharia de São Carlos, Universidade de São Paulo.

Several factors, such as costs, quality, flexibility and response time, influence the competitive advantages. In the metal working industries, the factors cost and quality are closely linked to the appearance of new materials difficult to machine (whose behaviors are still ignored). As a consequence, the appearance of new and expensive tool materials, together with the demands for high production, varied batches, range of tolerances more and more narrow and low production costs, what have been extrapolating the limits and abilities of operator's machine. With regards to the factors flexibility and response time, industries have been pointing to a need for reliable information about production performance and about machine-tools technological parameters. Systems of manual appointments are subject to lack of reliability, up date, detection of non conformities and other factors affecting negatively the production system. Additionally, they can generate work redundancy in the acquisition and database feeding. The proposed system contributes to achieve that need using communication and data acquisition technologies, that allows the monitoring and supervision of turning processes. It allows the monitoring of the dimensional quality and indirectly tools wear, as well as sharing shop floor information, in real time, with any place through intranet and/or Internet, aiding the integration of the manufacturing system.
\end{abstract}


Keywords: monitoring; supervision; turning; machining. 


\section{Introdução}

Com a rapidez com que as mudanças acontecem na atualidade, as indústrias, principalmente do ramo metal mecânico, têm apontado uma grande necessidade de informações confiáveis sobre desempenho da produção e informações sobre parâmetros tecnológicos das máquinas-ferramenta. Sistemas de apontamentos manuais mostram-se deficientes quanto à confiabilidade, velocidade de atualização, detecção de não conformidades e outros fatores prejudiciais à produção, além de gerarem redundância de trabalho na coleta e alimentação de banco de dados. Conseqüentemente, as informações geradas a partir desses apontamentos podem criar uma percepção diferente da realidade para os responsáveis pela tomada de decisões. Assim, informações podem, muitas vezes, mostrar um quadro diferente da realidade e com um retardo suficiente para o agravamento da situação. Em determinados casos, essas anomalias são capazes de levar à perda financeiras significativas através dos lotes de peças produzidas.

Para muitos profissionais a Internet será a principal ferramenta a ser utilizada na preparação de empresas para o próximo milênio, onde prevalecerá não somente a qualidade, ou a reengenharia, como nas décadas passadas, mas também a velocidade de ações, eliminando as barreiras das cansativas hierarquias de comando, conforme várias citações em GATES (1999), GIFFORD \& DUENA (1998), INTECH (1998) e INTERNACIONAL (2000).

A grande difusão e popularização da Internet (com sua conectividade global), juntamente com os avanços da tecnologia nas áreas de informação, redes e automação industrial, em um mercado cada vez mais competitivo, despertam um crescente interesse industrial pelos sistemas de supervisão (supervisory systems). Estes possibilitam o acompanhamento da produção com informações mais confiáveis e com menor atraso. Pode-se aplicá-los em células ou linhas de manufatura 
disponibilizando as informações para os vários departamentos, buscando uma rápida disseminação de informações com grande abrangência. Isso, sem dúvida, contribui para uma maior integração e globalização de fornecedores e clientes (e-Business), trazendo maior rapidez de análise e menor risco nas tomadas de decisão.

Conforme AGOSTINHO (1996), o sistema de manufatura pode ser representado basicamente como a composição das seguintes atividades: engenharia, chão de fábrica, suporte e negócios (esquema na figura 1.1).

\section{Atividade de Engenharia}

Pode ser dividida em:

- Engenharia de Produto: criação e desenvolvimento dos produtos a serem fabricados.

- Engenharia de Fabricação: desenvolvimento dos meios de manufatura: processos de fabricação, ferramental, equipamentos, etc.

\section{Atividade de Chão de Fábrica}

Responsável pela fabricação dos produtos nos prazos e quantidades determinadas. Possui como recursos: máquinas e equipamentos, mão de obra direta (operadores) e indireta (suporte relacionado diretamente à manufatura).

\section{Atividade de Suporte}

Responsável pelo suporte ao chão de fábrica, garantindo o desempenho e as características tanto de qualidade, quanto operacionais dos equipamentos.

\section{Atividade de Negócios}

Interface do Sistema de Manufatura com o mundo exterior (mercado consumidor e mercado supridor). É responsável pelo marketing, suprimentos e planejamento das atividades do sistema de manufatura. 
Cada atividade possui subatividades principais, como pode ser observado na figura 1.1.

A integração do sistema é diretamente proporcional à sua capacidade de providenciar os atributos de competitividade. Assim, as quatro atividades citadas devem manter uma integração suficiente para que viabilize as operações do sistema como um todo. As inter-relações internas e externas e seus respectivos vínculos operacionais são responsáveis por essas operações.

O sistema de manufatura é, na sua essência, um sistema de informações e o seu nível de integração estrutural depende, indispensavelmente, da sinergia do fluxo de informações, afirma AGOSTINHO (1996).

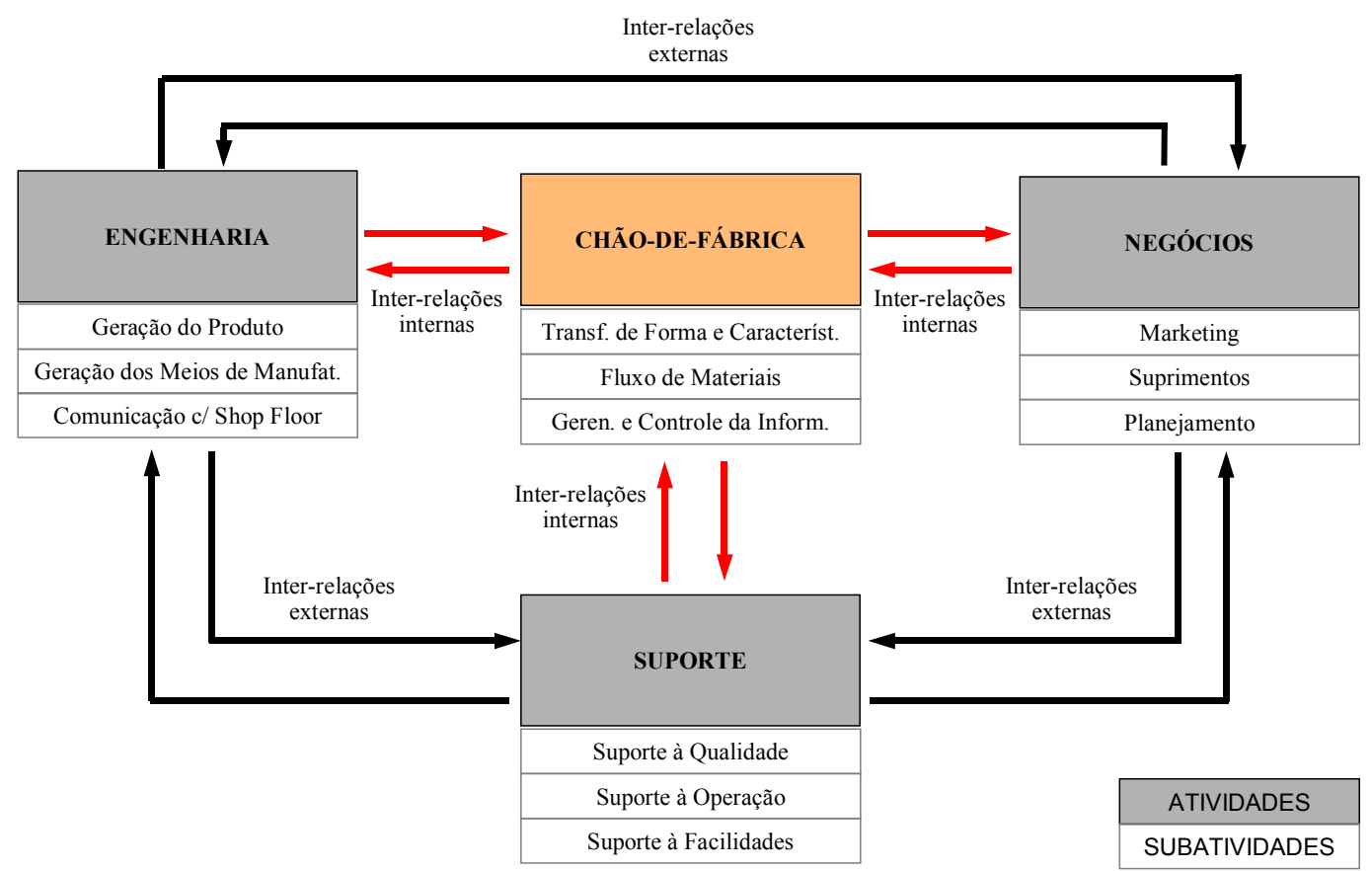

FIGURA 1.1 - Modelo de um sistema de manufatura. AGOSTINHO (1996)-modificado

Fazendo-se uma análise dos fatores de competitividade das últimas décadas, observa-se que estes variam constantemente. Segundo AGOSTINHO (1996), nas décadas de 50 e 60, os esforços foram concentrados na redução de custos. Já na década de 70, as atenções estavam voltadas para a qualidade de produtos. Atualmente, os fatores flexibilidade e tempo de reposta, inicialmente empregados nas décadas de 80 e 90 respectivamente, passaram a prevalecer, e a integração do 
Sistema de Manufatura tornou-se um grande diferencial competitivo, auxiliando na adaptação a novas realidades e aproveitamento de oportunidades.

A capacidade de manter-se competitivo está relacionada a diversos atributos, dentre os quais se destacam liderança e inovação e capacidade de resposta. Entretanto, todos dependem diretamente da capacidade de integração dos diversos componentes estruturais da organização.

O atributo liderança envolve uma série de sub-atributos, tais como foco no consumidor, qualidade, planejamento, competências centrais e melhoria contínua de desempenho. Já a inovação, é uma combinação de criatividade e geração de novas idéias (para atrair clientes ou melhorar o negócio) com a habilidade de implementação destas adequadamente. E finalmente, o segundo atributo necessário à competitividade numa organização é a sua capacidade de resposta aos estímulos externos. A busca efetiva de feedback dos clientes e dos fornecedores e a habilidade de se tornar uma empresa de ciclo rápido, são os principais elementos para a capacidade de resposta. Tem como principais sub-atributos a excelência nos processos de negócio, a integração de estratégias, a adoção de tecnologia comprovada, a ligação com clientes e fornecedores e a capacidade de adaptação.

Assim, tendo-se essa breve visão de Sistema de Manufatura e Padrões de Competitividade, pode-se observar, dentre vários outros fatores, a importância da integração da atividade de chão de fábrica com as demais atividades que compõem um Sistema de Manufatura, além da sua integração com clientes e cadeia de fornecedores.

Ter bons produtos, baixos custos, buscar a contínua satisfação de seus clientes e ter rapidez na tomada de decisões e adaptações às novas realidades, devem ser práticas fundamentais de empresas que querem se manter competitivas no mercado, que hoje não possui fronteiras. Desta forma, busca-se integração do Sistema de Manufatura, eliminação de barreiras hierárquicas de comando, visão global e clara do negócio, bem como maior integração com a cadeia de suprimentos (Supply Chain). A cadeia logística interna da empresa deve estar bem estruturada e integrada com as demais das empresas que formam a cadeia logística global do negócio (figura 1.2). O sucesso de cada empresa da cadeia depende do sucesso da cadeia como um todo, segundo ALLIANCE (1999) e LIMA (2000). 


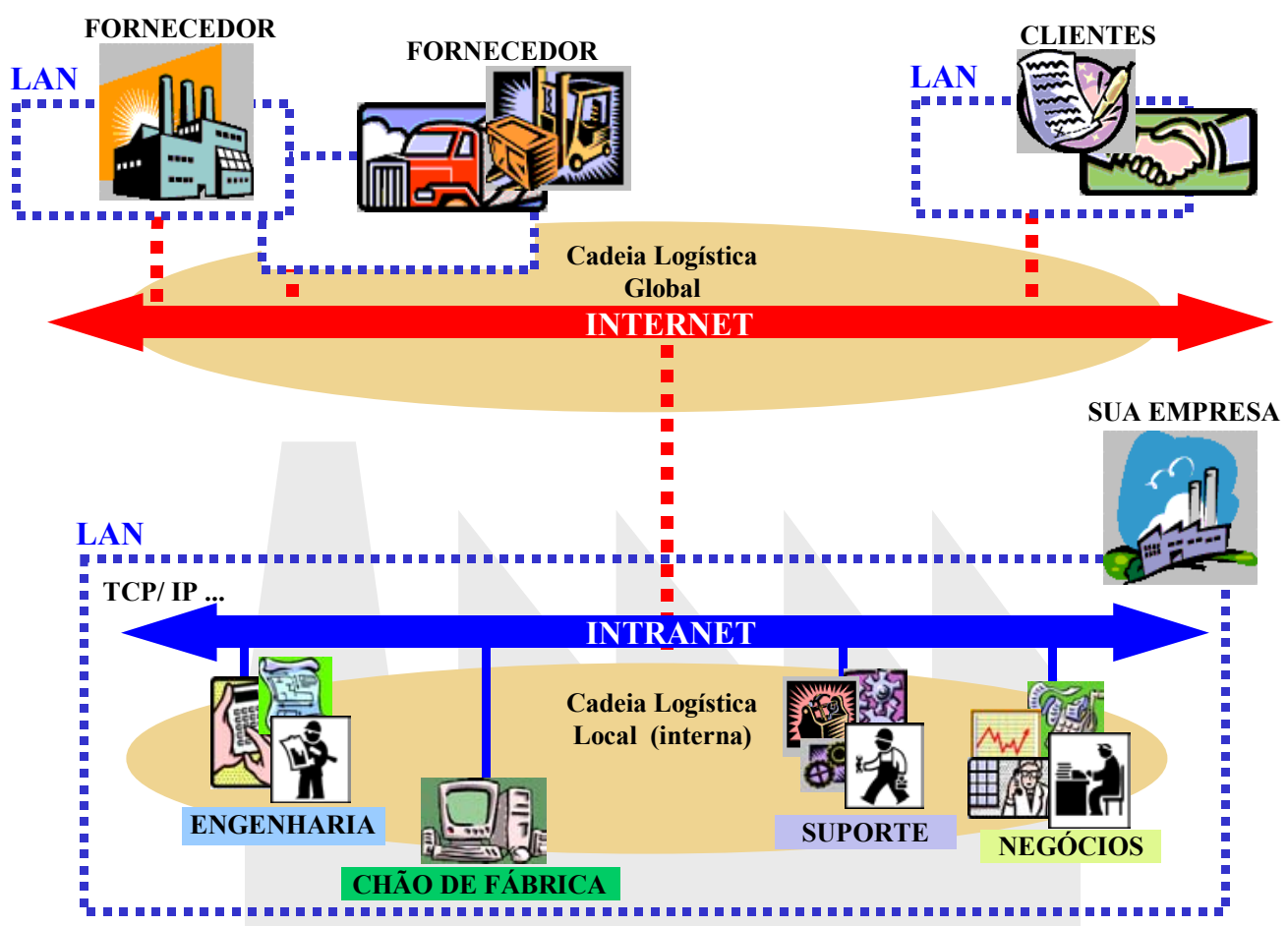

FIGURA 1.2 - Exemplo de integração de uma empresa com cadeia logística global

Como auxílio para que as empresas se ajustem a essa realidade, surgem, então, as soluções de Gestão Empresarial que buscam uma integração total do empreendimento, utilizando novas e modernas tecnologias, desde a interação com clientes e fornecedores até a automação/instrumentação dos setores de produção, disponibilizando informações a seus usuários de modo coordenado e seguro, conforme as suas necessidades e atribuições. Conforme ALLIANCE (1999) e LIMA (2000), aplicativos B2B (Business-to-Business) criam facilidades de comunicação e visibilidade, os ERP's (Enterprise Resource Planning) administram o empreendimento garantindo a correta gestão dos materiais e planejamento das atividades corporativas, os sistemas MES (Manufacturing Execution System) gerenciam a produção, executando, entre outras ações, a programação, rastreabilidade e controle de qualidade, e finalmente os sistemas e dispositivos de automação e instrumentação, que captam dados do chão de fábrica e/ou planta e executam as tarefas programadas.

Em uma "Cadeia Logística Global, com empresas interligadas via B2B, um fato extremamente importante é a integração e a sincronização dos sistemas ERP, 
MES e de automação para garantir a estabilidade e a visibilidade da produção e demais recursos da empresa" (LIMA, 2000, p.34). Todavia, segundo LIMA (2000), apesar de todo o avanço conseguido, a maioria das indústrias ainda busca atingir uma meta satisfatória de integração entre os dados de chão de fábrica e os dados corporativos. Desta forma, um sistema de supervisão e monitoramento mostra-se como uma contribuição para solucionar o problema de integração, atendendo a necessidade de disponibilização dos dados do chão de fábrica (desde dados de máquina até dados da produção e de processo). As informações são fornecidas de maneira confiável e com um mínimo de atraso, para diversas áreas dentro da empresa (suporte, engenharia, etc) e, conforme o interesse, para clientes, cadeia de fornecedores, etc. O sistema deve utilizar-se, para isso, de tecnologias de informação e padrões disponíveis comercialmente em máquinas-ferramenta, cujo CNC (Comando Numérico Computadorizado) são de arquitetura aberta (ou semi-aberta), baseados em plataforma Windows. Só assim poderá ser fácil e rapidamente implementado.

\subsection{Objetivo}

O presente trabalho objetiva:

1. Desenvolver um sistema de monitoramento e supervisão para o processo de torneamento, com base em tecnologia disponível, em termos de software e hardware. Utilizando-se de itens já presentes no mercado, um sistema de monitoramento e supervisão é proposto, de forma que diversos dados da máquina e da sua produção diária, em tempo real, possam ser consultados, bem como o monitoramento da ferramenta de corte possa ser realizado.

2. Implementar e testar o sistema proposto em uma máquina, disponibilizando os dados via Internet e realizando o monitoramento da ferramenta de corte. O sistema proposto é implementado em um torno com $\mathrm{CNC}$ de arquitetura aberta, possibilitando o acompanhamento de dados de produção em tempo real, e a compensação automática de desgaste da ferramenta de corte. 


\subsection{Estrutura da Dissertação}

Este documento - apresentado à Escola de Engenharia de São Carlos, da Universidade de São Paulo, como parte dos requisitos para a obtenção do título de Mestre em Engenharia Mecânica - está dividido em 9 capítulos:

- Capítulo 1 : introdução do presente trabalho, com o intuito de situar o leitor dentro do panorama em que se encontra o sistema proposto; apresenta também a estrutura da dissertação, que faz breve descrição dos capítulos que compõem o documento.

- Capítulo 2 : revisão bibliográfica do assunto, com subtítulos que tratam da Logística e Gestão da Cadeia de Suprimentos, Processos de Usinagem e Monitoramento, e finalmente, Sistemas de Supervisão e Controle de Processos. São informações preliminares essenciais para o entendimento do capítulo 3, que trata o assunto de forma mais direta.

- Capítulo 3 : apresentação do sistema proposto, através dos subtítulos: Descrição Geral, Tecnologias Utilizadas e Estratégias do Sistema.

- Capítulo 4 : métodos utilizados para a avaliação do sistema proposto, com o intuito de comprovar a eficácia do sistema de supervisão e monitoramento proposto.

- Capítulo 5 : resultados obtidos das avaliações em que foi submetido o sistema proposto, juntamente com uma discussão dos mesmos.

- Capítulo 6 : conclusões finais do presente trabalho. 
- Capítulo 7 : sugestões para trabalhos futuros, tais como melhorias e complementações possíveis de serem realizadas no presente trabalho.

- Anexo, para dar suporte esclarecedor relativo ao conteúdo do trabalho.

- Referências bibliográficas utilizadas e citadas que deram suporte a confecção do presente documento. 


\section{Revisão Bibliográfica}

A seguir tem-se uma breve descrição de alguns conceitos correlacionados com o desenvolvimento do sistema de supervisão e monitoramento do processo de torneamento, seguida da revisão bibliográfica de alguns dos principais tópicos abordados neste trabalho.

Muitos termos utilizados no decorrer deste trabalho ainda não possuem uma tradução consolidada na literatura. Deste modo, serão mantidos em sua língua de origem (em destaque) e uma tentativa de traduzi-los será apresentada entre parênteses, logo após os mesmos.

\subsection{Logística e Gestão da Cadeia de Suprimentos}

\subsubsection{Supply Chain (Cadeia de Suprimentos)}

De acordo com ALLIANCE (1999), LIMA (2000) e PIRES \& MUSETTI (2000), trata-se de uma complexa rede de relações organizacionais entre empresas que atendem a um determinado mercado com seus produtos, produzindo e transportando desde as matérias-primas básicas até os produtos para os clientes finais (esquema na figura 2.1).

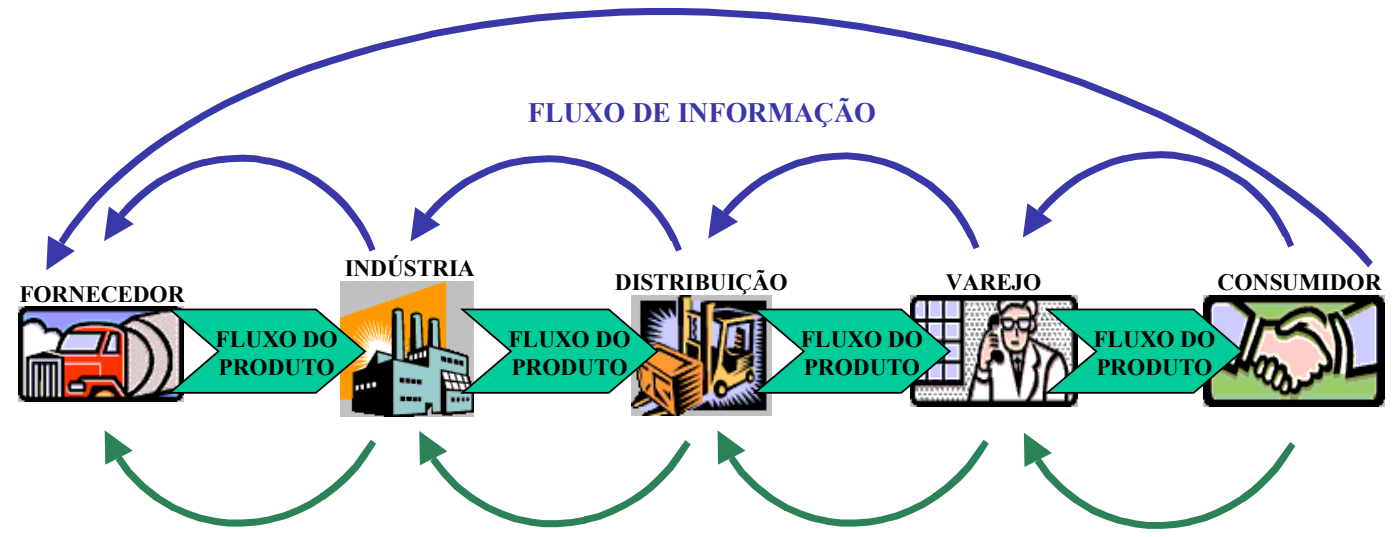

FLUXO FINANCEIRO

FIGURA 2.1 - Esquema de um Supply Chain 
Idealmente, a supply chain (cadeia de suprimentos) consiste de múltiplas companhias que funcionam com eficiência e efetivamente como uma única companhia, com todas as informações visíveis e integras.

Assim, competições entre empresas passam a competições entre cadeias de suprimentos.

\subsubsection{Supply Chain Management (Gestão da Cadeia de Suprimentos)}

Segundo ALLIANCE (1999), em uma visão superficial, Supply Chain Management (Gestão da Cadeia de Suprimentos) é a coordenação do fluxo de material, informação e financeiro entre todos os participantes do empreendimento:

- Fluxo de Material: envolve o fluxo físico do produto através da cadeia, desde os fornecedores de matéria-prima até a entrega do produto acabado aos consumidores, bem como o fluxo reverso via retorno de produtos, reciclagem, e sobra de estoque.

- Fluxo de Informação: envolve previsões de demanda, transmissão de ordens e disponibilização de status.

- Fluxo Financeiro: relacionado com informações em termos de créditos, relações de pagamentos, etc.

Novas tecnologias têm ajudado na solução de problemas surgidos com o aumento da complexidade e globalização das interações entre fornecedores, fabricantes, distribuidores, varejistas e consumidores. Dentre essas tecnologias temse a proliferação da Internet, a introdução de tecnologias de aquisição de dados e o crescimento de ferramentas de manipulação de dados.

\subsubsection{Logística}

"Logística é o processo da cadeia de suprimentos que planeja, implementa e controla o fluxo e o estoque de bens e serviços e as informações relativas, do ponto de origem ao ponto de consumo, de maneira eficiente e eficaz, buscando a satisfação das necessidades do cliente" (COUNCIL, 2000 apud PIRES \& MUSETTI, 2000). 
Assim, pode-se ter cadeia logística interna, que trata de visões estratégicas e controle de atividades internas da empresa, e cadeia logística global, que envolve toda a cadeia de suprimentos, como pode ser visto no esquema da figura 2.2.

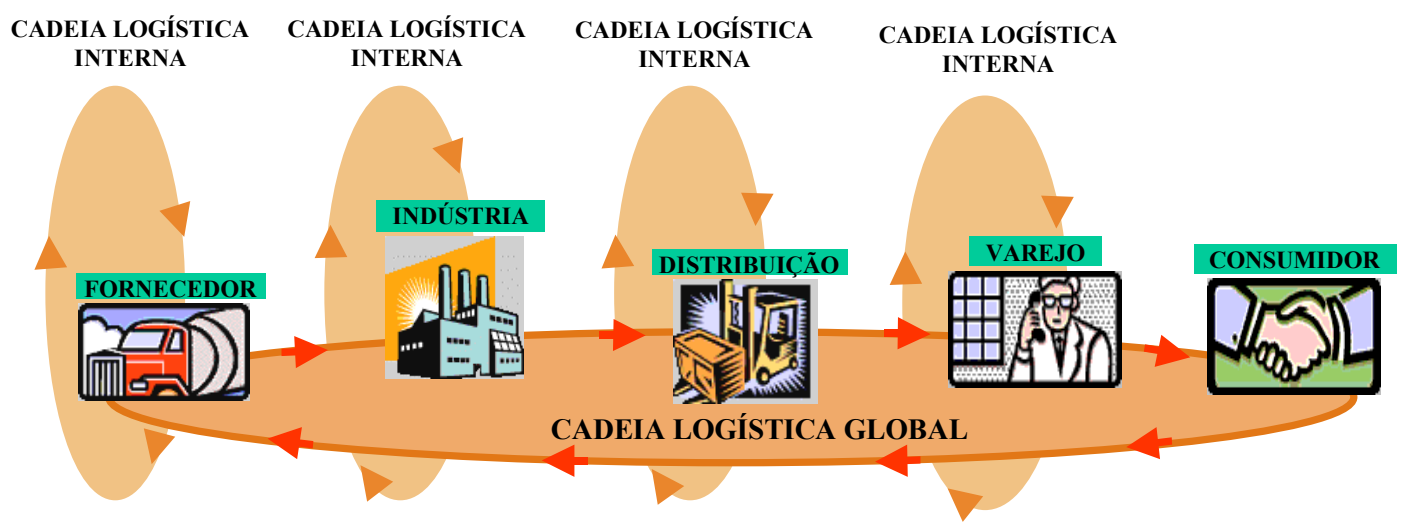

FIGURA 2.2 - Esquema de cadeias logísticas internas e global

\subsection{Processos de Usinagem e Monitoramento}

\subsubsection{Fenomenologia do Processo de Torneamento}

Segundo FERRARESI (1990), torneamento é um processo mecânico de usinagem destinado a obtenção de superfícies de revolução com auxílio de uma ou mais ferramentas monocortantes (figura 2.3).

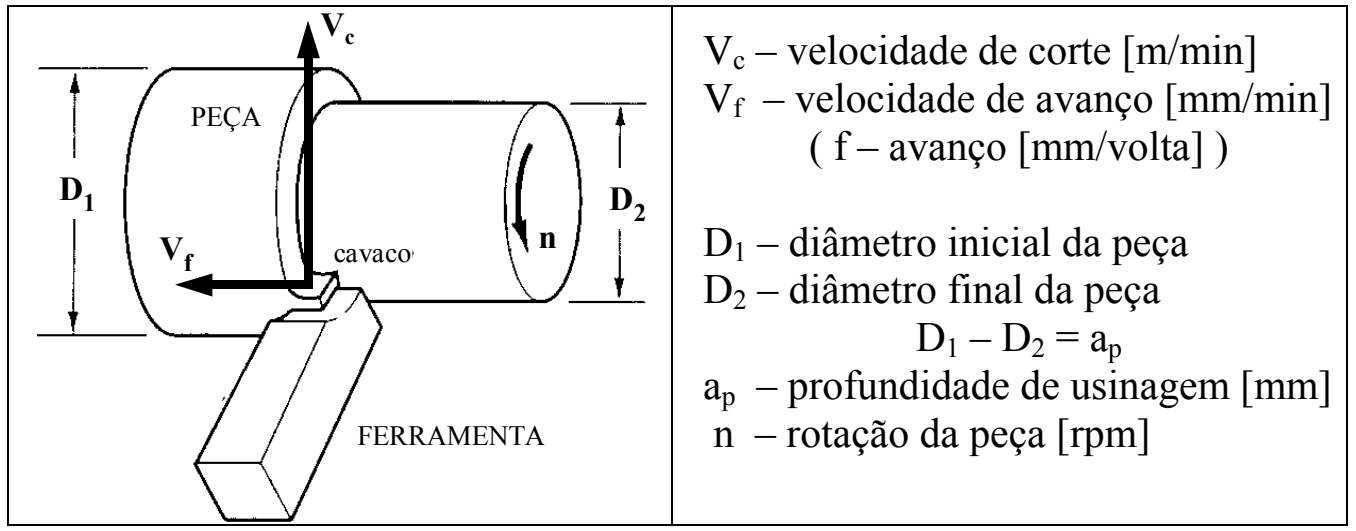

FIGURA 2.3 - Exemplo de um torneamento. DINIZ et al (1999) - modificado

O processo de torneamento é executado com a combinação de dois movimentos: avanço da ferramenta e rotação da peça. $\mathrm{O}$ avanço da ferramenta pode ser ao longo do eixo da peça, o que significa que seu comprimento será reduzido, e 
no sentido do centro da peça, diminuindo seu diâmetro. Em alguns casos, o avanço da ferramenta pode ser a combinação dessas duas direções, resultando em superfícies cônicas, conforme MODERN apud MEIRELES (2000).

Segundo FERRARESI (1990), pode ser classificado, quanto à finalidade, como:

- torneamento de acabamento: operação de usinagem destinada a obter na peça as dimensões finais, ou um acabamento superficial especificado, ou ambos. As condições de acabamento são leves, com profundidades de usinagem bastante reduzidas e avanços tão pequenos quanto os necessários para a obtenção da especificação da peça-obra.

- torneamento de desbaste: operação de usinagem anterior a de acabamento, visando obter na peça a forma e dimensões próximas das finais. A condição de desbaste deve ser tão severa quanto permitirem a espessura do cavaco, a vida da ferramenta, a potência do motor e a própria peça.

Para se obter faixas de tolerâncias dimensionais estreitas e bons acabamentos superficiais, é necessário realizar um ou mais passos na condição de desbaste, seguidos por um ou mais passos na condição de acabamento. Em alguns casos, uma ferramenta especial de acabamento é usada, mas geralmente a mesma ferramenta é usada para ambas condições, conforme DEGARMO et al (1997) apud MEIRELES (2000).

As operações de torneamento podem ser realizadas com a peça presa entre centros ou com a peça presa à placa numa de suas extremidades, com ou sem suporte na outra extremidade.

Quanto à forma da trajetória, conforme FERRARESI (1990), o torneamento pode ser classificado como:

- $\quad$ retilíneo: ferramenta se desloca segundo uma trajetória retilínea

- cilíndrico

- externo

- interno

- sangramento axial 


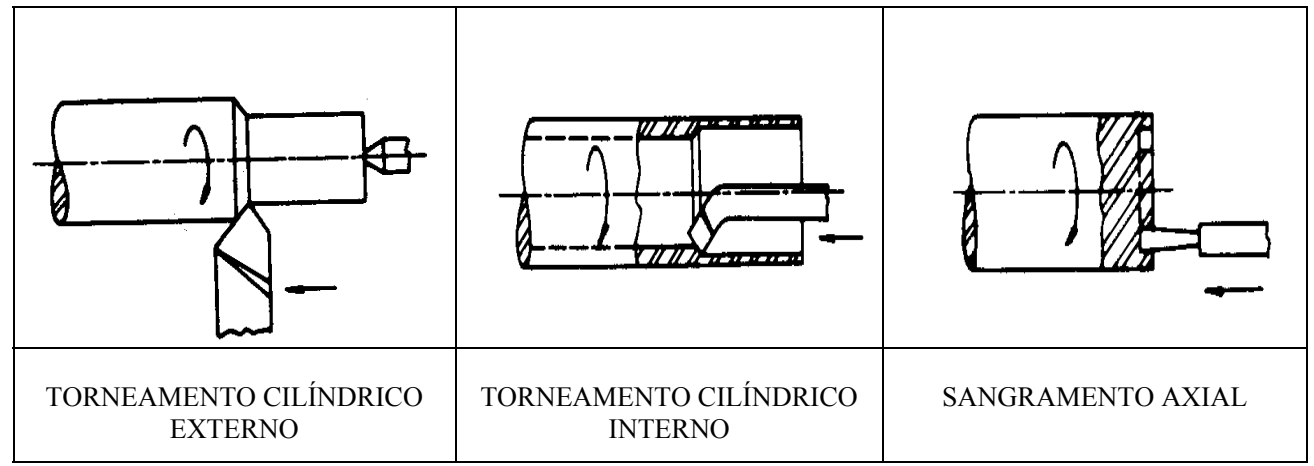

FIGURA 2.4 - Torneamento Cilíndrico. FERRARESI (1990)

- cônico

- externo

- interno

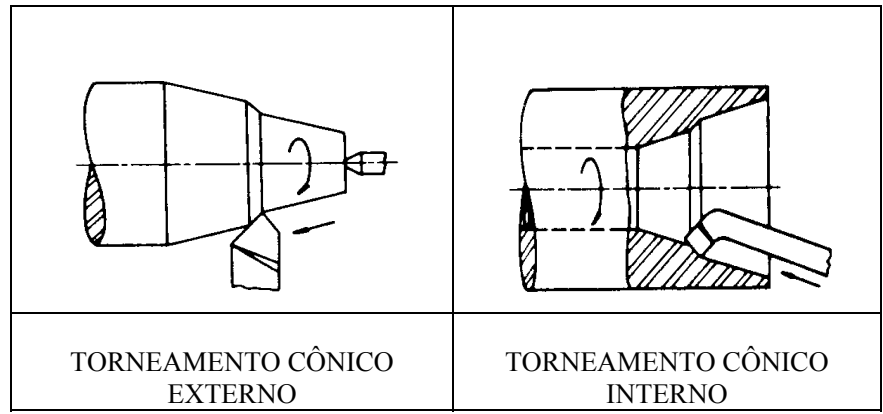

FIGURA 2.5 - Torneamento Cônico. FERRARESI (1990)

- radial

- faceamento

- sangramento radial

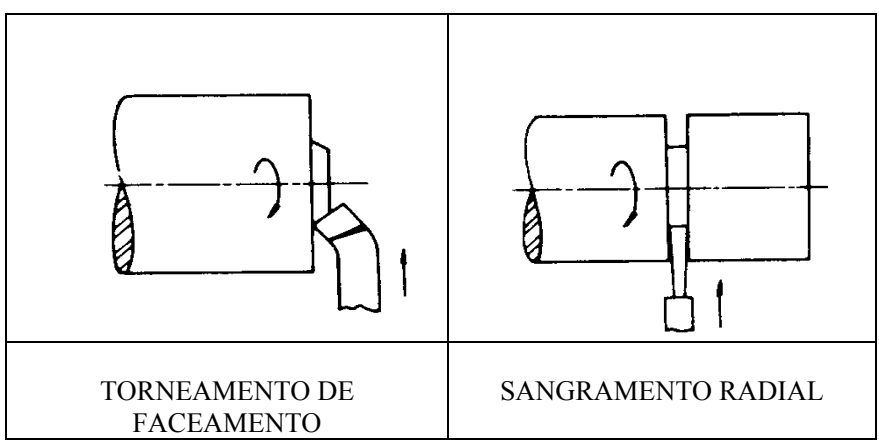

FIGURA 2.6 - Torneamento Radial. FERRARESI (1990) 
- curvilíneo

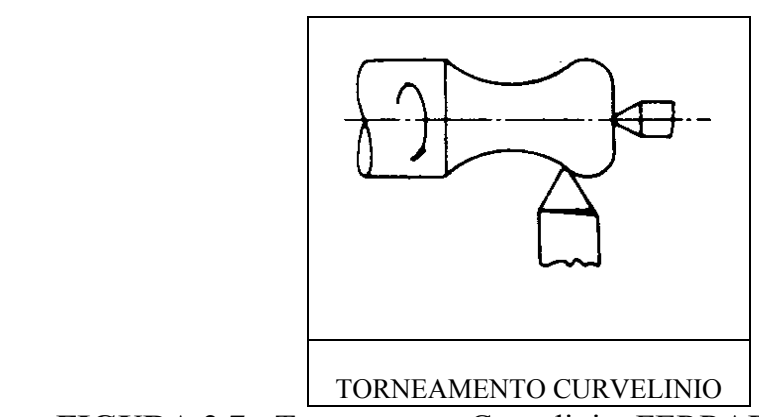

FIGURA 2.7 - Torneamento Curvelinio. FERRARESI (1990)

\subsubsection{Principais Problemas}

Conforme citado anteriormente, o processo de torneamento pode efetuar tanto operações de desbaste, quanto de semi-acabamento ou acabamento. Esta última operação fornece a qualidade superficial e dimensão final da peça-obra, cujo nível de precisão depende do sistema máquina-ferramenta.

LI (2001) afirma que o sistema máquina-ferramenta é composto basicamente por:

- servo drive (equipamentos de acionamento e controle)

- estrutura da máquina-ferramenta

- peça-obra

- processo de corte

As principais fontes de erros de peças, quanto à qualidade superficial e dimensional, segundo CHEN, S. et al (1998) apud LI (2001), derivam dos componentes:

- estrutura da máquina-ferramenta: erros térmicos, geométricos, e provocados por forças de vibração.

- servo drive: dinâmica dos acionadores, e erros de programas.

- processo de corte: flexão da máquina, ferramenta de corte e peça-obra, desgaste e quebra de ferramentas de corte. 
Essas fontes de erros vêm sendo minimizadas, chegando-se ao extremo no processo de torneamento de ultraprecisão, onde superfícies com rugosidade de alguns nanômetros são produzidas. Melhorias de projetos de estruturas de máquinas, além da contribuição de prognósticos realizados por modelos matemáticos, minimizam erros geométricos, e influências térmicas e de vibrações. Erros devido a distúrbios de forças de corte e inércia de controladores/ acionadores são reduzidos através de interpolações com funções de desaceleração e com o gradual avanço tecnológico dos mesmos. E, finalmente os erros de processos de corte vêm sendo minimizados com a utilização de sistemas de monitoramento de máquinas e ferramentas, e com o uso de modelos matemáticos que buscam o prognóstico de distúrbios do processo.

O presente trabalho aborda o monitoramento de desgaste de ferramentas, em processos de torneamento, além da proposta de supervisão via Intranet e/ou Internet.

\subsubsection{1 - Avarias e Desgastes de Ferramentas}

A ação de corte, durante a usinagem, provoca mudanças na geometria das ferramentas. Essas mudanças podem ser avarias e/ou desgastes.

As avarias são mais comuns no corte interrompido (fresamento), devido aos choques mecânicos e térmicos inerentes a tais processos. Já em corte contínuo (torneamento) são muito raras, a não ser em condições de corte acima das máximas recomendadas, ou escolha inapropriada de geometria da ferramenta, ou devido a um possível defeito de fabricação (o que é muito raro), de acordo com MACHADO \& SILVA (1999) .

Segundo FERRARESI (1990) e DINIZ et al (1999), as avarias da ferramenta podem ser (figura 2.8):

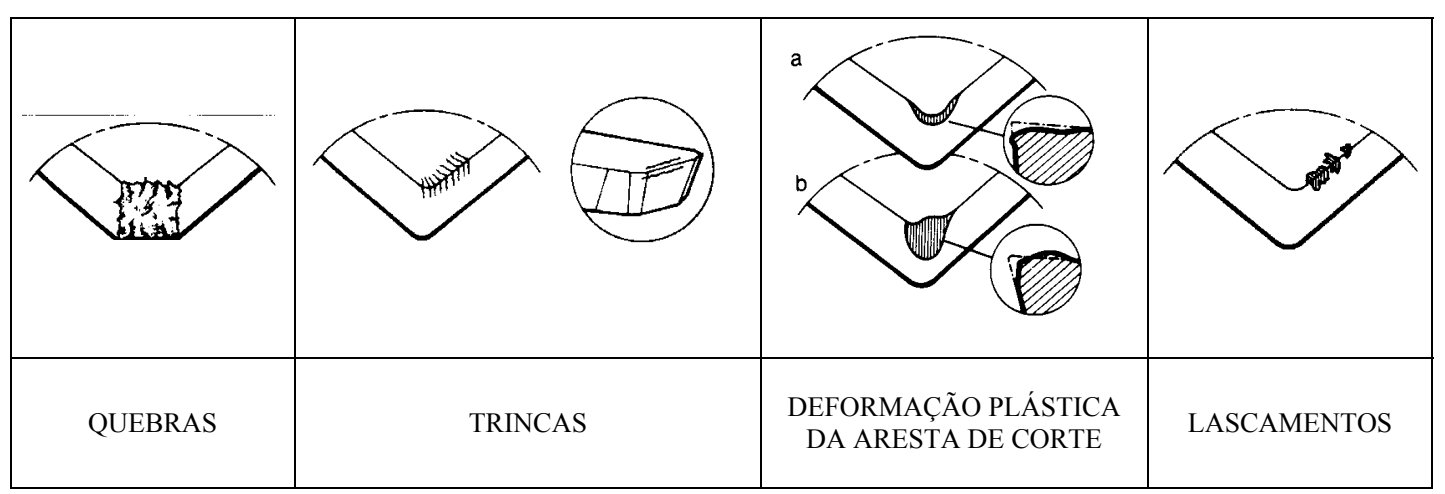

FIGURA 2.8 - Avarias de Ferramentas. DINIZ et al (1999) 
- quebras: ruptura da ponta ou da aresta de corte da ferramenta. Todos os desgastes e avarias podem levar a quebra. Porém, algumas vezes podem ocorrer de forma inesperada devido à alguns fatores, como por exemplo:

- raio de ponta, ângulo de ponta ou de cunha pequenos

- ferramenta de elevada dureza

- carga excessiva sobre a ferramenta

- cortes interrompidos

- parada instantânea do movimento de corte sem a retirada prévia da ferramenta da peça

- trincas: causadas pela variação da temperatura (trincas perpendiculares à aresta de corte) e/ou variação dos esforços mecânicos (trincas paralelas à aresta de corte).

- sulcos distribuídos em forma de pente: surgem no corte interrompido, na usinagem com avanço variável e no acesso irregular do refrigerante de corte, o que provocam uma variação de temperatura de corte.

- deformações plásticas da aresta de corte: avaria provocada pela pressão aplicada à ponta da ferramenta somada à alta temperatura de corte.

- lascamentos: partículas (maiores que nos desgastes) são retiradas de uma vez só. Ocorrem principalmente em ferramentas de material frágil e/ou quando a aresta de corte é pouco reforçada.

Segundo MACHADO \& SILVA (1999), quanto aos desgastes, estes ocorrem de forma progressiva, e podem se desenvolver por diferentes mecanismos. Acontecem tanto nas superfícies de folga como na superfície de saída das ferramentas, em cortes contínuos ou interrompidos. Conforme DINIZ et al (1999) podem ser classificados em:

- frontal: ocorre na superfície de folga da ferramenta, causada pelo contato entre a ferramenta e a peça. É o tipo de desgaste mais comum, surgindo em todo processo de usinagem . Podem ser identificadas como:

- desgaste de flanco: sempre presente nos processos de usinagem (figura $2.9-\mathrm{a}$ ). 
- desgaste de entalhe (notch wear): presentes em algumas ocasiões. Situadas sempre nos dois extremos de contato entre a superfície de folga da ferramenta e a peça (figura $2.9-\mathrm{b} / \mathrm{c}$ ).

- de cratera: ocorre na superfície de saída, causada pelo atrito entre ferramenta e cavaco (figura 2.9).

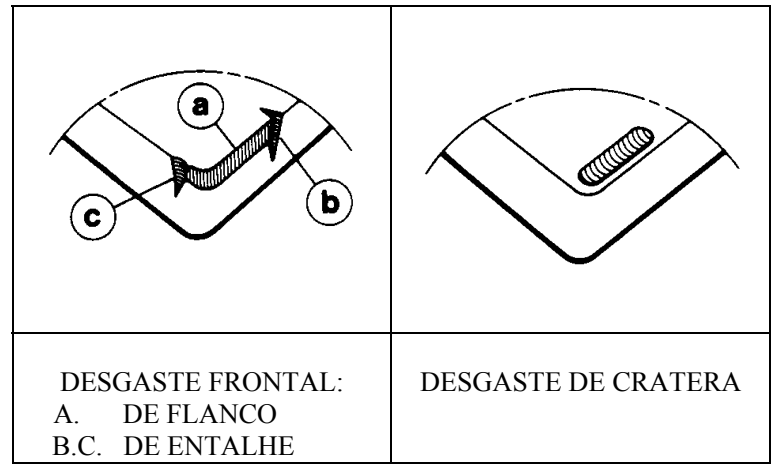

FIGURA 2.9 - Desgastes de Ferramentas. DINIZ et al (1999)

DINIZ et al (1999) e MACHADO \& SILVA (1999) afirmam que são vários os fenômenos causadores de desgastes, dentre os quais se destacam:

- aresta postiça de corte

- abrasão mecânica

- aderência

- difusão

- oxidação

\subsubsection{2 - Compensação de desgaste de ferramentas}

Conforme o exposto anteriormente, erros de peças podem ter sua origem no processo de corte, no qual tem-se, dentre as várias fontes, a influência das avarias e desgastes de ferramentas. Estas levam ao erro na qualidade superficial e dimensão final.

$\mathrm{Na}$ tentativa de corrigir esse erro, provocado por desgastes, diversos sistemas, como instrumentos de medição direta da peça e prognósticos realizados por modelagens, buscam compensar o desgaste da ferramenta corrigindo adequadamente os Parâmetros de Compensação devido ao Desgaste (para facilidade de dissertação, 
abreviado aqui por PCDD) no CNC (Comando Numérico Computadorizado) da máquina.

$\mathrm{O}$ esquema da figura 2.10 exemplifica erros dimensionais provocados por desgaste de ferramentas e falta de compensação do mesmo. A ferramenta no estado 1 (sem nenhum desgaste) e com PCDD 1, usina a peça 1 de acordo com o diâmetro de especificação. Já no estado 2 (com desgaste) e ainda com PCDD 1, usina a peça 2 com erro dimensional, pois a ponta da ferramenta não atinge a superfície ideal da peça. Agora, compensando-se o desgaste através da correção do PCDD, a ferramenta no mesmo estado 2 (com desgaste) mas com PCDD 2, usina a peça 3 de acordo com o diâmetro de especificação (tudo dependendo da grandeza da avaria e/ou desgaste da ferramenta).

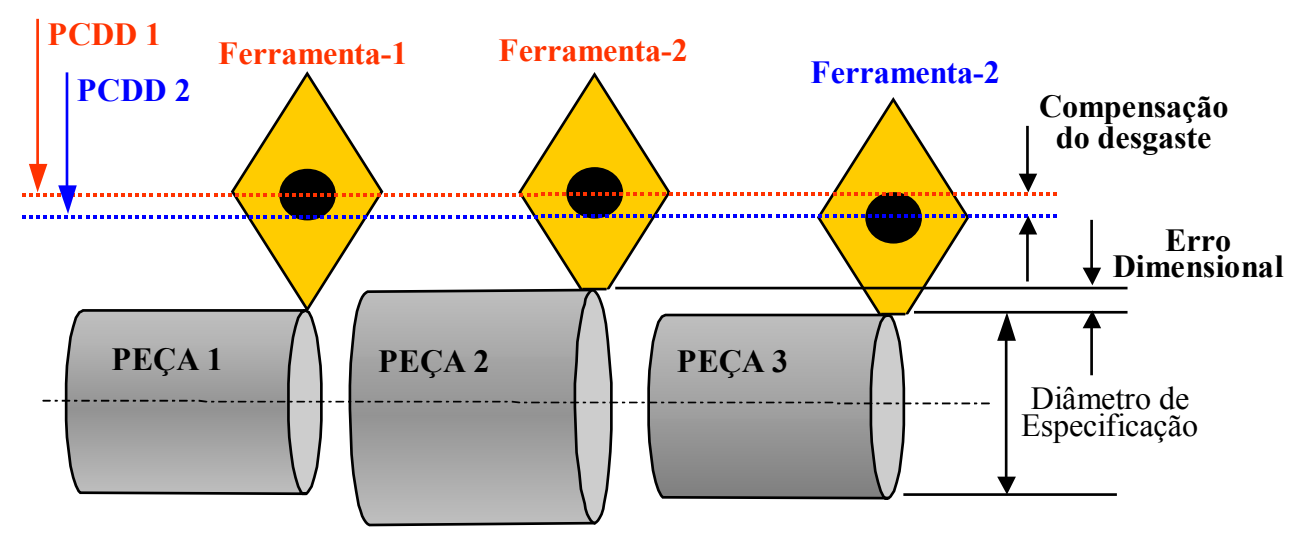

FIGURA 2.10 - Influência e Compensação de Desgastes

\subsubsection{Sistemas de Monitoramento e Controle do Processo de Usinagem}

Segundo BLUM et al (1988), GONÇALVES FILHO (1994) e DINIZ \& PIGARI (1995), o surgimento de novos materiais de difícil usinagem (cujos comportamentos ainda são desconhecidos), e como conseqüência o surgimento de novos materiais de ferramentas (de alto custo), juntamente com as exigências de alta produção, lotes variados, faixas de tolerâncias cada vez mais estreitas e baixo custo de produção, têm extrapolado os limites e habilidades de operadores de máquinas.

Máquinas $\mathrm{CNC}$ já realizam diversas funções antes executadas pelo homem (aproximação, afastamento e posicionamento da ferramenta, regulagem do avanço e 
velocidade de corte, etc), porém permanecendo ainda algumas sob responsabilidade do operador (troca da ferramenta, inspeção da peça, etc), enfatiza DINIZ \& PIGARI (1995).

Assim, sistemas de monitoramento e controle de processos de usinagem buscam atender essa necessidade, minimizando e/ou auxiliando a atuação do homem nas máquinas ferramentas.

Segundo GRAHAM (1989) apud SOUZA (1999), os três tipos de sistemas de monitoramento mais comuns em uma máquina-ferramenta com Comando Numérico são os monitoramentos da peça, da ferramenta e da máquina, conforme esquematizado na figura (2.11).

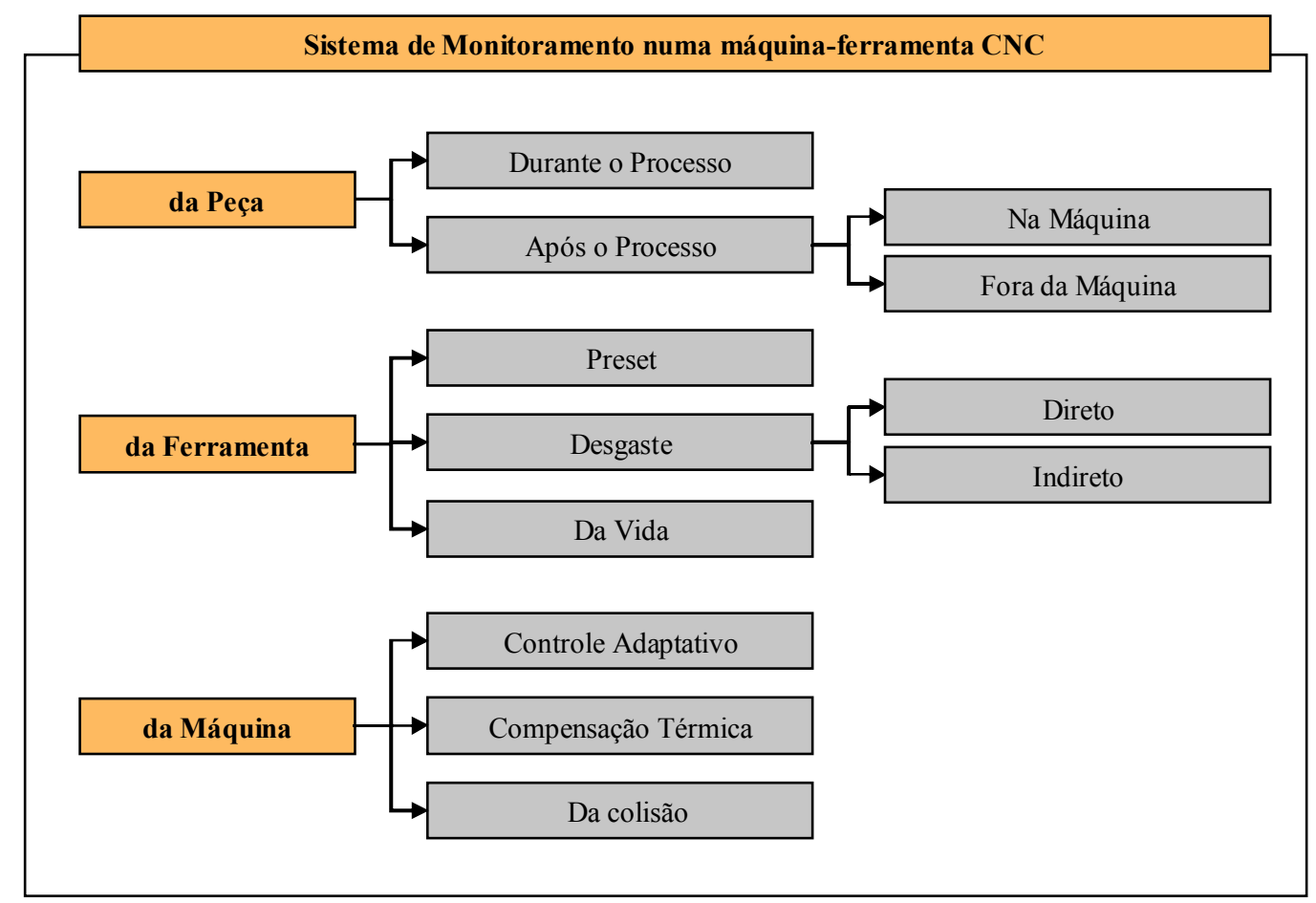

FIGURA 2.11 - Sistemas de Monitoramento. GRAHAM (1989) - modificado.

As avarias e desgastes de ferramentas são os maiores fatores que influem a qualidade e o ritmo de produção, conforme BLUM et al (1988). Além disso, segundo DINIZ \& PIGARI (1995), com o emprego de ferramentas de corte de alto custo, sua utilização otimizada torna-se imprescindível; entretanto, vem-se utilizando, em processos convencionais de usinagem, métodos estatísticos para trocas de ferramentas, que são ineficientes por não garantir a utilização total de sua vida. 
Todos esses fatores, entre outros, contribui para o surgimento de diversos métodos para o monitoramento de condições de ferramentas de corte, podendo estes ser divididos em, segundo BLUM et al (1988):

- Métodos Diretos (off-line): medição direta do desgaste ou detecção da quebra da ferramenta, após a interrupção da usinagem.

- Métodos Indiretos (on-line): medição indireta do desgaste ou detecção da quebra da ferramenta, através de sinais que possuem correlações com o processo de corte. Portanto, a medição é realizada durante a usinagem.

Segundo DU et al (1995), as tarefas do monitoramento, conforme esquematizado na figura (2.12), são principalmente compostas por três partes : aquisição do sinal, processamento do sinal e monitoramento/tomada de decisão.

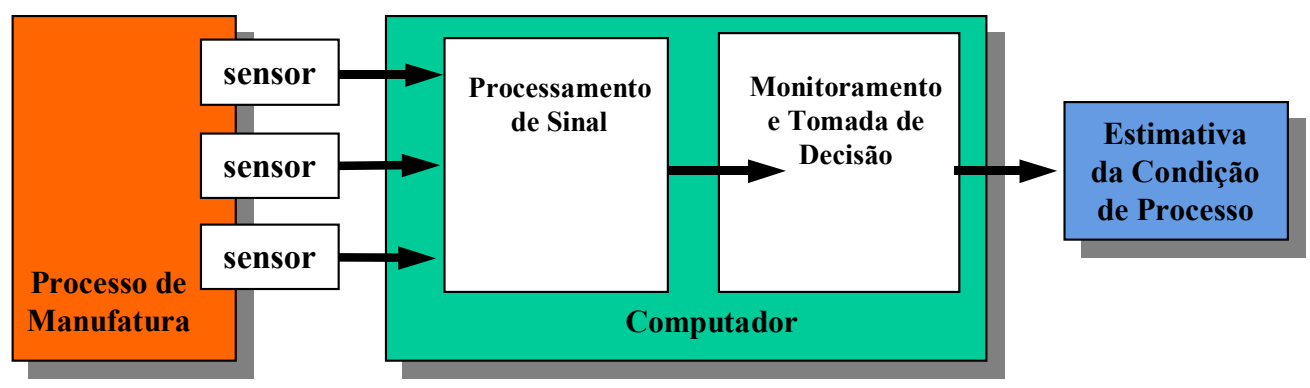

FIGURA 2.12 - Monitoramento de Processos de Manufatura.DU et al (1995)-modificado

Os sensores são os elementos chaves de muitos sistemas de monitoramento de processos e ferramentas, afirma JEMIELNIAK (1999). Segundo o mesmo, muitos têm sido inventados e aplicados em laboratórios, mas somente poucos vêm sendo usados comercialmente. $\mathrm{Na}$ tabela 2.1, tem-se alguns dos principais sensores utilizados em sistemas de monitoramento de condições de ferramentas de corte, com o respectivo método empregado, segundo MATHEW \& DAN (1990) apud SOUZA (1999), JEMIELNIAK (1999)*1, BYRNE et al (1995)*1, BLUM et al (1988)*2. 
TABELA 2.1 - Métodos para o monitoramento de estado de ferramentas de corte

\begin{tabular}{|c|c|c|c|}
\hline MÉTODO & PROCEDIMENTO & MEDIDA & SENSOR \\
\hline DIRETO & $\begin{array}{l}\text { Óptico } \\
\text { Partículas do desgaste e } \\
\text { radioatividade } \\
\text { Resistência peça- } \\
\text { ferramenta } \\
\text { Tamanho da peça } \\
\text { Distância peça-ferramenta }\end{array}$ & $\begin{array}{l}\text { Forma ou posição da borda } \\
\text { Tamanho da partícula de } \\
\text { concentração } \\
\text { Alteração na resistência } \\
\text { elétrica da junção } \\
\text { Dimensão da peça sendo } \\
\text { usinada } \\
\text { Distância entre ferramenta } \\
\text { ou suporte à peça }\end{array}$ & $\begin{array}{l}\text { Câmera de TV, sensor } \\
\text { óptico, espectrofotômetro, } \\
\text { cintilador } \\
\text { Medidor de radioatividade } \\
\text { Ohmímetro } \\
\text { Apalpador, sensor: } \\
\text { eletromagnético, ultra- } \\
\text { sônico, óptico } \\
\begin{array}{l}\text { Micrômetro, medidor de } \\
\text { deslocamento (LVDT) }\end{array}\end{array}$ \\
\hline INDIRETO & $\begin{array}{l}\text { Força de Corte } \\
\text { Emissão Acústica } \\
\text { Som e Ultra-som } \\
\text { Vibração } \\
\text { Temperatura } \\
\text { Potência } \\
\text { Rugosidade } \\
\text { Torque *1 } \\
\text { Velocidade de rotação *2 }\end{array}$ & $\begin{array}{l}\text { Alterações na Força } \\
\text { Energia nas ondas de } \\
\text { deformação ou stress } \\
\text { Ondas acústicas } \\
\text { Vibração da ferramenta/ } \\
\text { porta-ferramenta } \\
\text { Variação da temperatura } \\
\text { no ponto de corte } \\
\text { Corrente ou consumo de } \\
\text { potência do motor de } \\
\text { acionamento } \\
\text { Rugosidade da peça } \\
\text { Alterações de Torque } \\
\text { Alterações devido às } \\
\text { variações de torques }\end{array}$ & $\begin{array}{l}\text { Dinamômetro, strain gage } \\
\text { Transdutor piezoelétrico } \\
\text { Microfone } \\
\text { Acelerômetro } \\
\text { Termopar, Pirômetro } \\
\text { Amperímetro, sensor de } \\
\text { corrente (efeito Hall) } \\
\text { Agulha mecânica, sensor } \\
\text { ótico, laser } \\
\text { Sensor de torque } \\
\text { Tacômetro }\end{array}$ \\
\hline
\end{tabular}

Segundo DU et al (1995), processamento do sinal e monitoramento/tomada de decisão podem ser chamados de estratégia de monitoramento.

Existem basicamente duas estratégias. Uma utiliza-se de técnicas de aquisição de sinais, na qual sinais de saída mostram alguma relação com as características do processo. Assim, pode-se determinar sinais que representam um estado normal do processo, e compará-los com posteriores sinais, com o intuito de 
detecção de inconformidades. A outra, utiliza-se de modelos que relacionam os sinais de saída com os mecanismos do processo. Assim, juntamente com as informações dos sensores usa-se um modelo matemático para prognosticar o comportamento do processo, conforme afirmado por BYRNE et al (1995). No entanto, pelo menos até o final de 1996, segundo SANTOCHI et al (1997), não existe nenhum exato ou confiável modelo matemático para processos de corte, com a capacidade de prognosticar o desgaste de ferramentas, a quebra, a qualidade, a temperatura de corte, força e potência.

Um simples método de extrair informações de sinais de sensores é a utilização de limites (thresholds) adequadamente determinados. Assim, segundo BYRNE et al (1995), se o limite é cruzado pelo sinal, tal fato deve-se a alguma situação do processo, como colisões, quebra de ferramentas, etc. Alguns dos principais tipos de limites são, conforme JEMIELNIAK (1999):

1. Limites fixados

São limites fixos ou flutuantes (de acordo com o número de ciclos realizados).
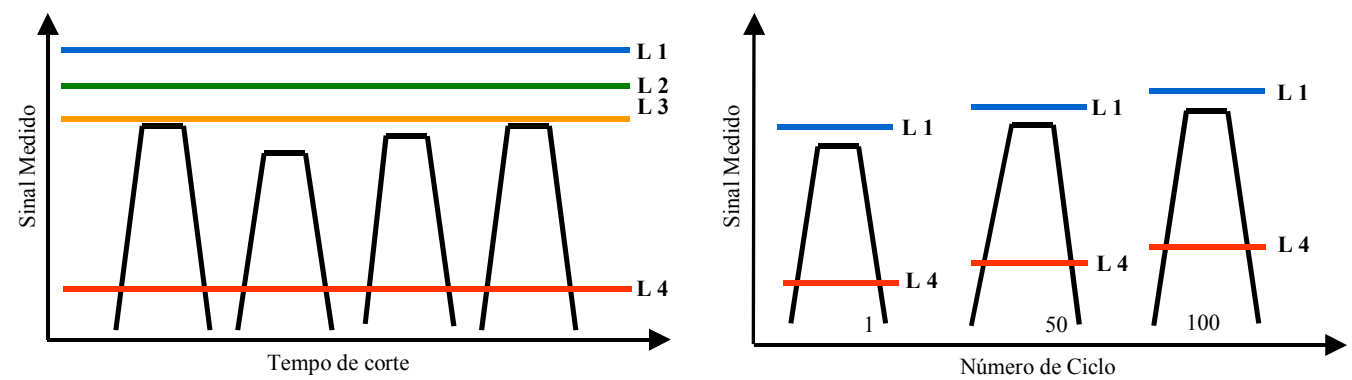

FIGURA 2.13 - Estratégia de Monitoramento: Limites Fixos e Flutuantes

2. Limites definidos pelo tempo

São limites fixos que variam com o tempo.

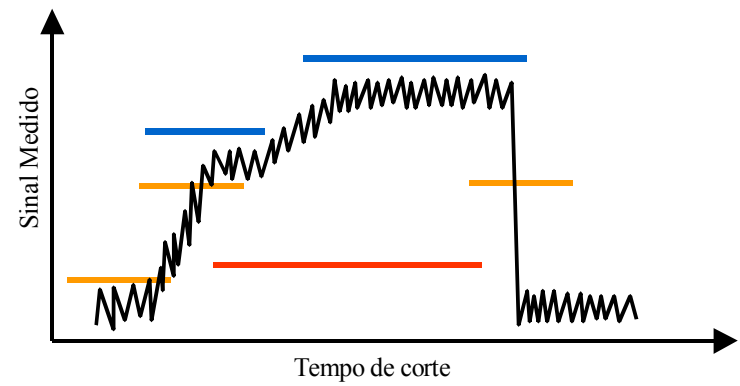

FIGURA 2.14 - Estratégia de Monitoramento: Limites definidos pelo tempo 
3. "Assinatura da peça"

São limites que variam baseados no tempo ou posição, no decorrer do processo de corte.

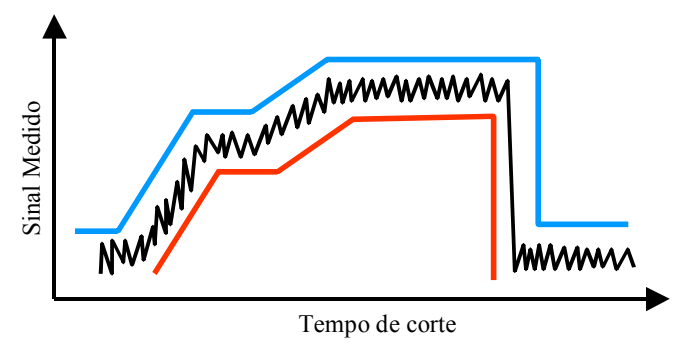

FIGURA 2.15 - Estratégia de Monitoramento: "Assinatura da peça”

4. Reconhecimento de padrão

Os limites são determinados por sinais históricos de situações, usando-se freqüentemente estatística, como a quebra de diversos tipos de ferramentas.

\subsection{Sistemas de Supervisão e Controle de Processos}

Os componentes básicos de um Sistema de Supervisão e Controle de Processos variam de acordo com o tipo de processo, porém possuem vários aspectos em comum, tais como certos tipos de sensores, controladores e redes de campo.

Normalmente os processos industriais são classificados, segundo AUTOMACAO.NET (2001), em:

- Processos Contínuos: possui regime permanente, onde a quantidade de produto final está relacionada com a quantidade de matéria prima.

- Processos por Bateladas: o produto final é resultado da adição de quantidades definidas de matérias primas no decorrer do processo.

- Processos Discretos: a matéria prima é trabalhada em várias etapas até atingir o produto final. 
Assim, o processo de usinagem é classificado como processo discreto, para o qual o sistema proposto foi desenvolvido.

\subsubsection{Descrição Geral}

Tem-se, a seguir, uma descrição resumida dos componentes básicos de um Sistema de Supervisão e Controle de Processos Discretos (figura 2.16), com posterior detalhamento dos mesmos.

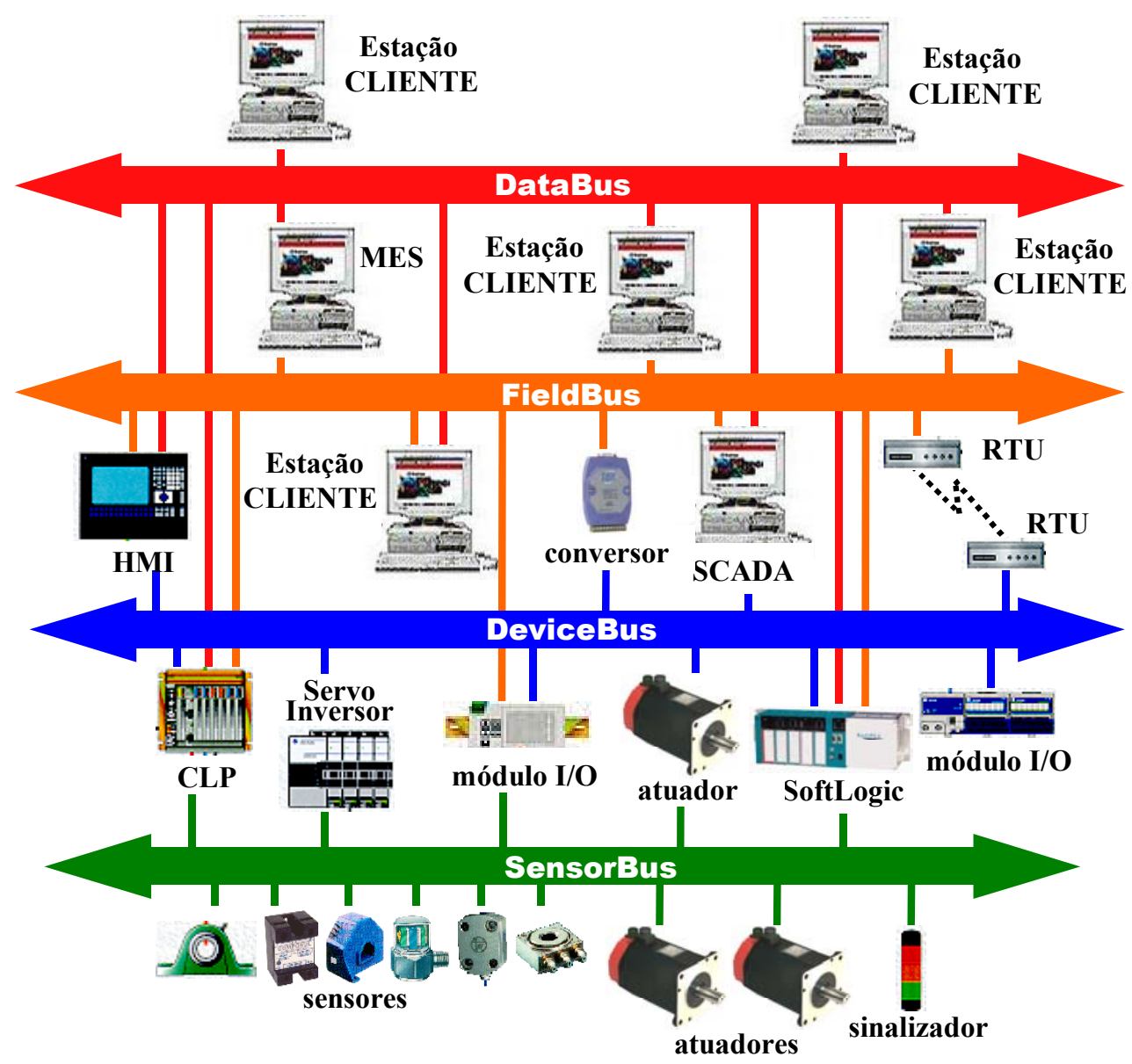

FIGURA 2.16 - Esquema geral de um sistema de supervisão e controle de processos. 


\section{Equipamento de Campo}

Responsáveis pela "leitura" de grandezas físicas, tomada de decisões e atuações no processo. Fazem parte :

- Sensores

- Módulos de aquisição de sinais (analógicos ou digitais)

- Controladores (CLP, SoftLogic, CNC, painel de relés, etc.)

- Atuadores: equipamentos (motores, inversores de freqüência, contatores, relés, solenóides, etc) que efetivamente atuam no processo.

\section{Redes de Comunicação}

Responsáveis pela troca de dados entre os equipamentos de campo e softwares. Suas principais funções são, segundo HONEYWELL (2000), ROCKWELL (2000), SIEMENS (2000), WONDERWARE (2000):

- Controlar: permite troca de dados em tempo real com os atuadores, através de uma variedade de métodos, tais como: taxas de refresh em I/O selecionados, compartilhamento de inputs, interlocking entre controladores, etc.

- Configurar: possibilita configurar todos os equipamentos que estão na rede, de qualquer localidade da mesma. Pode-se configurar equipamentos em start-up, modificar parâmetros com um click de mouse ou através de um controlador lógico, sem ter qualquer impacto no desempenho do controle.

- Coletar Dados: permite a coleta de dados de equipamentos de campo, possibilitando a visualização em displays HMI, cálculos de tendências e análises, administração de manutenção e solução de problemas.

Possuem características diferentes, dependendo do nível de automação em que se encontram. Segundo ROCHA (1998), são resumidamente classificadas em:

- DataBus

- FieldBus 
- DeviceBus

- SensorBus

\section{Softwares}

Responsáveis pela programação e comunicação com os equipamentos de campo, interface homem-máquina, controle do processo e manipulação de informações. Nos sistemas de Supervisão e Monitoramento, encontramos principalmente os softwares:

- SCADA (Supervisory Control And Data Acquisition)

- $\quad$ MMI ou HMI (Man Machine Interface ou Human Machine Interfacing)

- Softwares para programação de CLPs

\subsubsection{Equipamentos de Campo}

Segundo BUZATTO (1999), a automação de máquinas e processos passou por diversas fases de tecnologias:

1. relés e contatores

Problemas relacionados com relés eletromecânicos, como queima de contatos, desgaste mecânico, espaço ocupado, etc.

2. relês de estado sólido, baseados em semicondutores (TTL - transistortransistor logic, ou DTL - diodo-transistor logic)

Problemas nas interligações entre os diversos estágios da lógica, que eram feitas através de fios.

3. microprocessadores

Surge então a lógica programada, que por uma simples troca de programa pode-se alterar o fluxograma da arquitetura de controle.

"No campo de controles de modo geral, o Controlador Lógico Programável, CLP, foi o produto que criou uma cultura própria, substituindo totalmente os painéis de relês. Na área de controle de máquinas-ferramentas, o Controle Numérico, que havia nascido ainda no tempo da lógica DTL, passou a se chamar CNC, Controle 
Numérico Computadorizado, e vivenciou uma evolução vertiginosa" (BUZATTO, 1999, p. 70)

Paralelamente a essas fases de tecnologias de automação e controle industrial, houve uma evolução vertiginosa de computadores pessoais.

Hoje se torna cada vez mais comum o emprego de computadores no meio industrial para automação e controle de processos.

Inicialmente empregados na administração e supervisão de tarefas "off-lines", passaram a ser utilizados para coleta de dados de chão de fábrica, interligação em redes, e, mais recentemente, em lugar de CPUs de CNCs e substituindo totalmente tarefas antes desempenhadas por CLP, afirma BUZATTO (1999).

Segundo GONÇALVES FILHO (1994), com o advento de novos materiais, difíceis de usinar, juntamente com exigências de qualidade com tolerâncias na faixa de 1 a $2 \mu \mathrm{m}$, os melhores operadores de máquinas chegaram ao limite de suas habilidades ou possibilidades. Esses requisitos aliados com a necessidade de flexibilidade de fabricação, levaram a uma forma de controle automático de máquina conhecido pelo nome genérico de Comando Numérico $(\mathrm{CN})$.

No início da década de 70, com a prática do conceito CAM (Computer-Aided Manufacturing), aumentou-se a ênfase do uso do computador na manufatura, levando o surgimento de novas formas de Comando Numérico, como o CNC (Comando Numérico Computadorizado). Desde então, vem sofrendo melhorias contínuas e aumento do seu emprego na produção. Finalmente, em 1992 surgiram os primeiros CNC abertos (arquitetura aberta), que possibilitam modificações visando comandos e funções específicas do cliente, afirma GONÇALVES FILHO (1994).

Atualmente, no parque industrial brasileiro, encontramos CNCs tanto de arquitetura proprietária quanto de arquitetura aberta, ou até mesmo um misto das duas (arquitetura híbrida).

Conforme COELHO et al (1999), pode-se dizer que o CNC é um equipamento eletrônico capaz de receber informações através de uma entrada de dados própria, tratar estas informações e transmiti-las em forma de comando à máquina-ferramenta de modo que esta, sem a intervenção do operador realize as operações na seqüência programada. De forma geral os CNCs podem receber informações através de leitora de fitas (os mais antigos), manualmente pelo painel de 
controle da máquina (forma mais comum) e através de outros microcomputadores ligados em redes locais ou através da Internet, de qualquer parte do globo. Na figura 2.17, tem-se um esquema geral de uma unidade de controle de um sistema CNC .

No CNC são carregados os programas em linguagem $\mathrm{G}$, que contém as etapas de usinagem a serem executadas, juntamente com as condições de usinagem como o avanço, rotação, etc. Esses parâmetros são devidamente enviados para o CLP e Controladores através de linguagens próprias (Flags e Q, respectivamente) . Estes (CLP e Controlador), por sua vez, executam suas funções com base nessas informações. Os CLPs além de receberem informações do CNC, também recebem dados de sensores, relés, etc

Quanto aos controladores, estes recebem informações tanto do CNC quanto do CLP, controlando adequadamente os atuadores .

Em um CNC de arquitetura aberta, dados do programa CN e do CLP (até mesmo dados on-line) podem ser acessados e até modificados (este último com algumas limitações por questões de segurança) por programas aplicativos, através de bibliotecas DLL (Dynamic Linking Libraries), garantindo maior flexibilidade e melhor proveito da máquina, possibilitando melhores desempenhos.

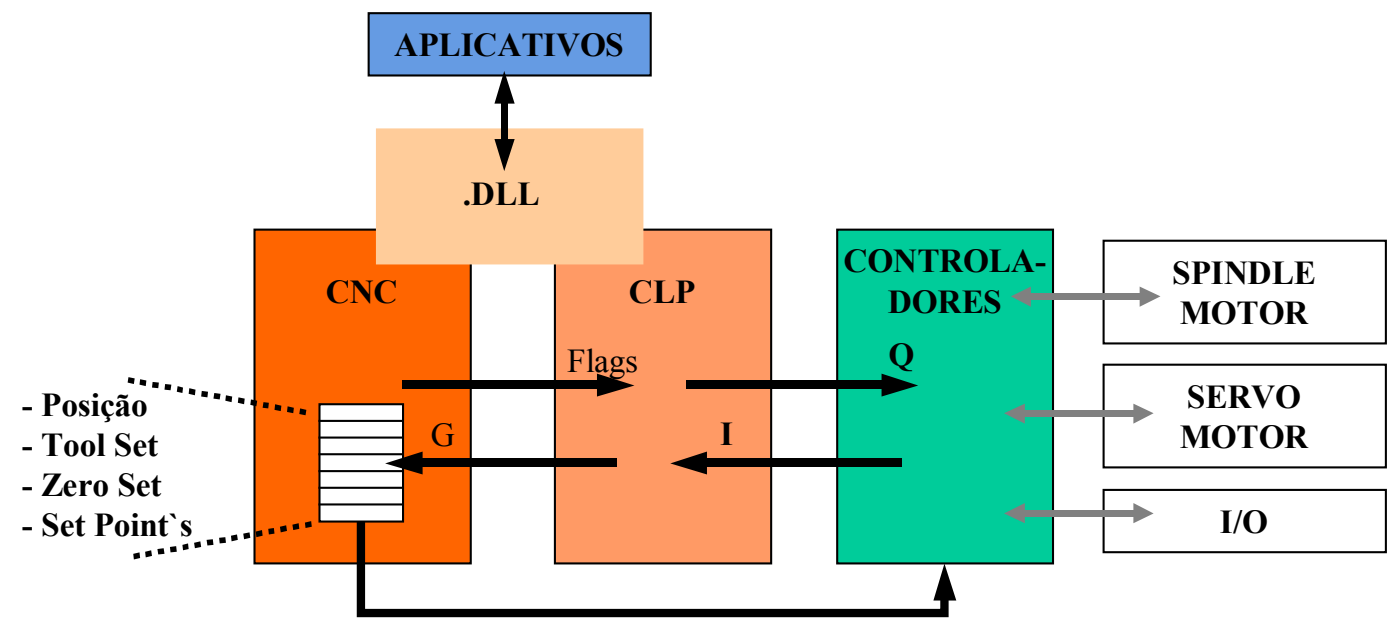

FIGURA 2.17 - Esquema geral de CNC de arquitetura aberta

Controladores Lógicos Programáveis (CLP) são equipamentos de controle que tomam decisões baseando-se em sinais de outros hardwares e/ou transdutores (botões, chaves de fim de curso, sensores, CNCs, CLPs, computadores, etc) e em 
lógicas previamente programadas, através de linguagem Ladder (diagrama de contatos). São disponibilizados em módulos, tendo como os principais :

- módulo CPU

- módulo de entradas e saídas digitais e/ou analógicas

- módulo de interface de comunicação com redes de campo e wireless

- fonte de alimentação

"Segundo a ARC (Automation Research Corporation), SoftLogic é uma classe de software designada para executar em um microcomputador comum as mesmas funções ou tarefas executadas pelos sistemas baseados em hardware, os CLPs ou SDCDs (Sistemas Digitais de Controle Distribuídos)" (MARINO, 2000, p. $31)$.

Assim como os CLPs, também são constituídos em módulos. Entretanto, por ser executado em um computador, apresenta características adicionais, tais como:

- servidor FTP (File Transmission Protocol)

- servidor WEB

Segundo ISA (2000), sensores são equipamentos que produzem sinais de tensão ou corrente, representando alguma propriedade física medida (temperatura, força, pressão, velocidade, vazão, etc). Geralmente, esses sinais requerem algum tipo de processamento antes de serem utilizados. Os sensores são também conhecidos como "detectores" ou "elementos primários".

Estes sensores podem fornecer sinais através de comunicação direta com equipamentos, ou remotamente, através de Unidades de Terminal Remotas (RTU Remote Terminal Unit).

\subsubsection{Redes de Comunicação}

Segundo INTERBUSCLUB (2001), o aumento do grau de automação em máquinas e sistemas também aumentou a necessidade de redes de cabos paralelos 
devido ao grande número de canais I/O (Inputs/Outputs). Como conseqüência dessa crescente utilização de redes de cabos paralelos, houve o aumento de esforços para sua configuração, instalação, start-up e manutenção. Além disso, cabos paralelos possuem freqüentemente custos elevados, principalmente os utilizados para a transmissão de dados analógicos.

Como solução para este problema, surge em meados do final da década de 70 a primeira rede industrial de comunicações, comumente conhecida como Fieldbus.

Trata-se de uma rede de comunicação serial, que com apenas um único cabo de comunicação conecta-se a vários I/Os, podendo ainda se comunicar com vários outros níveis de automação (desde os Sensores\&Atuadores até os níveis de Gerenciamento e Administração, dependendo do tipo de rede), a ser explicado no próximo tópico.

Dentre as diversas vantagens do Fieldbus em relação às redes de cabos paralelos, estão (ilustração na figura 2.18):

- redução de cabos, reduzindo custos e tempo para planejamento, instalação, configuração;

- redução de terminais e gabinetes de controle;

- capacidade de autodiagnóstico, reduzindo tempo de start-up, manutenção e tempos de paradas;

- melhor confiabilidade, com maiores proteções contra falhas em sinais analógicos ;

- possibilidade de comunicação com vários níveis de automação; 


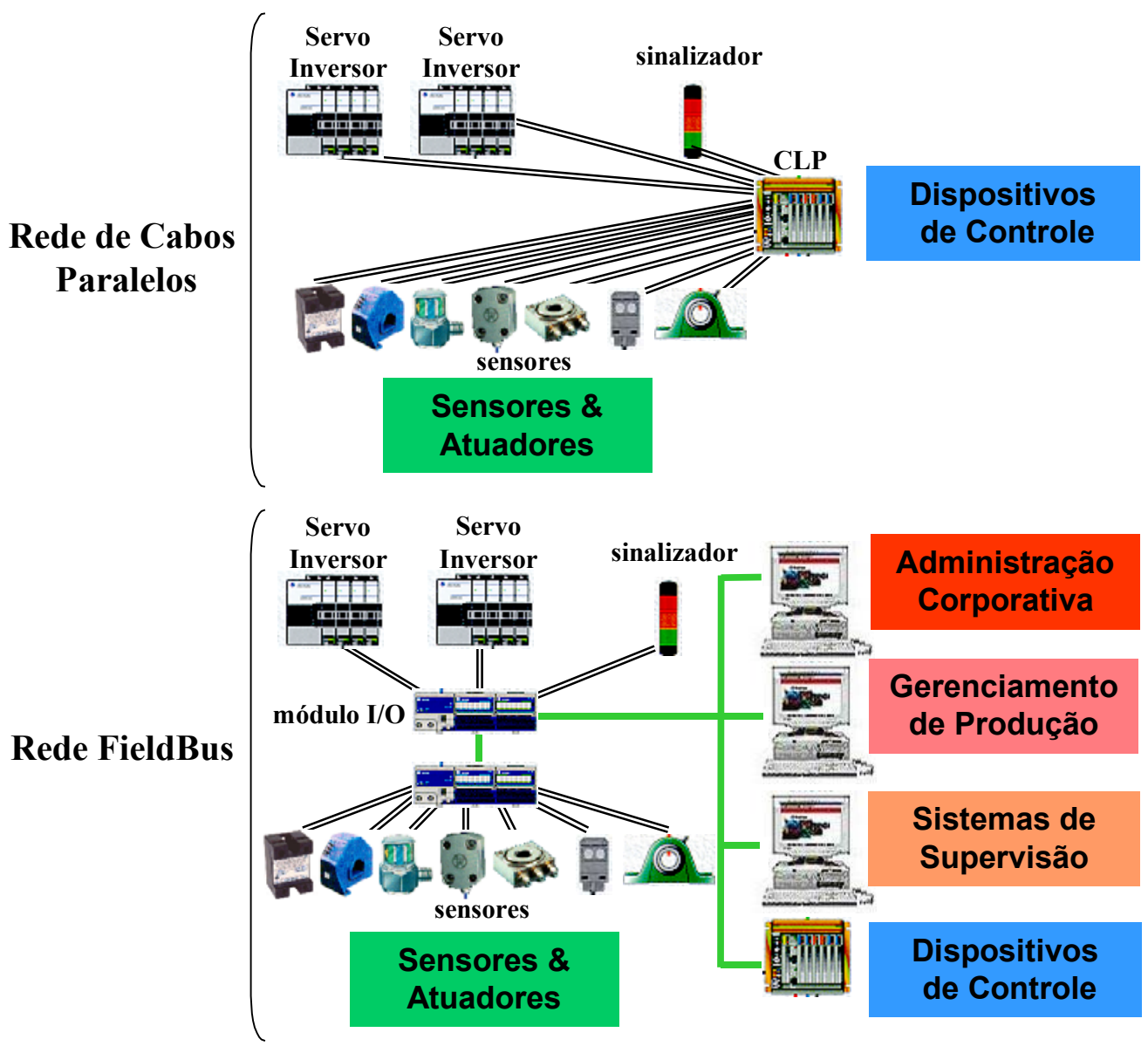

FIGURA 2.18 - Diferença entre redes de cabos paralelos e fieldbus

Atualmente existe uma grande quantidade de tecnologias de concepção aberta ou proprietária disponível no mercado em situação consolidada, sendo especificamente desenvolvidas para atender aos requisitos de cada um dos cinco níveis de dispositivos e equipamentos característicos de um sistema de automação. Contudo há sobreposições de atuações, como vem ocorrendo com o uso do Ethernet TCP/ IP em áreas antes exclusivas da classe FieldBus (figura 2.19 - adaptada de ROCHA (1998)). 
Quatro classes de redes de comunicação se destacam, segundo ROCHA (1998) :

- SensorBus : destinada para comunicação ao nível dos sensores e atuadores. Determinística e tempos de resposta extremamente curtos. Ex: AS-i, Seriplex, etc.

- DeviceBus : específico para dispositivos de controle e seus periféricos. Determinística e tempos de resposta curtos. Ex: DeviceNet, Interbus-S, Profibus-DP, etc.

- FieldBus : aplicada para comunicação entre unidades inteligentes (sistemas de supervisão e gerenciamento de produção). Determinístico, com alta performance. Ex: Fieldbus Foundation, Fieldbus WorldFIP, Modbus, Profibus-FMS, Profibus-PA, etc.

- DataBus : destinada para comunicação entre computadores. Estocástica, mas com capacidade de manipular grandes quantidades de informação em tempo não crítico. Ex: Ethernet TCP/IP, FDDI, etc.

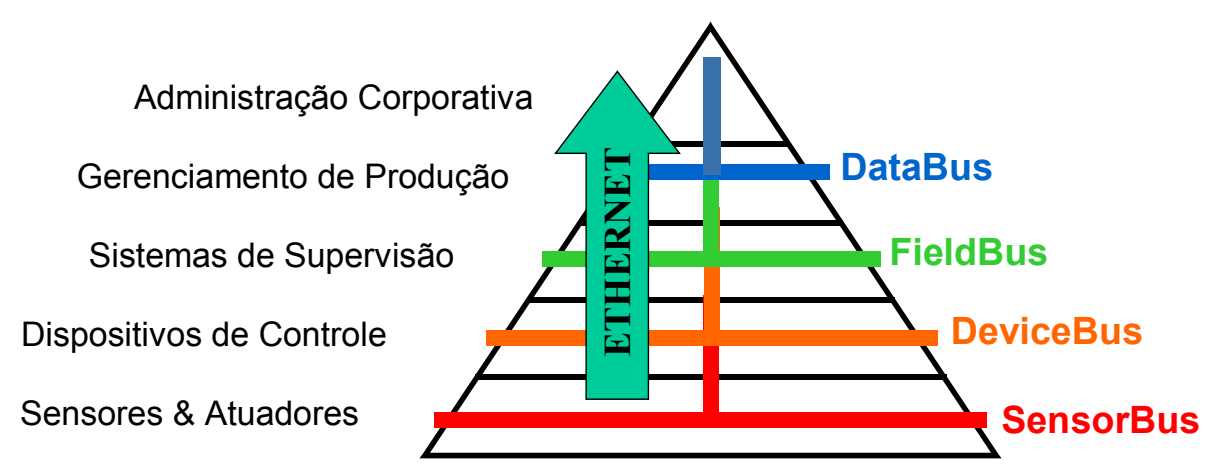

FIGURA 2.19 - Níveis de automação e tipos de redes

Para aplicações de supervisão utiliza-se, tipicamente, rede do tipo FieldBus que realiza a coleta de dados e controle de processos. Em geral são redes proprietárias (onde se encontra dificuldades de integração com equipamentos de fabricantes diferentes) e de custo elevado, porém determinísticas (pois não há colisões de dados) e de alto desempenho. 
Segundo ROCHA (1998), as principais características para uma boa escolha de rede de comunicação são:

\section{a) Confiabilidade}

Este conceito está baseado na capacidade da rede em garantir o transporte de dados em tempo compatível e a idoneidade das informações. Os principais fatores que impactam na confiabilidade são:

1. Concepção Determinística: identifica a capacidade da rede em garantir a disponibilidade de informações entre seus integrantes em um tempo determinado. Embora sendo uma característica intrínseca das Redes Determinísticas, dependendo da aplicação, algumas Redes Probabilísticas podem apresentar tal concepção onde a probabilidade de disponibilizar informações em um tempo determinado seria suficientemente elevada para traduzir-se em garantia.

2. Tratamento de Erros: caracteriza a capacidade da rede em identificar e tratar erros ocorridos no intercâmbio de informações. Visto que o erro é uma característica inerente do processo de comunicação associado a fatores de natureza diversa, a rede deve ser capaz de identificar e tratar adequadamente tal ocorrência, de forma a evitar que uma informação, partindo de uma origem e tendo sofrido distorções durante o processo de comunicação, não seja interpretada no destino como correta.

3. Imunidade Elétrica: deve conferir à rede características de isolação e susceptibilidade eletromagnética compatíveis com o ambiente elétrico, no qual a rede será aplicada. A não observação deste fator implica em conseqüências altamente negativas à confiabilidade e ao desempenho da rede, devido à dificuldade de identificar e corrigir problemas dessa natureza.

4. Segurança: onde deve ser observada a compatibilidade da rede com o ambiente físico, no qual a mesma será aplicada tal como: áreas com risco de 
explosão, ambientes com umidade excessiva, presença de substâncias corrosivas, etc.

\section{b) Desempenho}

Identifica a eficiência e a eficácia da rede como instrumento de intercâmbio de informações. Entre os fatores que a caracterizam temos:

1. Tempo de Resposta : identifica o tempo consumido pela rede para transferir informações. É importante destacar que não se trata da velocidade de comunicação, a qual não é fator de medida direto do desempenho, visto que a mesma considera a taxa de transferência total de dados da rede, ou seja, incluindo informações de controle e gestão, as quais compõem o chamado Envelope de Comunicação (Overhead). O tempo de resposta deve considerar medidas como o Throughput, que define exclusivamente a taxa de transferência de informações (sem o envelope), ou o Tempo de Ciclo, que identifica o tempo total necessário para o intercâmbio de informações na rede, considerando um determinado volume de dados e/ ou uma determinada quantidade de integrantes.

2. Método de Acesso : define como é gerido o uso da rede por seus integrantes. Algumas redes de acesso livre, por exemplo, podem permitir a apropriação por um tempo excessivo, tornando-a indisponível aos demais nesse período. Já redes com princípio Pergunta-Resposta (Query-Response), por exemplo, exigem um ciclo adicional para cada ciclo de comunicação. Filosofias de acesso compartilhado, apesar dos limites de acesso impostos, permitem um uso mais democrático dos recursos de comunicação sem prejuízos ao desempenho.

\section{c) Capacidade Operacional}

Os recursos disponíveis para a efetivação da comunicação de dados em uma aplicação compõem a capacidade operacional da rede sendo definida pelos seguintes fatores : 
1. Quantidade de Integrantes : determina o número de elementos que podem ser interligados na rede de comunicação de forma simultânea e que deve ser compatível com a quantidade de dispositivos que se deseja integrar através da rede considerando ainda futuras expansões.

2. Área de Cobertura : especifica a abrangência física da rede em termos da distância máxima, a qual deve atender às necessidades de posicionamento remoto dos vários integrantes da mesma.

3. Topologia : define a adaptação geográfica da rede na localidade onde a mesma será implantada. Entre as topologias mais conhecidas temos : Barramento (Bus), Anel (Ring), Estrela (Star) e Árvore (Tree).
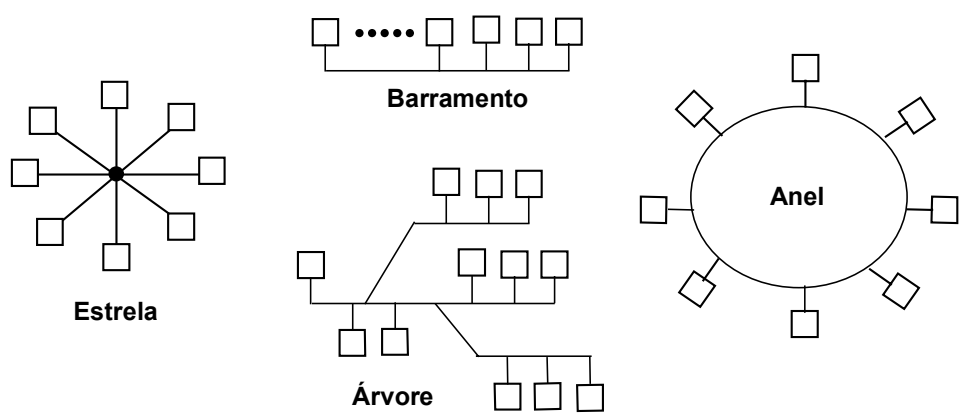

FIGURA 2.20 - Exemplos de topologias de redes

4. Protocolo de Comunicação : considerado o principal elemento tecnológico das redes de comunicação, ao qual estão associadas todas as suas características operacionais. Entre elas, destacamos o procedimento de acesso que deve garantir a transparência dos integrantes da rede, através de técnicas de endereçamento, definição de dados, seleção de dispositivos, priorização e outras e, ainda as funções operacionais que a rede é capaz de executar entre seus integrantes, tais como: operações de escrita e leitura únicas ou múltiplas, verificação de status entre outras. 


\section{d) Fatores Econômicos}

A fim de conduzir a uma estratégia factível, é necessário considerar os aspectos econômicos que envolvem a adoção de uma rede de comunicação industrial, os quais estão associados aos seguintes custos :

1. Custos de Desenvolvimento : apesar de normalmente não ser considerado na análise econômica, o custo de desenvolvimento pode impactar significativamente no resultado final. Redes de comunicação complexas demandam maior tempo de projeto, devido à riqueza de detalhes e à necessidade de procedimentos de programação, configuração e parametrização mais elaborados.

2. Custos de Instalação : a importância dada a outros componentes econômicos, como o custo dos produtos que serão interligados pela rede, acaba favorecendo a desconsideração do custo de implementação da própria rede, o que leva erros que podem inviabilizar o projeto. Os componentes necessários para constituir a rede, tais como: cabos, conectores, caixas de derivação, roteadores, interfaces, repetidores e outros, devem ser considerados a fim de revelar o valor associado com a rede isoladamente.

3. Custo de Manutenção : a maneira com a qual a rede deve ser tratada para corrigir uma situação de falha pode representar tempos de parada excessivos, que levam a demasiadas perdas de produção ou danos irreversíveis ao processo. A necessidade do uso de ferramentas especiais e treinamento também constituem custos adicionais a serem considerados.

4. Custo dos Produtos : obviamente o custo de um produto dotado de interface de comunicação é superior ao do mesmo produto sem esta característica, uma vez que os ganhos da adoção de tecnologias de comunicação e uso de dispositivos inteligentes revelam-se ao se analisar o empreendimento como um todo. Entretanto, o custo dos produtos pode variar conforme a rede de comunicação visto que, devido a fatores diversos, um mesmo produto pode 
possuir preços diferentes em função da rede de comunicação com a qual o mesmo é compatível.

\section{e) Posição no Mercado}

Devido à importância e à natureza estratégica que a escolha da rede de comunicação possui no sistema de automação, é importante analisar os aspectos relacionados à tecnologia da rede a fim de obter garantias quanto à sua posição no mercado. Para tanto, destacamos os seguintes fatores:

1. Padrão Consolidado : a tecnologia utilizada pela rede deve obter amplo reconhecimento do mercado como instrumento potencial para atender às necessidades apresentadas. Tecnologias não reconhecidas pela indústria possuem baixa probabilidade de sobrevivência, tendendo a desaparecer em curtos espaços de tempo.

2. Base Instalada : normalmente utilizada como indicador da aceitação da rede no mercado, a base instalada deve considerar as aplicações nas quais a rede tem sido utilizada.

3. Referências : a indicação de empresas que utilizam a rede de comunicação em análise permite o conhecimento de vários fatores relacionados ao cotidiano da sua utilização, podendo revelar aspectos normalmente difíceis de considerar quando da sua avaliação ou, ao menos, fornecer garantias adicionais da sua adoção.

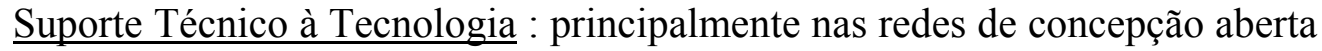
suportadas por associações, clubes, fundações, organismos de normalização ou outras entidades, torna-se importante analisar a estrutura técnica por trás da tecnologia. A rede de comunicação também é um produto e, portanto, deve ser adequadamente suportada por estruturas sólidas e competentes a fim de garantir sua sustentação no mercado. 


\subsubsection{Softwares}

Conforme IAS (2000) e INTECH (2000), tecnologia HMI (Human Machine Interfacing) ou MMI (Man Machine Interfacing) é definida como sistema de hardware/software que serve de interface entre operadores e equipamentos de planta. Permitem o controle de equipamentos através de plataformas computacionais. Equipamentos operacionais e funcionais da manufatura de um produto podem ser facilmente controlados por um "click de mouse". Nas tecnologias de HMI tem se utilizado muito de recursos gráficos nos últimos 10 anos e atualmente, em muitos casos, dispondo de animações do processo de manufatura em telas de computadores. Operadores podem ser alertados para problemas através de alarmes visuais ou sonoros que previnem a ocorrência de problemas potenciais.

Segundo AUTOMACAO.NET (2001) e DANEELS \& SALTER (1999), SCADA (Supervisory Control and Data Acquisition) são softwares que além de servirem como interface homem/ máquina, como os softwares HMI ou MMI (Human Machine Interfacing ou Man Machine Interfacing), podem também efetuar controles e distribuir informações entre estações via rede, com bom desempenho e segurança. São softwares robustos e confiáveis para aplicações de grande porte e para aplicações distribuídas em várias estações de trabalho.

São comumente utilizados em indústrias de processos, como: processamento de aços, geração de energia (convencional e nuclear) e distribuição, processos químicos, indústrias de alimentos e bebidas, indústrias de açúcar e álcool, etc. O tamanho de cada planta pode variar de centenas à dezenas de milhares de canais input/output (I/O), afirma GERMAIN \& CLARKE (1998) .

São implementados no topo de sistemas de controle (centrais de controle figura 2.21), que, através de redes, e de unidades de terminais remotos (RTUs Remote Terminal Units) e/ou de CLPs, comunicam-se com equipamentos da planta de produção. Segundo TEK (1999) apud MEIRELES (2000), nestas centrais de controle (ou salas de controle), operadores podem acompanhar o funcionamento de 
equipamentos e o andamento da produção, com auxílio de interfaces gráficas especialmente desenvolvidas para auxiliar a visualização e a solução de problemas de chão de fábrica.

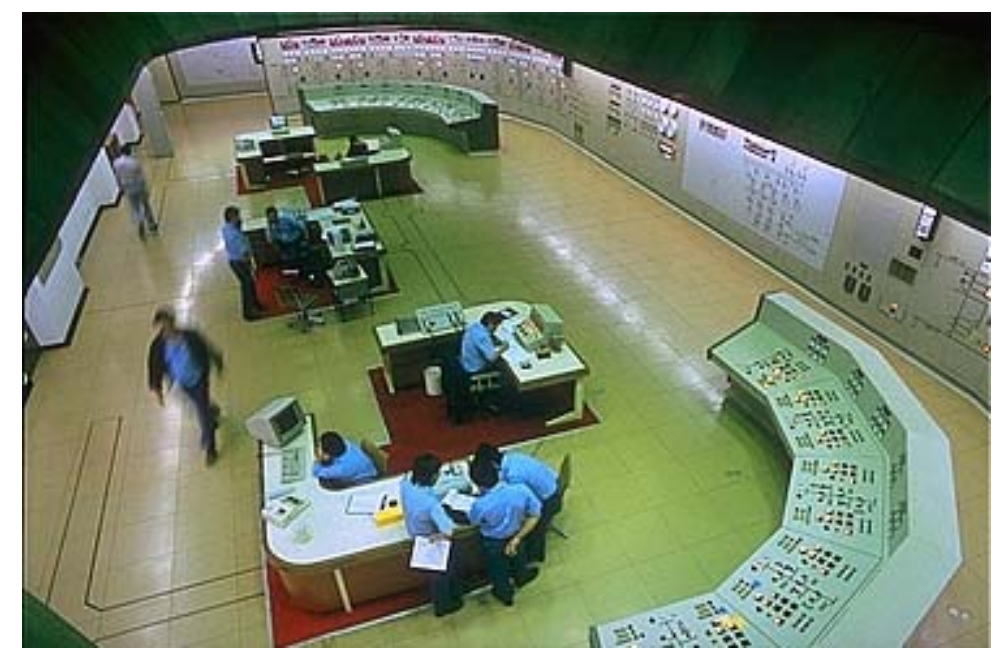

FIGURA 2.21 - Exemplo de Central de Controle

Resumidamente, suas principais características são:

- Aquisição de dados: aquisição de dados das estações remotas de I/O via drivers de comunicação.

- Controle: controle automático em malha fechada ou controle via atuação do operador.

- Displays de Processo: representações gráficas dos equipamentos de campo atualizadas automaticamente para retratar uma situação atual, como visto na figura 2.22 .

- Standby: sistemas duplicados em espera com a capacidade de tomar o controle no caso de uma falta do sistema principal.

- Integração: permite comunicação com sistemas corporativos, pois suporta SQL/ ODBC (Structured Query Language/ Open Database Connectivity).

- Segurança: Controle de acesso por usuário aos vários componentes do sistema.

- Gerenciamento da Rede: Monitoramento das condições de comunicação da rede.

- Outros: possui banco de dados proprietário, relatórios formatados, históricos, receitas, alarmes e CEP (Controle Estatístico de Processos), como visto na figura 2.22 . 


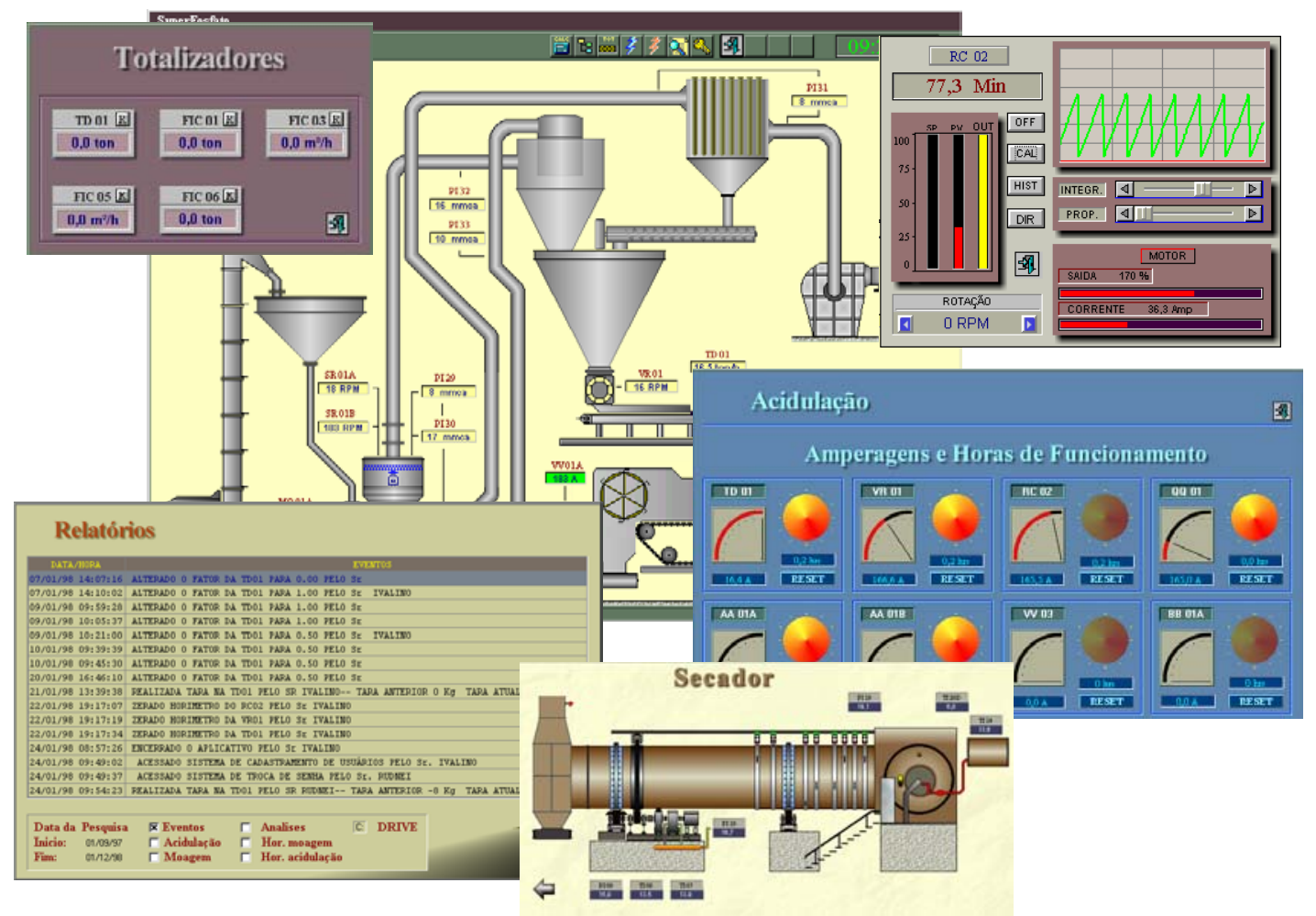

FIGURA 2.22 - Exemplos de telas de supervisão

Para a comunicação entre equipamentos, há a necessidade de protocolos (regras) a serem seguidos, e tecnologias a serem utilizadas. Segundo AUTOMACAO.NET (2001) e OPC (2001), os principais protocolos e tecnologias para troca de dados entre hardwares de chão de fábrica e softwares aplicativos são :

COM (Component Object Model) : Disponibiliza uma interface padrão de comunicação entre componentes. Possibilita que uma aplicação utilize recursos de outra ou do sistema operacional.

DCOM (Distributed component object model) : É o COM para aplicações em Rede; disponibiliza objetos remotos e locais; criado para Windows NT. 
OLE (Object Linking and Embedding) : Antecessor do COM. Disponibiliza integração entre aplicativos, permitindo troca de vários tipos de informações. Criado pela Microsoft em 1992, OLE é mais flexível, eficiente, e robusto do que o DDE, mas não possui a performance necessária para automação.

DDE (Dynamic Data Exchange) : Nasceu com o Windows 3.0; é um protocolo padrão de troca de dados entre aplicações Windows. Utilizando Driver DDE, é possível coletar dados do chão-de-fábrica em Planilhas Excel, por exemplo. É um protocolo lento, não confiável e foi desenvolvido para trabalhar em uma máquina e modificado para pequenas aplicações em rede (NetDDE). Possui variações como FastDDE e AdvancedDDE que possuem os mesmos problemas do DDE original não foi desenvolvido para aplicações que necessitam de integridade de dados e alta velocidade. Deverá ser totalmente substituído pelo OPC.

NetDDE (Network Dynamic Data Exchange): protocolo para a troca dinâmica de dados entre quaisquer redes suportadas por Windows, como TCP/ IP, NETBEUI, IPX/ SPX e entre aplicações Windows, como Excel, Word, etc.

OPC (OLE for Process Control) : protocolo padrão de interfaces, propriedades e métodos para o uso de aplicações em controle de processos e automação da manufatura. Baseado nas tecnologias OLE (Object Linking and Embedding) e DCOM (Distributed Component Object Model), o OPC permite uma interface comum de comunicação com diversos dispositivos de controle de processo, indiferentemente do software de controle ou dispositivos no processo.

DLL (Dynamic Linking Libraries) : tipo de tabela que várias aplicações com rotinas comuns podem acessar ao mesmo tempo. Possui velocidade e integridade conforme programação das rotinas de acesso; normalmente é utilizada por aplicativos na mesma máquina. 


\section{Sistema de Supervisão e Monitoramento Proposto}

\subsection{Descrição Geral}

O projeto proposto é composto de dois sistemas que podem atuar simultaneamente durante o processo de torneamento: um de supervisão e outro de monitoramento. O sistema de supervisão permite o acompanhamento on-line de informações tecnológicas do torno, informações do processo e da produção, através de uma Intranet, ou até mesmo Internet. E, o sistema de monitoramento possibilita o acompanhamento e a compensação automática dos desgastes de ferramentas de corte, e o auxílio à escolha do momento mais adequado para a sua troca.

A figura 3.1 ilustra a arquitetura do sistema.

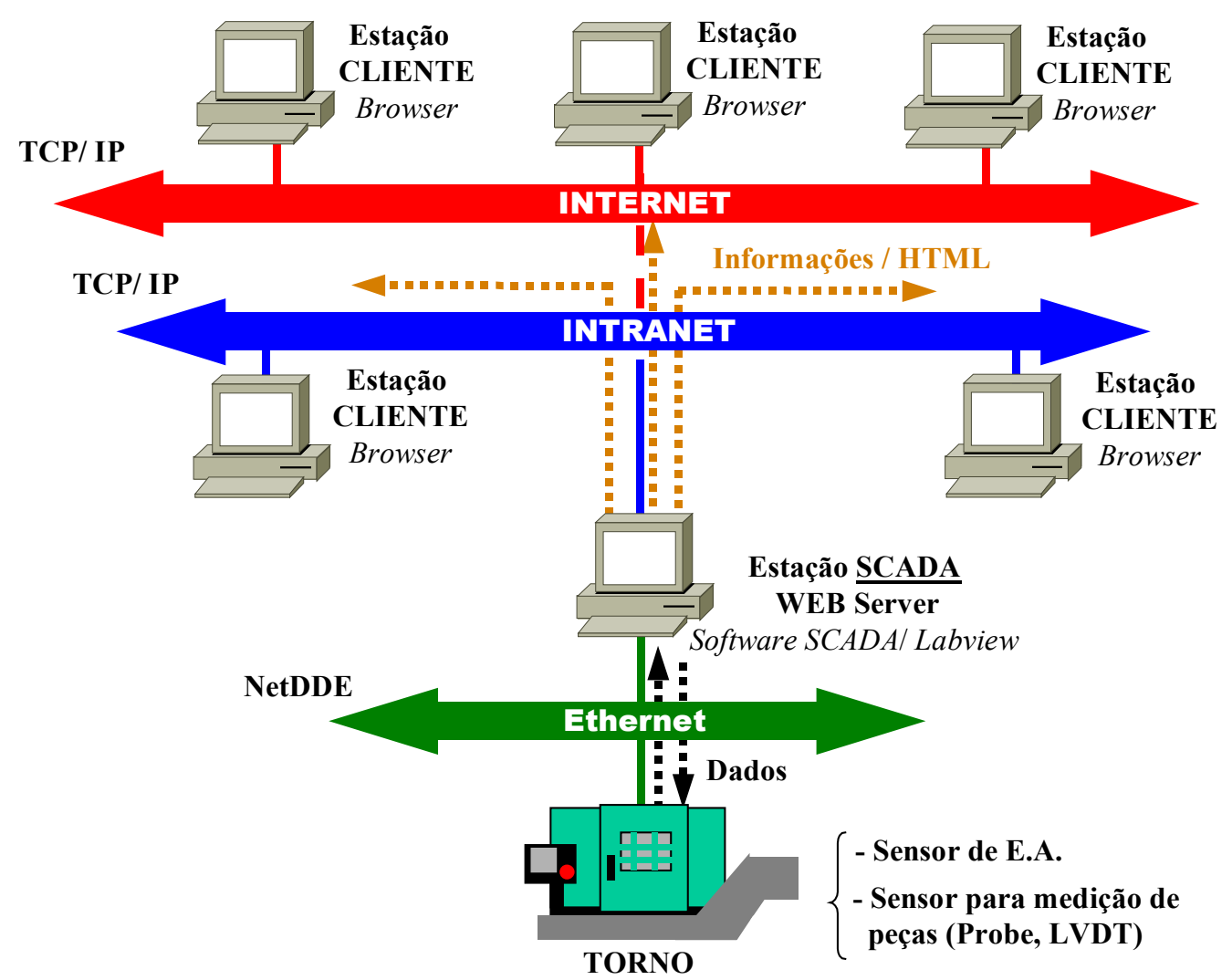

FIGURA 3.1 - Esquema geral do sistema 
A estação SCADAMEB Server (Supervisory Control And Data Aquisition/ Servidor $W E B$ ) recebe dados de máquina e de processo do torno (ex. velocidades de corte e avanço atuais, posição do castelo porta-ferramenta, bits do CLP, temperatura do motor, etc.), dados do programa $\mathrm{CN}$ (ex. velocidades e profundidade de corte de setpoint, dimensões básicas da peça, etc.) e de sensores (ex. emissão acústica, dimensão da peça acabada, contato ferramenta-peça, etc.), e as transformam em informações de produção (números de peças produzidas, peças fora de especificação, ritmo de produção, etc) que são disponibilizadas em telas no formato de páginas HTML (HyperText Markup Language), possibilitando a supervisão em estações CLIENTES através de softwares browsers (navegadores de páginas HTML). Assim a supervisão do processo de torneamento pode ser realizada via Intranet ou Internet, através de uma estação servidora com software SCADA e Servidor WEB, e estações clientes com programas comerciais (browsers - "navegadores" de páginas HTML) do tipo Netscape Comunicator, Internet Explorer, etc. Quanto ao monitoramento, a mesma estação SCADA/WEB Server recebendo dados das dimensões das peças acabadas, acompanha o desgaste das ferramentas de corte, realizando correções do posicionamento destas em relação às superfícies a serem usinadas. Além disso, indica o momento adequado para a troca de tais ferramentas de corte, tendo como referência as correções acumuladas das mesmas.

\subsubsection{Vantagens competitivas}

Tendo em vista o Modelo de Sistema de Manufatura (descrito no capítulo 1. Introdução), composto pelos departamentos de Engenharia, Chão de Fábrica, Suporte e Negócios, onde o fluxo de informações é vital para seu bom funcionamento, o sistema proposto busca auxiliar a troca de informações do Chão de Fábrica com os demais departamentos. 


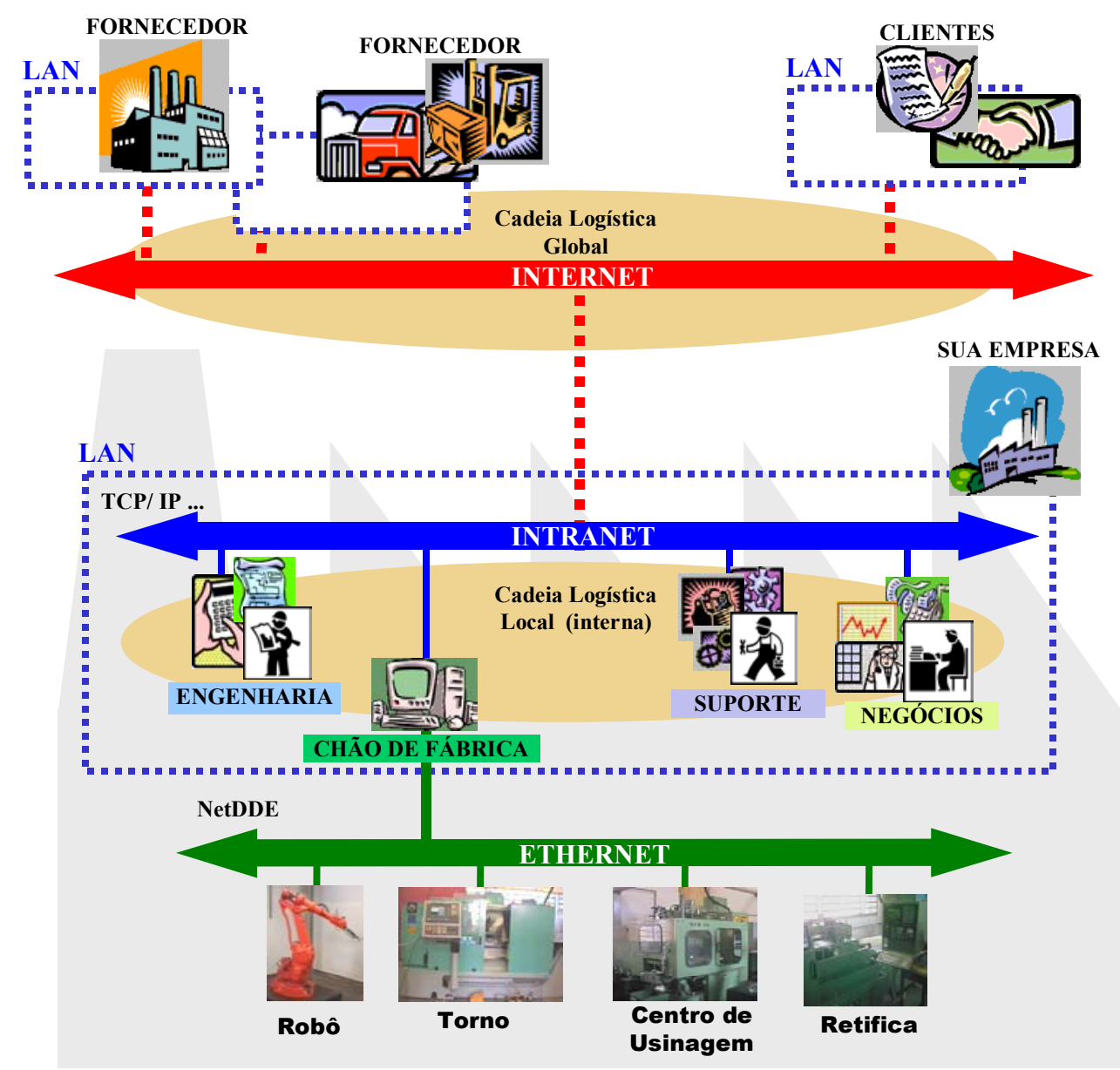

FIGURA 3.2 - Exemplo de aplicação do sistema como ferramenta de competitividade

$\mathrm{Na}$ figura 3.2 tem-se um exemplo de aplicação do sistema de supervisão como uma ferramenta de competitividade. Pode-se observar, na figura 3.2, uma empresa com seu Chão de Fábrica composto por máquinas interligadas por uma rede de campo (no caso uma rede Ethernet), disponibilizando informações adequadamente em uma Intranet para os departamentos, tais como:

1. Informações do processo (tempos de ciclo, tempos de corte, etc) para o departamento de Engenharia, permitindo futuras otimizações de ciclos de produção.

2. Informações de parâmetros tecnológicos das máquinas, possibilitando o acompanhamento e garantindo o bom funcionamento das mesmas pelo departamento de Suporte. 
3. E, finalmente, informações da produção (ritmo da produção, número de peças acabadas, refugadas, etc) para os departamentos de Negócios, auxiliando nas relações comerciais com seus clientes e fornecedores.

Isso conduz a uma melhor estruturação da cadeia logística local, auxiliando assim na sua integração com as demais empresas que formam a cadeia logística global, que podem acessar informações, conforme o interesse, agora através da Internet.

Além do sistema de supervisão, o sistema de monitoramento também se mostra como uma boa ferramenta de competitividade. Sabendo-se que as avarias e desgastes de ferramentas são os maiores fatores que influem na qualidade e no ritmo de produção, e que com o emprego de ferramentas de corte de alto custo torna-se imprescindível sua utilização otimizada, não é difícil justificar o emprego de sistemas de monitoramento de ferramentas de corte. O sistema proposto, utilizandose de um Comando Numérico Computadorizado (CNC) de arquitetura aberta e método direto (off-line) de monitoramento de desgaste de ferramentas de corte, torna automática a compensação de desgaste e auxilia na determinação do momento mais adequado para a troca de ferramentas, garantindo o seu máximo aproveitamento, além de peças produzidas dentro de suas especificações dimensionais e qualidades superficiais. 


\subsection{Tecnologias Utilizadas}

$\mathrm{Na}$ figura 3.3, a seguir, é apresentado um esquema geral dos componentes do sistema de supervisão e monitoramento proposto. Todos estes serão tratados com mais detalhes nos próximos itens.

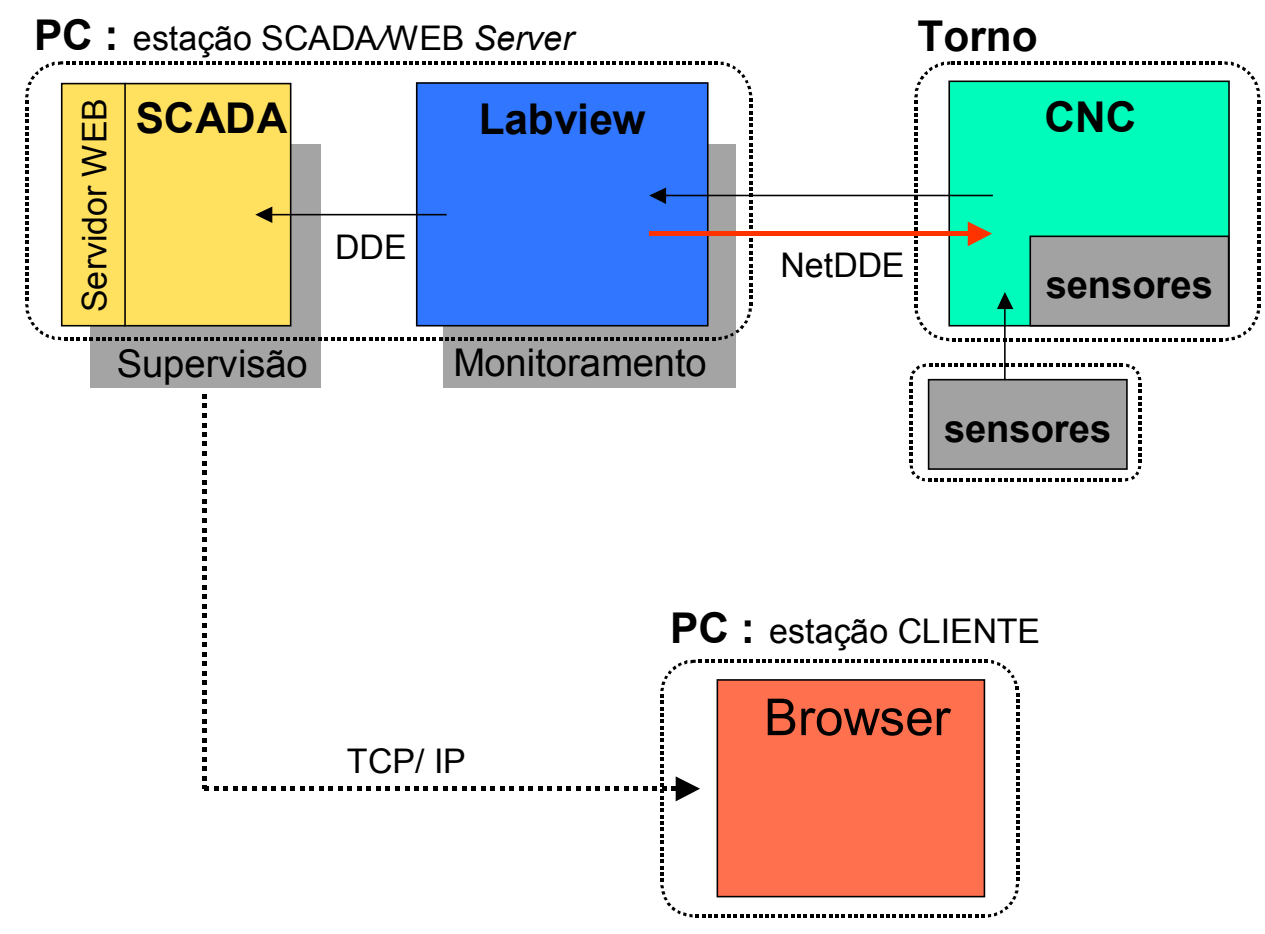

FIGURA 3.3 - Componentes do sistema de supervisão e monitoramento

O sistema foi desenvolvido em um torno CNC de arquitetura aberta (Siemens Sinumerik 810D), utilizando sensores originais de fábrica, e sensores adicionais para medição de peças (probe e/ou LVDT) e para a detecção de início de corte (sensor de emissão acústica). O CNC do torno, por ser de arquitetura aberta, permite troca de informações e/ou dados ${ }^{1}$ através de um protocolo padrão (NetDDE - Network Dinamic Data Exchange), via rede com padrão Fast-Ethernet.

\footnotetext{
${ }^{1}$ Dados são os componentes básicos a partir dos quais as informações são extraídas.
} 
No PC (Personal Computer) da estação SCADA/ WEB Server encontra-se os sistemas de monitoramento e supervisão do torno.

O sistema de monitoramento, que foi desenvolvido em software Labview, realiza comunicação com o torno (via protocolo NetDDE), obtendo dados e informações da máquina, do processo, do programa $\mathrm{CN}$ em execução e de sensores. Esses dados e informações são manipulados adequadamente, executando o monitoramento dos desgastes das ferramentas de corte, e gerando informações de processo (tempo de ciclo, de corte, etc), da produção (número de peças produzidas, peças acabadas, etc) e da máquina (temperatura do motor, informações do cooler do gabinete principal, etc) para o sistema de supervisão. Percebe-se, assim, que por realizar o monitoramento, há troca de dados nos dois sentidos entre o torno e o sistema de monitoramento.

O sistema de supervisão foi desenvolvido em software SCADA, utilizando-se também de um software servidor WEB. O software SCADA recebe as informações (de processo, produção e de máquina) do software Labview via protocolo DDE, organiza e as transforma em páginas de formato HTML, que juntamente com o servidor WEB distribui essas informações para as estações clientes, que podem estar em uma Intranet, ou até mesmo Internet. Ou seja, o software SCADA é a interface homem/ máquina do sistema, que dispõe de recursos gráficos, displays e animações do processo de torneamento.

Para as estações CLIENTES terem acesso a essas informações, necessitam apenas de um navegador de páginas HTML (software browser). Assim, independe do sistema operacional utilizado, garantindo boa portabilidade, grande abrangência e custos reduzidos de compartilhamento e expansão do sistema de supervisão. Tudo isto em contraste com sistemas típicos de supervisão onde há a necessidade de softwares SCADA em cada estação cliente, além do compartilhamento de informações ficar restrito a rede em que se encontra a estação servidora. 


\subsubsection{CNC de Arquitetura Aberta}

O Torno CNC INDEX GU-600 possui comando numérico Siemens Sinumerik 810D que é de arquitetura aberta. Portanto, utiliza-se de protocolos padrões não proprietários, o que facilita a integração com softwares aplicativos de qualquer outra origem.

Possui diversas funções que facilitam a aquisição de dados, tais como função de medição (MEAS) e registradores temporários $\left(\mathrm{R}_{\mathrm{i}}\right)$.

A função de medição utiliza o comando especial MEAS. Este permite a gravação da medida relativa de posição da ferramenta em um registrador $R_{i}$, no momento exato em que se recebe um pulso de $24 \mathrm{~V}_{\mathrm{cc}}$ na porta serial (DB9) do CNC. Esse sinal pode ser gerado por um sensor com probe ao tocar a superfície da peça usinada.

Os registradores temporários $\left(\mathrm{R}_{\mathrm{i}}\right)$ são variáveis globais que podem ser utilizadas nos programas $\mathrm{CN}$, e podem ser lidas ou modificadas por aplicativos utilizando-se do protocolo NetDDE .

O CNC utiliza sistema operacional Windows Workgroup 3.11 e placa de rede que permite comunicação com redes Ethernet TCP/ IP. Através do protocolo NetDDE, disponibiliza uma série de dados - desde sinais de sensores e de módulos I/O (sensores de posição, de temperatura dos motores, bits, bytes, etc) até dados de parâmetros de usinagem (velocidades de corte, de avanço, etc).

\subsubsection{Rede Ethernet}

No sistema de supervisão e monitoramento proposto, optou-se por utilizar uma rede de arquitetura aberta (cujas soluções de problemas possam ser encontradas com mais de um fabricante), e de padrão consolidado no mercado. Além disso, devido ao sistema não efetuar o controle do processo, torna o fator determinístico não essencial na escolha do tipo de rede.

Desta forma, adotou-se uma arquitetura de redes TCP/ IP com padrão FastEthernet (IEEE 802.3u). Trata-se de uma rede muito popular, altamente difundida, de baixo custo e com numerosas técnicas de instalação e manutenção. Possui bom desempenho para coleta de dados de chão de fábrica, e embora não tendo origem 
determinística, pode ser utilizada para controle de processos com a condição da utilização de hub, switch e/ou roteador especiais, conforme MACIEL \& RITTER (1998) e WOJCIK \& RANGANATHAN (2000).

O protocolo para comunicação entre a estação SCADA/ WEB Server e o Torno é o NetDDE - protocolo para a troca dinâmica de dados entre quaisquer redes suportadas por Windows, como TCP/ IP, NET-BEUI, IPX/ SPX e entre aplicações Windows, como Excel, Word, etc. E, para a comunicação entre a estação SCADA/ WEB Server e as estações Clientes é o TCP/ IP (protocolos de transporte e de rede) e HTTP (HyperText Transfer Protocol - protocolo de aplicação), padrão da WEB, utilizando páginas HTML .

\subsubsection{Sensor para medição de peças}

O sistema de supervisão e monitoramento foi desenvolvido com a flexibilidade de escolha entre diversos tipos de sensores para medição de peças. Para testar o sistema um sensor de deslocamento do tipo LVDT (Linear Variable Differential Transformer) foi utilizado.

No sistema, o sensor utilizado para a medição dos diâmetros da peça foi um LVDT da Macro Sensors (GHSA 750 125), com curso de $12 \mathrm{~mm}$.

O LVDT é fixado ao suporte porta-ferramentas modelo DIN (figura 3.4). Suas leituras são repassadas diretamente para a estação SCADA/ WEB Server, utilizando-se de uma placa de aquisição A/D National Instruments PCI-MIO-16E-4.

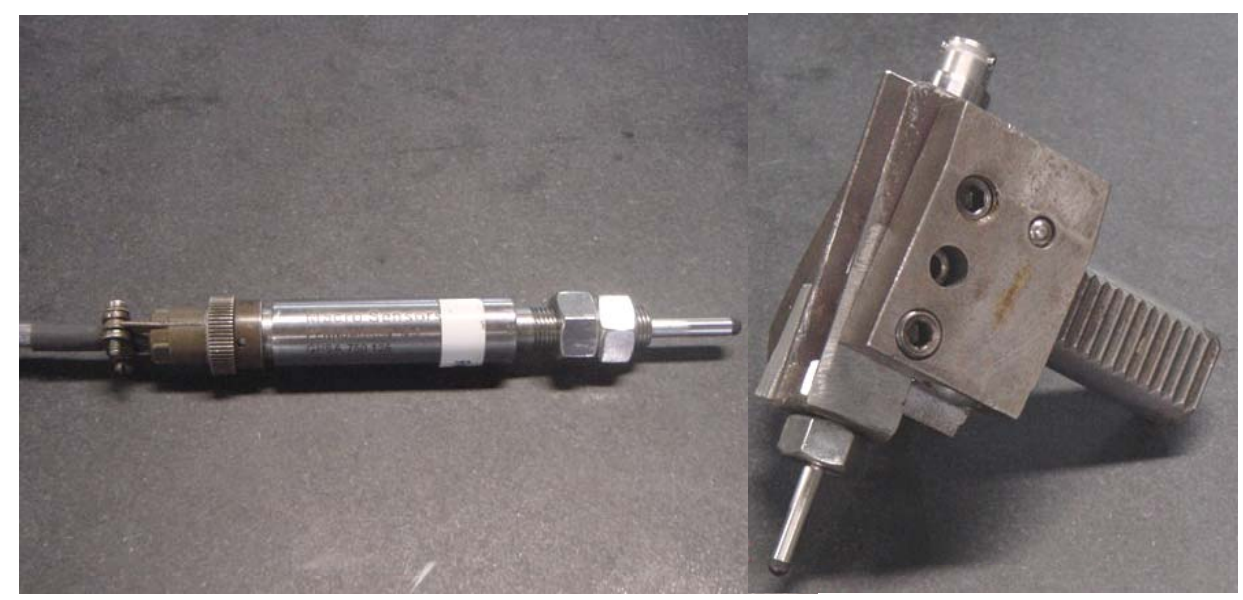

FIGURA 3.4 - Sensor LVDT e detalhe de sua fixação no suporte de ferramenta 


\subsubsection{Sensor de emissão acústica}

O sensor de emissão acústica utilizado foi o da empresa Sensis, com unidade de tratamento de sinais (amplificação, filtragem e retificação) modelo BM12 (figura 3.5) da mesma empresa. Possui o recurso de comparar o sinal de emissão acústica com valores pré-configurados (thresholds), disparando níveis lógicos $\left(24 \mathrm{~V}_{\mathrm{cc}}\right.$ ou 0 $\mathrm{V}_{\mathrm{cc}}$ ) em uma de suas portas de disparo (canal de saída).

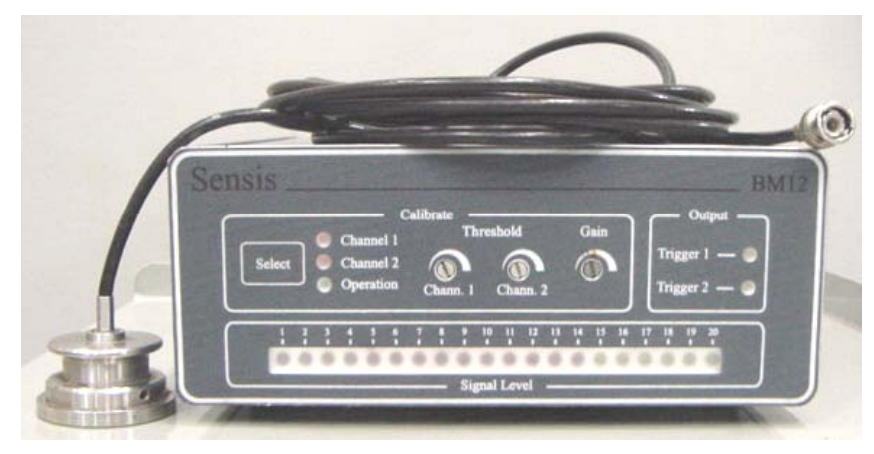

FIGURA 3.5 - Sensor de emissão acústica e BM12

O sensor foi fixado na base do cilindro hidráulico responsável pelo giro do magazine porta-ferramentas, permitindo a aquisição de emissão acústica sem comprometer a troca de ferramentas quando do giro no magazine.

\subsubsection{Software SCADA}

Optou-se em utilizar um software que possuísse a característica de aquisição de sinais (com possibilidades de comunicação com CLP's, sensores, etc, via rede) com boa interface homem/máquina. O software escolhido foi o do tipo SCADA (Supervisory Control And Data Acquisition) que serve como interface homem/máquina, como os softwares HMI ou MMI (Human Machine Interfacing ou Man Machine Interfacing), e permitem a supervisão de máquinas e/ou processos através de visualizações em telas de computadores, podendo também efetuar controles e distribuição de informações entre estações via rede, com bom desempenho. São softwares robustos e confiáveis para aplicações de grande porte e para aplicações distribuídas em várias estações de trabalho. São desenvolvidos e 
amplamente utilizados em processos contínuos, contudo atendendo de modo satisfatório às linhas e/ou células de produção de processos discretos.

O software SCADA utilizado foi o Elipse Pro v2.20 .

O front end do SCADA do sistema (figura 3.6), foi dividido em:

- dados de processo (tempo total de trabalho e de parada, parâmetros de usinagem)

- dados de produção (peças produzidas, acabadas, re-trabalhadas, refugadas)

- dados da última peça produzida (dados de processo e de qualidade dimensional)

- dados gerais (nome da peça, dimensões, tolerâncias e croqui)

- carta de controle de erros dimensionais (erro dimensional $X$ peças produzidas)

- dados de manutenção (displays indicadores on-line da temperatura do motor e do funcionamento do cooler do gabinete central do torno)

Utilizando-se do módulo WEB do SCADA, tem-se esse front end em formato de página HTML (figura 3.7), com atualizações de dados realizados por Applets Java.

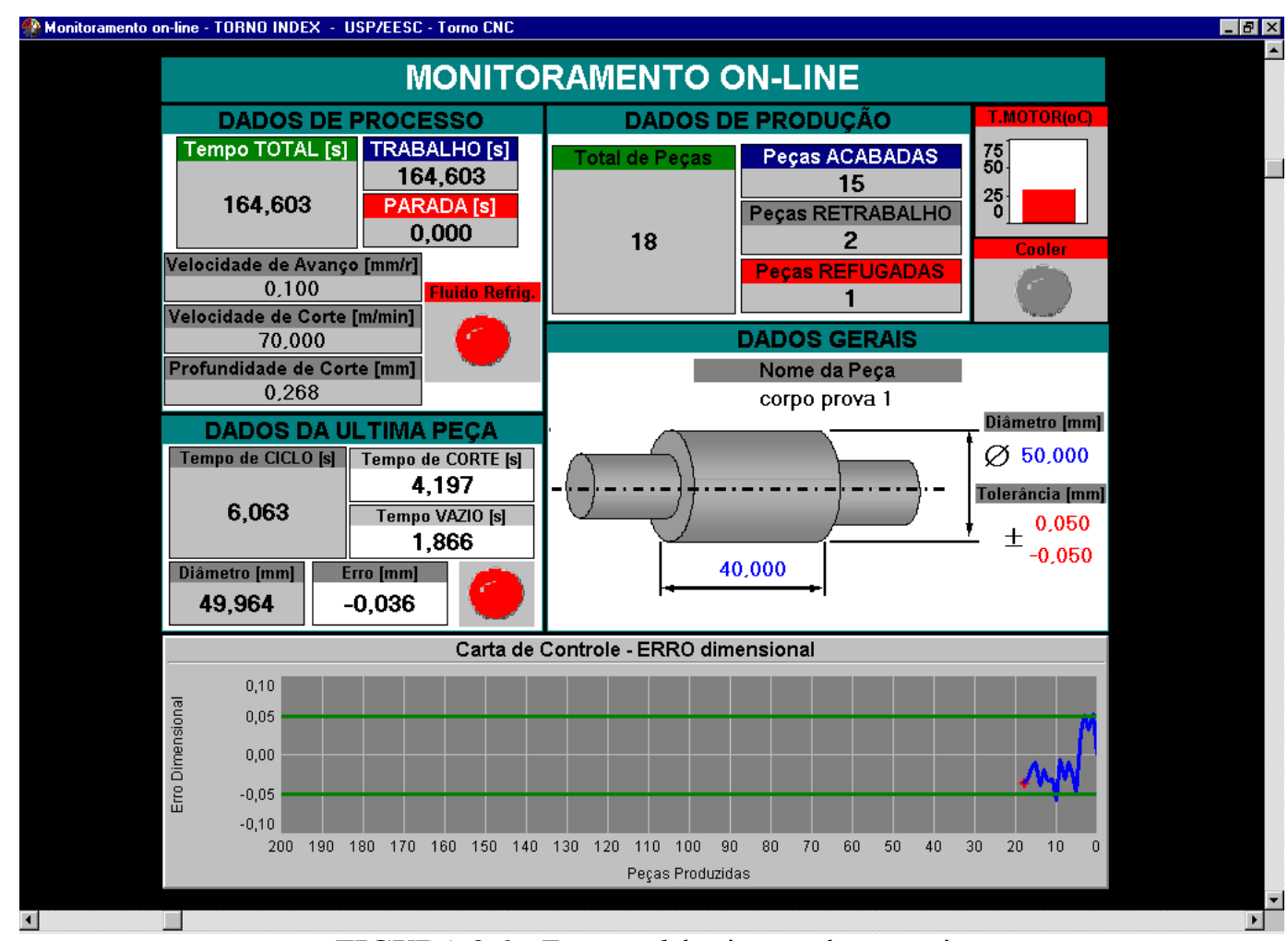

FIGURA 3.6 - Front end do sistema de supervisão 


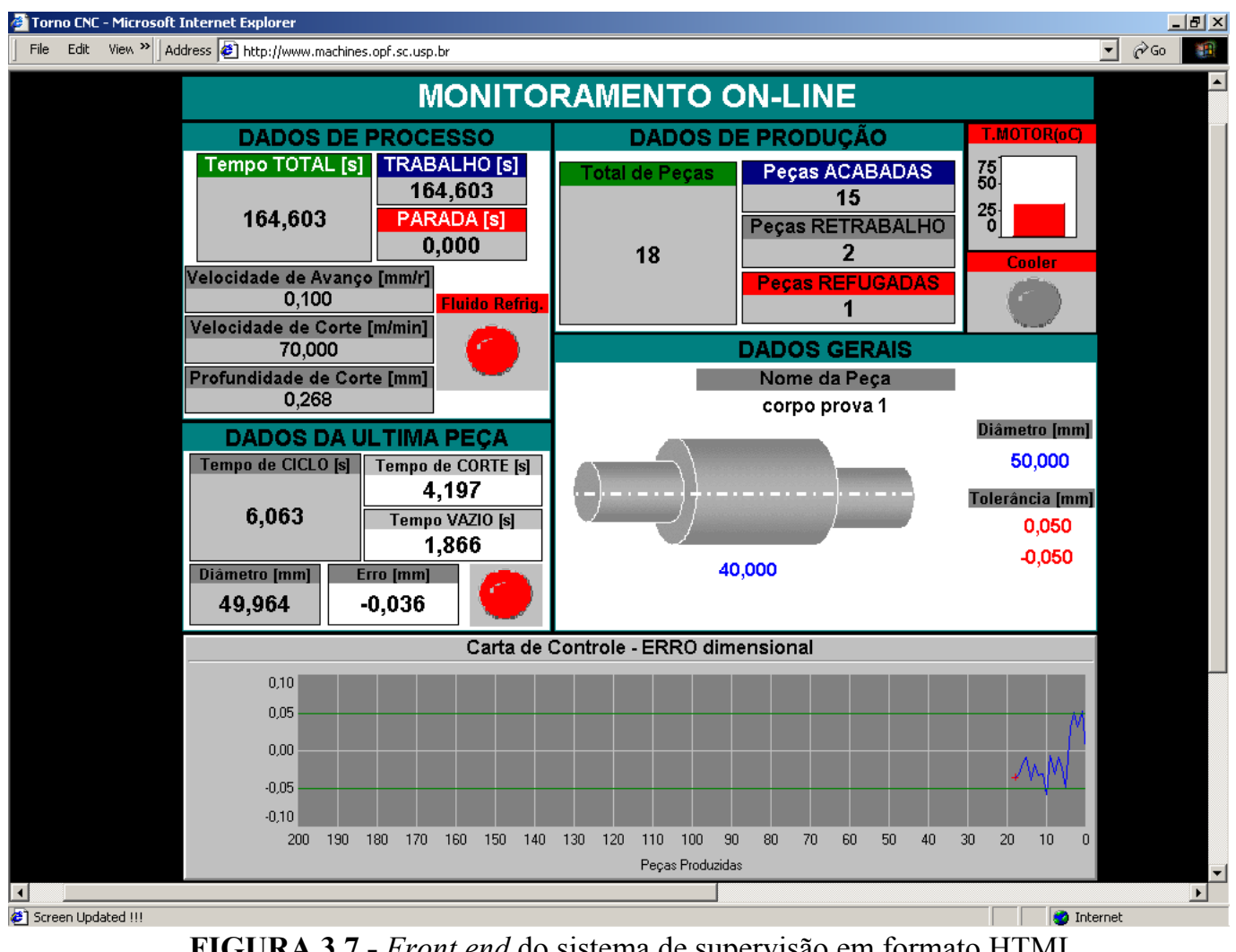

FIGURA 3.7 - Front end do sistema de supervisão em formato HTML

\subsubsection{Software de Aquisição e Manipulação de Dados (LabView)}

O software SCADA utilizado possui a limitação de não estabelecer comunicação através do protocolo NetDDE entre aplicativos situados em computadores diferentes, que no caso seria entre o torno e a estação SCADA/WEB Server. Assim, foi utilizado o software LabView, servindo então como intermediário na comunicação entre estes . Há também dificuldades de programação do software SCADA para a realização de operações de cálculos seguindo seqüências de eventos, como ocorrem nos processos de torneamento (processo discreto). Tal fato deve-se a falta de ferramentas no software SCADA, pois o mesmo é desenvolvido para ser aplicado em processos contínuos ou por bateladas. Assim, decidiu-se utilizar o software SCADA somente como front end (interface homem-máquina) do sistema, e o software LabView para estabelecer comunicação entre o torno e o SCADA, e para a realização de cálculos, tais como tempo de ciclo, tempo de corte, tempos de paradas, etc. 
Tem-se a seguir, na figura 3.8, o front end do software de aquisição e manipulação de dados, programado em LabView .

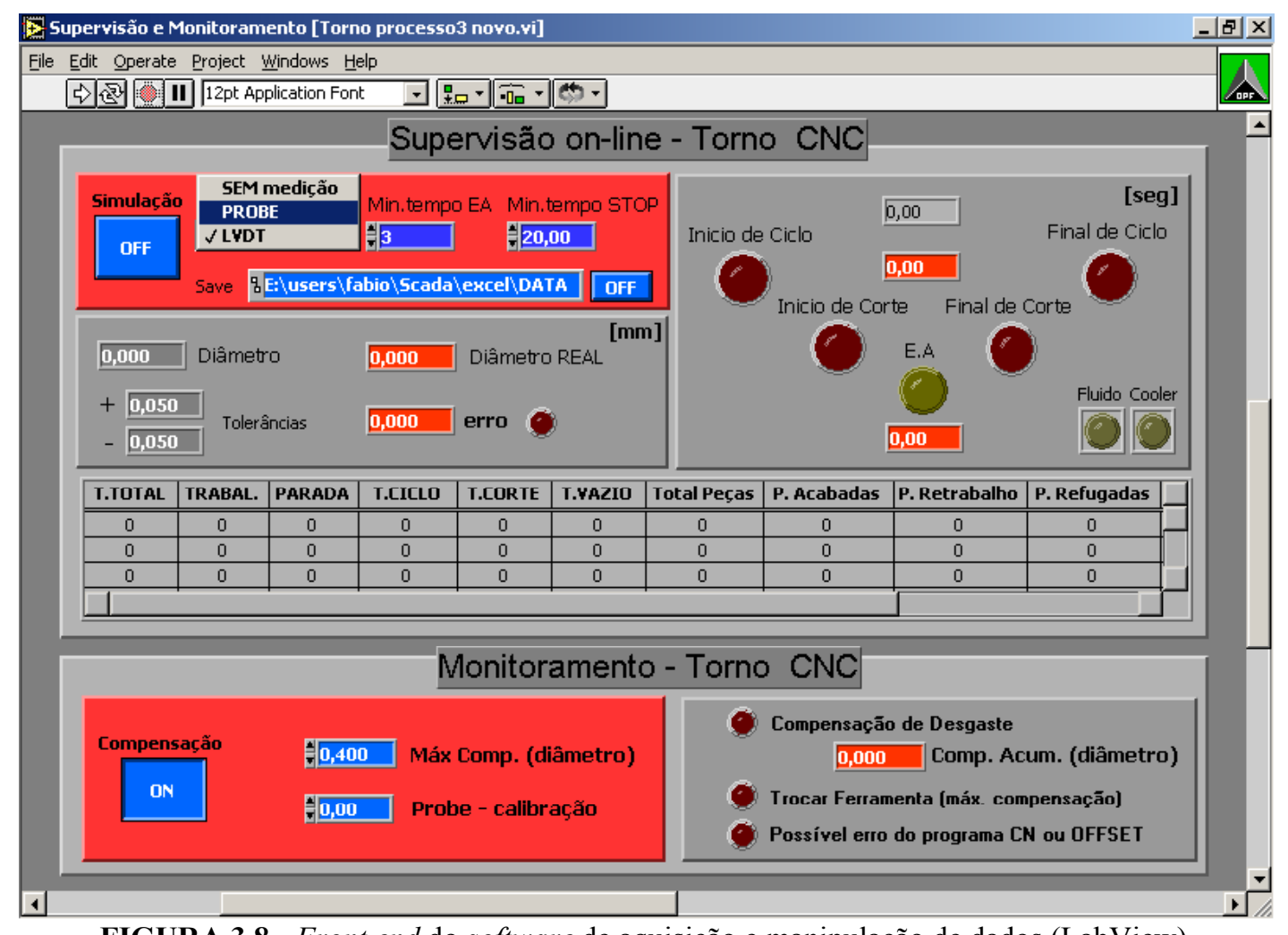

FIGURA 3.8 - Front end do software de aquisição e manipulação de dados (LabView)

O software de aquisição e manipulação de dados possui algumas características que facilitam a sua operação:

1. é dividido em dois módulos, podendo ser executados independentemente: módulo de supervisão e módulo de monitoramento.

2. os parâmetros a serem configurados encontram-se nas "caixas" vermelhas, e em cor azul.

3. nas "caixas" cinzas, encontram-se as informações obtidas e calculadas do processo de torneamento.

Breves comentários à respeito das características do software desenvolvido são feitas a seguir:

口 Módulo de Supervisão

○ Parâmetros de configuração ("caixa" vermelha) 
- Botão "Simulação"

o software pode ser utilizado com o torno, ou com o software de simulação do processo de torneamento (a ser explicado nos próximos capítulos). Para tal, basta desabilitar ou habilitar o botão "Simulação".

- Caixa de escolha: "SEM medição e LVDT" configuração para não realizar medições de peças ("SEM medição"), ou realiza-las através dos sensor LVDT.

- Controle digital "Min.tempo EA" mínimo tempo de emissão acústica ("Min_tempo_EA”) acima do threshold (configurado por hardware) que confirma o início de ciclo de corte. Permite, assim, eliminar ruídos ou picos de emissão acústica (E.A.) que ocorram fora do processo de corte.

- Controle digital "Min.tempo STOP" mínimo tempo de parada necessário para que possa ser somado no tempo total de paradas. Assim, pode-se levar em consideração que o tempo de carga e descarga, por exemplo, é tempo de trabalho e não tempo de parada, simplesmente por não estar durante o ciclo de torneamento.

- Botão e caixa de escolha para "Save" gravar ou não, especificando local de gravação, dados gerais do processo de torneamento em planilhas ou qualquer outro tipo de arquivo compatível.

○ Informações de especificação da peça ("caixa" cinza, logo abaixo da "caixa" vermelha)

- Display digital "Diâmetro" diâmetro de especificação da peça a ser usinada.

- Displays digitais “+” e “_” de "Tolerâncias” tolerâncias de especificação da peça.

- Display digital "Diâmetro REAL" diâmetro da peça usinada, obtido pelo sensor de medição.

- Display digital "erro" 
erro do diâmetro da peça usinada em relação ao diâmetro de especificação.

○ Informações on-line do processo de torneamento ("caixa" cinza, ao lado direito da "caixa" vermelha)

- Display digital e LEDs "Inicio de Ciclo", "Final de Ciclo", "Inicio de Corte", "Final de Corte" e "E.A"

displays que permitem o acompanhamento do processo, juntamente com o tempo de ocorrência : início e fim de ciclo e de corte, e seus intervalos de tempo

- LEDs "Fluido" e "Cooler"

displays que permitem verificar a utilização ou não de fluído refrigerante ("Fluido"), e funcionamento do cooler (sistema de refrigeração) do gabinete principal (“Cooler”).

○ Informações gerais do processo de torneamento ("caixa" cinza, abaixo das demais)

- Display em forma de tabela

displays de informações de processo e produção, tais como: tempo de trabalho, tempo de parada, tempo de ciclo e de corte, total de peças produzidas, peças acabadas, peças refugadas, e enviadas para retrabalho, etc.

a Módulo de Monitoramento

○ Parâmetros de configuração ("caixa" vermelha)

- Botão "Compensação"

realizar ou não a compensação do desgaste da ferramenta de corte.

- Controle digital "Máx Comp. (diâmetro)"

configuração da máxima compensação a ser realizada na ferramenta de corte.

- Controle digital "Probe-calibração"

parâmetro de calibração do probe.

○ Informações do monitoramento da ferramenta de corte ("caixa" cinza)

- LED “Compensação de Desgaste” e display digital "Comp. Acum. (diâmetro)" 
display que indica a realização da compensação de desgaste, e de quanto ela já foi realizada.

- LED “Trocar Ferramenta (máx. compensação)"

display que indica a necessidade da troca de ferramenta - quando a compensação acumulada (“Comp. Acum. (diâmetro)”) é maior ou igual à máxima compensação a ser realizada ("Máx Comp. (diâmetro)") .

- LED "Possível erro do programa CN ou OFFSET"

display que indica um possível erro no programa $\mathrm{CN}$ ou no OFFSET da ferramenta - quando o diâmetro da peça é menor que o diâmetro especificado.

\subsubsection{Servidor WEB}

O servidor WEB é um dos elementos-chave da arquitetura baseada em Intranet/Internet. Suas principais funções são, segundo ZAMPRONHA (1998) :

- hospedar telas de supervisão, em formato HTML, a serem acessadas pelos clientes ;

- enviar Applets Java aos clientes ;

- enviar dados novos cada vez que haja alteração ;

No sistema utilizou-se inicialmente para testes o software PWS (Personal Web Server, da Microsoft) para uma rede Intranet, e posteriormente o IIS-4 (Internet Information Server 4, da Microsoft) para rede Intranet e/ou Internet, permitindo acessos à partir de qualquer localidade do mundo, desde que se tenha uma conexão na Internet. A URL (Uniform Resource Locator) escolhida para o sistema foi:

http://www.machines.opf.sc.usp.br 


\subsection{Estratégias do sistema}

A seguir, serão apresentadas as estratégias de supervisão e monitoramento para aquisição de dados, geração de informações e compensação de desgastes e auxílio à troca de ferramentas de corte.

\subsubsection{Estratégia de Supervisão}

A supervisão do processo é realizada com o auxílio de sensores já disponíveis no torno, tais como sensores de temperatura, régua de medição, etc, e principalmente de sensores instalados especialmente para esse propósito, tais como o de medição de peças (LVDT) e para a detecção de início de corte (sensor de emissão acústica).

Informações e dados da máquina, do programa $\mathrm{CN}$ em execução e de sensores são adquiridos com comunicação direta da estação SCADA/WEB Server com o CNC da máquina (Siemens Sinumerik 810D) via rede com padrão FastEthernet, utilizando protocolo de comunicação NetDDE (Network Dinamic Data Exchange ). A tabela 3.1 mostra alguns dos dados e informações obtidas.

TABELA 3.1- Dados e informações obtidos da Máquina, Programa CN e Sensores

\begin{tabular}{|l|}
\hline $\begin{array}{l}\text { Dados e Informações da } \\
\text { Máquina (on-line) }\end{array}$ \\
\hline Sinal de início de ciclo \\
\hline $\begin{array}{l}\text { Velocidade de avanço } \\
\text { atual }\end{array}$ \\
\hline Rotação atual \\
\hline Temperatura do motor \\
\hline Mensagens de alerta \\
\hline $\begin{array}{l}\text { Sinais de sensores em } \\
\text { geral }\end{array}$ \\
\hline $\begin{array}{l}\text { Posições do castelo porta- } \\
\text { ferramenta }\end{array}$ \\
\hline
\end{tabular}

\begin{tabular}{|l|}
\hline \multicolumn{1}{|c|}{$\begin{array}{c}\text { Informações do } \\
\text { Programa CN }\end{array}$} \\
\hline Sinal de fim de ciclo \\
\hline $\begin{array}{l}\text { Velocid. de Avanço de } \\
\text { setpoint }\end{array}$ \\
\hline $\begin{array}{l}\text { Velocidade de Corte de } \\
\text { setpoint }\end{array}$ \\
\hline $\begin{array}{l}\text { Dimensões básicas da } \\
\text { peça }\end{array}$ \\
\hline Comprimento de corte \\
\hline Profundidade de corte \\
\hline $\begin{array}{l}\text { Nome do programa em } \\
\text { execução }\end{array}$ \\
\hline $\begin{array}{l}\text { Linha do programa CN em } \\
\text { execução }\end{array}$ \\
\hline
\end{tabular}

\section{Dados dos Sensores}

Sinais de início e fim de ciclo de corte

Sinais de distinção de ciclos de corte e em vazio

Dados para obtenção das dimensões reais de peças Acabadas

Algumas informações do programa $\mathrm{CN}$ são obtidas com comunicação direta com o CNC do torno, tais como o nome do programa em execução, e a linha do programa $\mathrm{CN}$ em execução. Outras, porém, devem ser indicadas pelo usuário durante a programação do mesmo, através de "cabeçalhos" de registradores $R_{i}$ 
previamente definidos, tal como o exemplificado logo abaixo, na figura 3.9, e no programa do Anexo A .

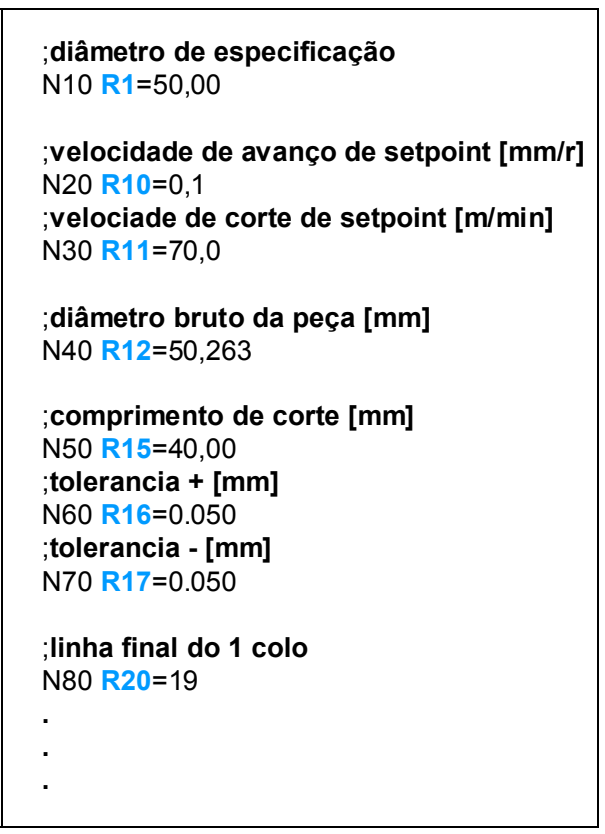

FIGURA 3.9 - Exemplo de cabeçalho de registradores $\mathrm{R}_{\mathrm{i}}$ de um programa $\mathrm{CN}$

Quando tal programa é executado, estas informações são carregadas adequadamente nos registradores $\mathrm{R}_{\mathrm{i}}$ do $\mathrm{CNC}$, possibilitando posteriores leituras dos mesmos pelo programa de supervisão e monitoramento proposto.

Por manipulações adequadas dos dados dos sensores e do programa $\mathrm{CN}$, são obtidas informações do processo e produção, tais como os expostos na tabela 3.2.

TABELA 3.2 - Algumas informações de processo e produção obtidos

\begin{tabular}{|c|c|c|}
\hline Dados utilizados & $\begin{array}{c}\text { Informações de processo e produção } \\
\text { obtidas }\end{array}$ & Recurso utilizado \\
\hline $\begin{array}{l}\text { - Sinais de início e fim } \\
\text { de ciclo }\end{array}$ & $\begin{array}{l}\text { - Tempo de Ciclo } \\
\text { - Tempo de Trabalho } \\
\text { - Tempo de Paradas }\end{array}$ & $\begin{array}{l}\text { Linha do programa } \\
\mathrm{CN} \text { em execução, e } \\
\text { relés }\end{array}$ \\
\hline $\begin{array}{l}\text { - Sinais de início e fim } \\
\text { de ciclo de corte }\end{array}$ & $\begin{array}{l}\text { - Tempo de Ciclo de corte } \\
\text { - Identificação de ciclo de corte e em } \\
\text { vazio } \\
\text { - Tempo de Trabalho } \\
\text { - Tempo de Paradas }\end{array}$ & Sensor de E.A. \\
\hline $\begin{array}{l}\text { - Dimensões de peças } \\
\text { acabadas }\end{array}$ & $\begin{array}{l}\text { - Número de peças : - Acabadas } \\
\text { - Refugadas } \\
\text { - Retrabalhadas } \\
\text { - Acompanhamento de desgaste } \\
\text { de ferramentas }\end{array}$ & $\begin{array}{l}\text { Probe ou LVDT, } \\
\text { Régua de Medição }\end{array}$ \\
\hline - Temperatura do Motor & $\begin{array}{l}\text { - Temperatura do Motor } \\
\text { - Identificação de superaquecimento }\end{array}$ & Sensor de temperatura \\
\hline
\end{tabular}


A seguir, tem-se explicação da obtenção dos principais dados empregados para a coleta de informações de processo e produção.

\subsubsection{Sinais de início e fim de ciclo}

O sinal de início de ciclo é obtido através da leitura do acionamento de um relê através do botão de start do CNC do torno. Quanto ao sinal de fim de ciclo, sabendo-se previamente a linha do programa $\mathrm{CN}$ em que ocorre o final do ciclo (através do "cabeçalho" dos registradores $\mathrm{R}_{\mathrm{i}}$ ) e tendo-se a possibilidade do acompanhamento da linha do programa $\mathrm{CN}$ em execução, sabe-se então o momento exato do final de ciclo. No exemplo do programa $\mathrm{CN}$ dado anteriormente, figura 3.9, tem-se que o final do ciclo ocorre na linha $19(\mathrm{R} 20=19)$.

\subsubsection{Sinais de início e fim de corte}

Conforme a tabela 3.2, tais sinais são obtidos através do sensor de E.A. (emissão acústica). Para tal, utilizou-se de um limite (threshold) configurado no BM12, de modo a limitar sinais de E.A. identificando situações de usinagem ou não das peças. O BM12 utiliza o "cruzamento" do sinal de E.A. com esse threshold como trigger ("gatilho") para disponibilizar ou não um sinal de $24 \mathrm{~V}_{\mathrm{cc}}$ em um de seus canais, de acordo com a situação do sinal de E.A. (acima ou abaixo do threshold respectivamente). Esse canal é conectado à uma porta DI (digital input) do módulo I/O do torno. Assim, a estação SCADA/ WEB Server pode "ler" o bit da porta DI do módulo I/O que recebe este sinal, e tomar as decisões apropriadas.

\subsubsection{Dimensões das peças acabadas}

As medições dos diâmetros das peças acabadas feitas pelo LVDT são repassadas diretamente para a estação SCADA/ WEB Server através de uma placa de aquisição instalada na mesma. No trecho do programa $\mathrm{CN}$ que trata da rotina para medição das peças, figura 3.10 , tem-se : 


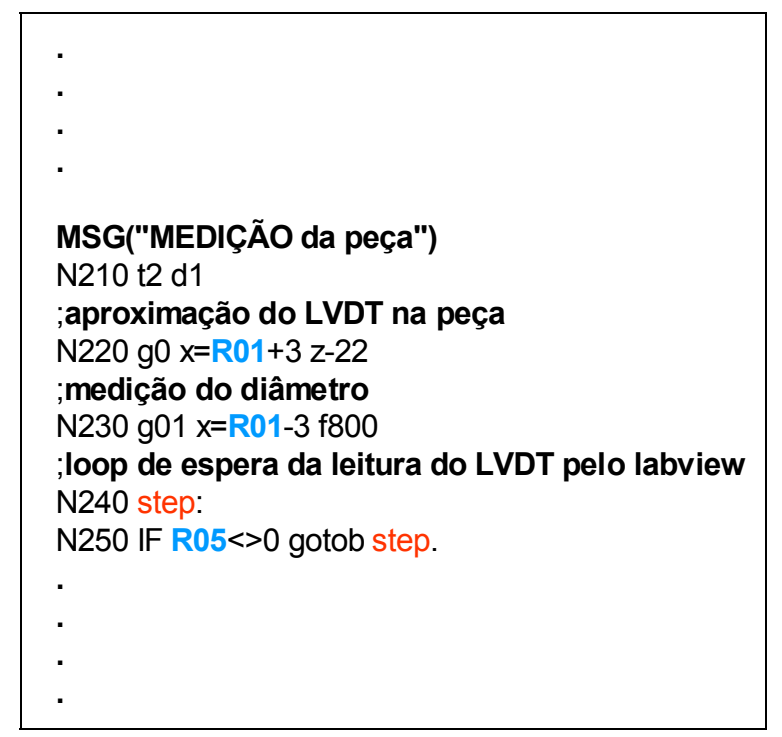

FIGURA 3.10 - Trecho do programa CN pra medição de peças

Na linha N210 tem-se uma mudança do porta-ferramentas para o magazine t2, onde encontra-se o LVDT.

Sabendo-se que R01 é o diâmetro de especificação, na linha N220 tem-se uma aproximação do LVDT na peça, em g0 (comando de interpolação linear com avanço rápido), chegando-se à aproximadamente $3,0 \mathrm{~mm}(\mathrm{x}=\mathrm{R} 01+3)$ da peça usinada.

Finalmente, nas linhas N230, N240 e N250 tem-se a medição do diâmetro. O LVDT é aproximado na peça com velocidade de avanço de $800 \mathrm{~mm} / \mathrm{min}$ (g1 f800), “entrando" aproximadamente 3,0 mm (x=R01-3) na peça. O LVDT é mantido nessa posição até que o registrador R5 passe para valor igual a zero (loop das linhas N240 e N250). Assim, permite que a leitura do LVDT seja realizada pelo LabView. Após essa leitura, o próprio LabView envia um valor igual a zero para o registrador R5, permitindo o prosseguimento da execução do programa $\mathrm{CN}$.

As medições dos diâmetros utilizam como referência o valor do sinal do LVDT da medição da primeira peça usinada dentro das especificações. Mantendo-se sempre igual à aproximação do LVDT nas peças à serem medidas, e comparando-se tais valores do LVDT com o valor de referência, tem-se, finalmente, os novos valores de medições de diâmetros. A grande vantagem desse tipo de medição é a exclusão da necessidade de se determinar o off-set do LVDT no porta-ferramentas, 
que se trata de uma atividade demorada, difícil e sujeita a erros. Na figura 3.11 temse um esquema da arquitetura do sistema utilizando um sensor LVDT para medições.

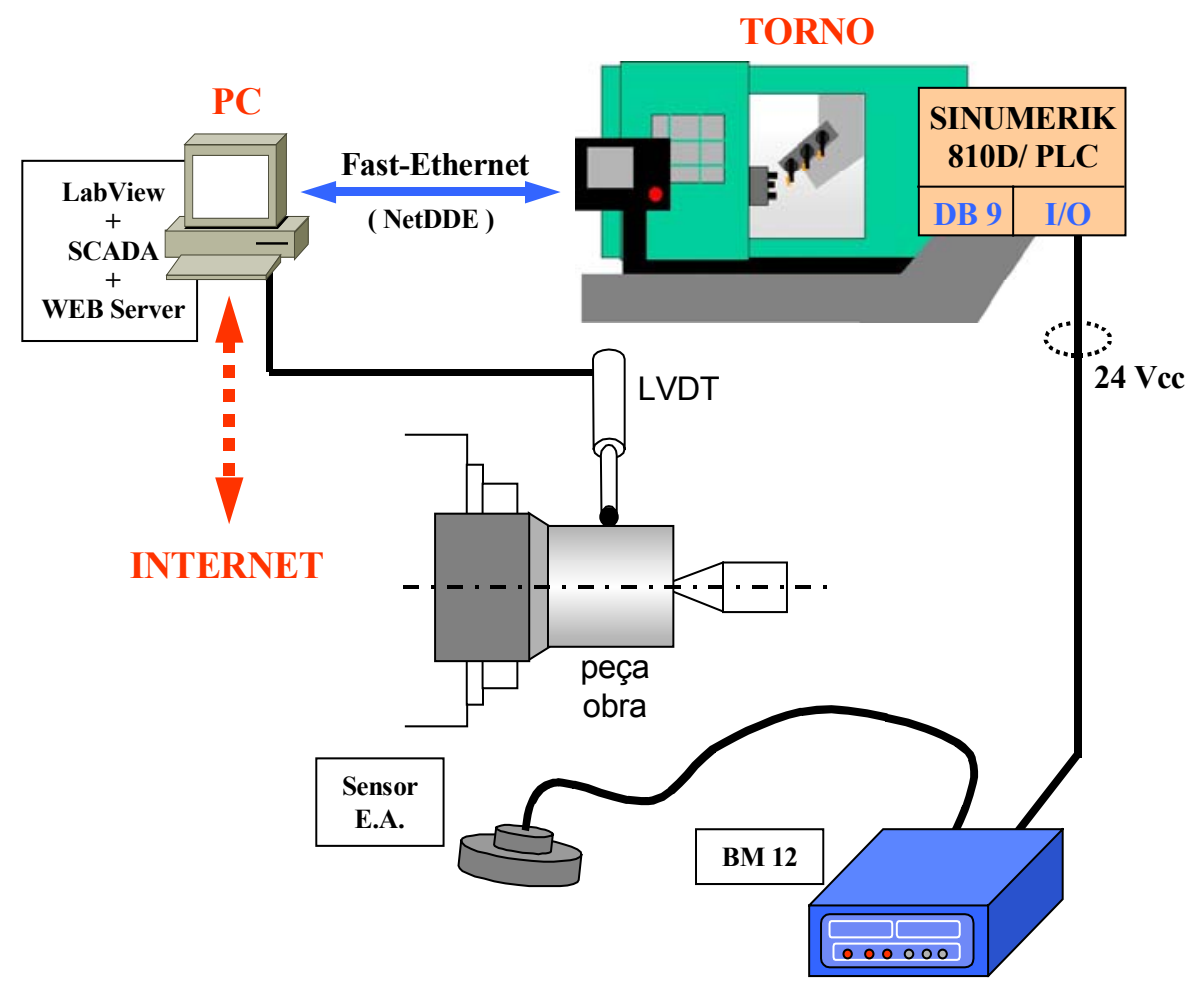

FIGURA 3.11 - Esquema do sistema utilizando sensor LVDT

\subsubsection{Estratégia de Monitoramento}

O sistema de monitoramento proposto (de compensação automático de desgastes de ferramentas de corte) baseia-se em um monitoramento direto (off-line) através de medições de diâmetros de peças usinadas, utilizando-se o LVDT, preso ao porta-ferramentas. Essas medidas são "capturadas" pelo software do sistema, desenvolvido em LabView, que executa uma seqüência lógica para a determinação da compensação a ser realizada (parâmetro de compensação devido ao desgaste PCDD), e para a classificação das peças como:

○ peça acabada : dentro dos limites de especificação

○ peça para retrabalho : acima do limite superior de especificação LSE (Limite Superior de Especificação)

○ peça refugada : abaixo do limite inferior de especificação - LIE (Limite Inferior de Especificação) 
Esse PCDD, calculado após cada peça usinada, é repassado para o CNC do torno através do registrador R04. Assim, permite que a próxima peça seja usinada já com a compensação do desgaste da ferramenta. No programa $\mathrm{CN}$, figura 3.12, notase a utilização do registrador R04 para a realização da compensação do desgaste da ferramenta.

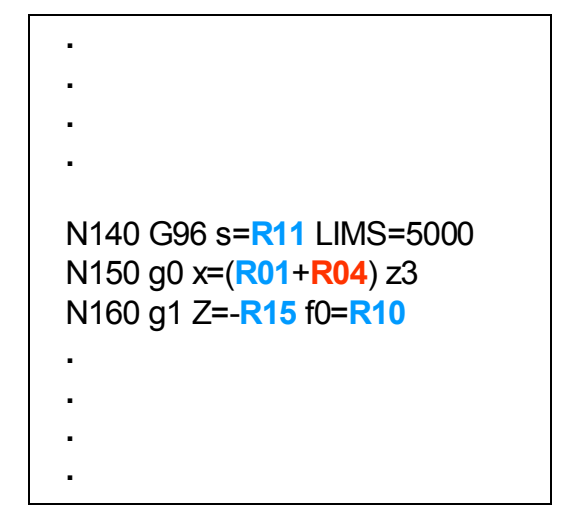

FIGURA 3.12 - Trecho do programa CN para compensação do desgaste da ferramenta

Nas linhas N140 e N160 tem-se o preset dos parâmetros de usinagem: $\boldsymbol{V}_{\boldsymbol{c}}=$ $70 \mathrm{~m} / \mathrm{min}$ (R11), limitado a uma rotação máxima de $5000 \mathrm{rpm}$, e $\boldsymbol{f}=0,1 \mathrm{~mm} / \mathrm{r}$ (R10).

E, finalmente, na linha N150 tem-se o posicionamento da ferramenta na peça (no eixo x) igual ao diâmetro de especificação (R01) mais o PCDD (R04).

O software do sistema permite a configuração da máxima compensação de desgaste da ferramenta de corte (Máx. Comp.) a ser realizada, tendo em vista que um aumento exagerado da mesma poderia levar a uma qualidade superficial não adequada, entre outros possíveis problemas na peça obra e até mesmo na máquinaferramenta. Quando a máxima compensação de desgaste da ferramenta de corte é alcançada, o sistema imediatamente indica no seu front-end (tela) a necessidade da troca da mesma. 
$\mathrm{Na}$ figura 3.13 tem-se o algoritmo do programa, onde se nota a seqüência lógica para a determinação do PCDD e para a classificação da peça usinada.

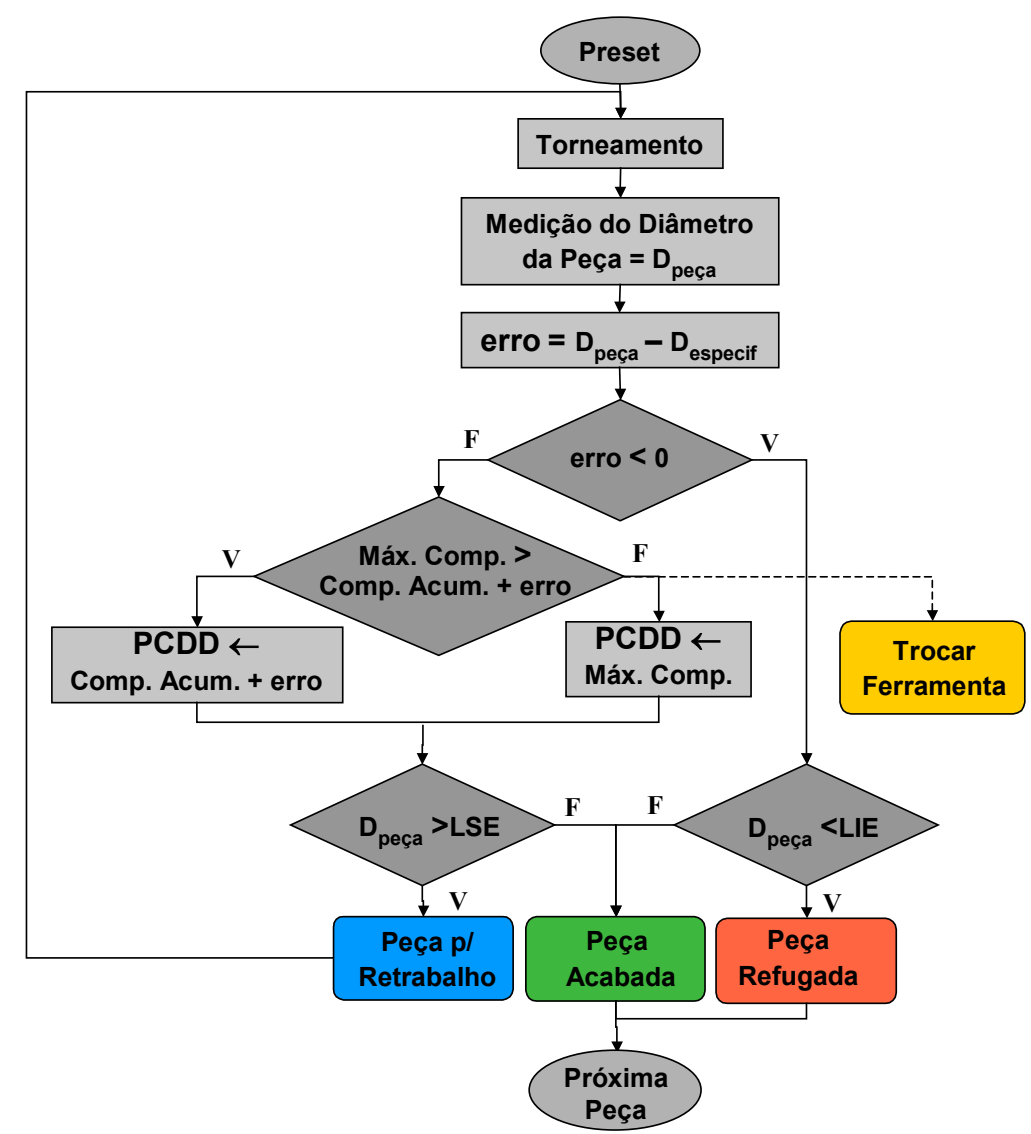

FIGURA 3.13 - Algoritmo para cálculo do PCDD e classificação de peças 


\section{Avaliação do Sistema Proposto}

A seguir, serão apresentados os métodos utilizados para a avaliação do sistema de supervisão e monitoramento proposto, com o intuito de comprovar sua eficácia.

Inicialmente, utilizou-se um simulador do processo de torneamento para auxiliar o desenvolvimento do sistema, e realizar testes preliminares. Finalmente, depois de modificações realizadas com o auxilio do simulador, testou-se o sistema em um ensaio experimental na tentativa de simular uma situação real de chão de fábrica.

\subsection{Simulador}

O simulador do processo de torneamento usou o LabView, o qual permitiu o acompanhamento do comportamento do sistema frente a situações variadas, o que seria de difícil execução sem a utilização do mesmo. O Simulador comunica-se com o sistema proposto utilizando o mesmo protocolo (NetDDE) que o torno, permitindo, deste modo, avaliar também esse tipo de comunicação. Tem-se a seguir o front end do simulador (figura 4.1). 


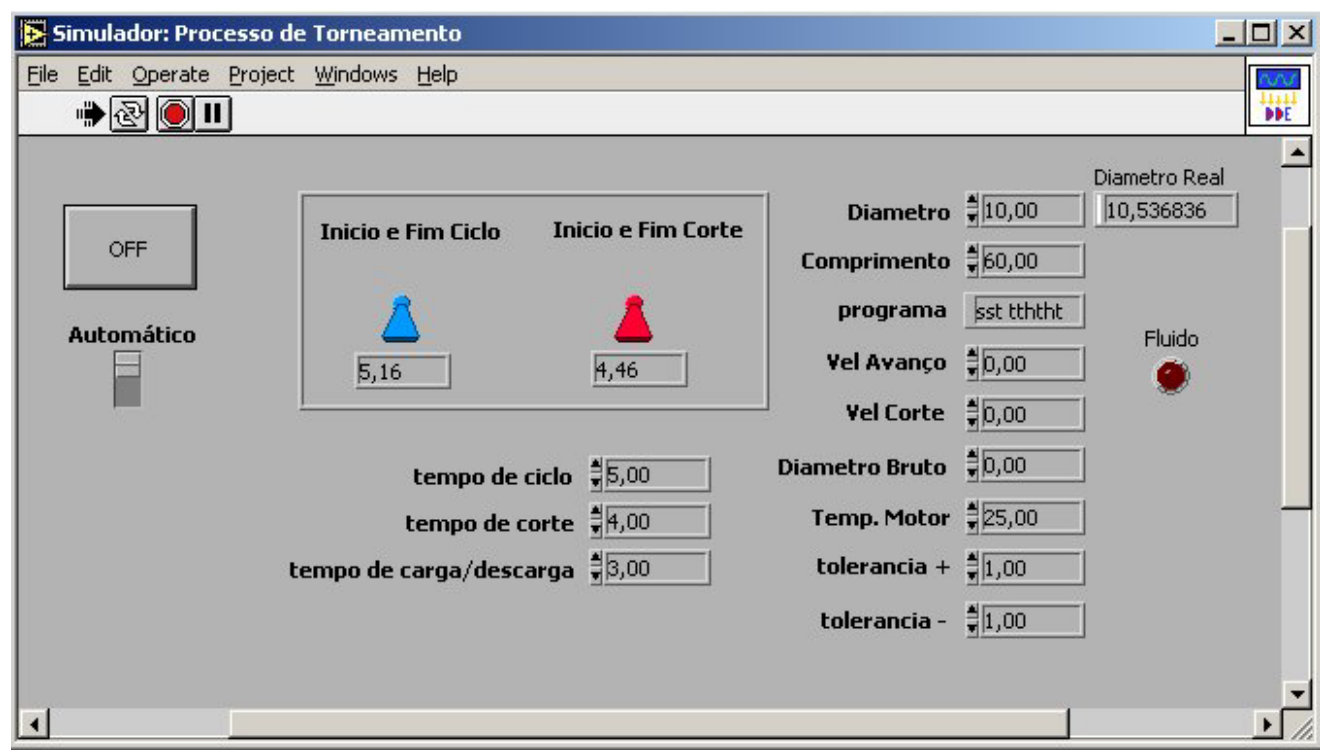

FIGURA 4.1 - Front End do simulador do processo de torneamento

Assim como o torno, o simulador disponibiliza informações e/ou dados da Máquina, do programa $\mathrm{CN}$, e de sensores. No simulador, essas informações são préconfiguradas, e algumas, como a temperatura do motor e o diâmetro da peça produzida, têm seus valores variando aleatoriamente em torno de $15 \%$ do valor préconfigurado. Essas informações são:

1. diâmetro de especificação da peça ("Diâmetro")

2. diâmetro da peça produzida ("Diâmetro Real")

3. diâmetro da peça antes de ser torneada ("Diâmetro Bruto")

4. comprimento da peça ("Comprimento")

5. nome do programa $\mathrm{CN}$ ("programa")

6. velocidade de avanço ("Vel Avanço")

7. velocidade de corte ("Vel Corte")

8. temperatura do motor ("Temp.Motor")

9. limite superior de especificação ("tolerância +")

10. limite inferior de especificação ("tolerância -")

11. tempo de carga/descarga de peças ("tempo de carga/descarga")

Os tempos de ciclo e de corte podem ser simulados de modo manual ou automático. Na figura 4.1, ver "chave" "Automático". 
No modo manual, esses tempos são iniciados e finalizados utilizando-se das "chaves" azul ("Inicio e Fim Ciclo") e vermelha ("Inicio e Fim Corte"), com os respectivos displays dos tempos logo abaixo destas. E, no modo automático, o início e fim de tais tempos são realizados de modo automático, tendo como base uma préconfiguração dos mesmos ("tempo de ciclo" e "tempo de corte”). Esses tempos préconfigurados possuem, propositalmente, variações aleatórias de no máximo 15\%, permitindo o acompanhamento da capacidade do sistema em registrar tais valores.

Por exemplo, observando-se a figura 4.1, nota-se:

- valores pré-configurados:

tempo de ciclo : $5,00 \mathrm{seg}$.

tempo de corte : 4,00 seg.

- tempos de simulação automática (displays dos tempos):

tempo de ciclo $: 5,16 \mathrm{seg}$.

tempo de corte : 4,46 seg.

Com o simulador, pôde-se testar o sistema de supervisão e monitoramento proposto em diversas situações, utilizando-se tanto do modo manual quanto do modo automático.

\subsection{Ensaio Experimental}

O ensaio experimental foi empregado com o propósito de finalizar os testes do sistema de supervisão e monitoramento através de uma situação real, e principalmente testar o sistema de compensação automático de desgaste. Assim, procurou-se realizar operações de torneamento de modo que garantisse um acentuado desgaste da ferramenta. Optou-se, deste modo, em usinar corpos de prova de aço ABNT 4340 temperado (45-50 HRc), com insertos SNMG 1204 08-QM classe coromant H13A - Sandvik, em condições de corte propositalmente escolhidas acima das recomendadas, afim de acelerar o desgaste. As condições foram: $V_{c}=70 \mathrm{~m} / \mathrm{min}$, 
$\mathrm{f}=0,1 \mathrm{~mm} / \mathrm{r}, \mathrm{a}_{\mathrm{p}}=0,263 \mathrm{~mm} 1_{\mathrm{c}}=40 \mathrm{~mm}$, mantidas para ambas as etapas em que foi dividido o experimento.

Para a primeira etapa, 30 corpos de prova (figura 4.2, 4.3 e 4.4) foram torneados em condições de corte muito suaves, para uma mesma dimensão. Medido esse lote, encontrou-se diâmetros de 50,661 mm $\pm 2 \mu \mathrm{m}$. Finalmente, utilizando-se de um inserto novo, submeteu-se esse lote às condições de usinagem descritas anteriormente, mas sem a utilização do sistema, ou seja, sem a compensação do desgaste da ferramenta. Após essa, fez-se medições de seus diâmetros com micrômetro Mitutoyo. O objetivo dessa primeira etapa foi o de acompanhar o erro dimensional das peças usinadas, devido ao desgaste da ferramenta.

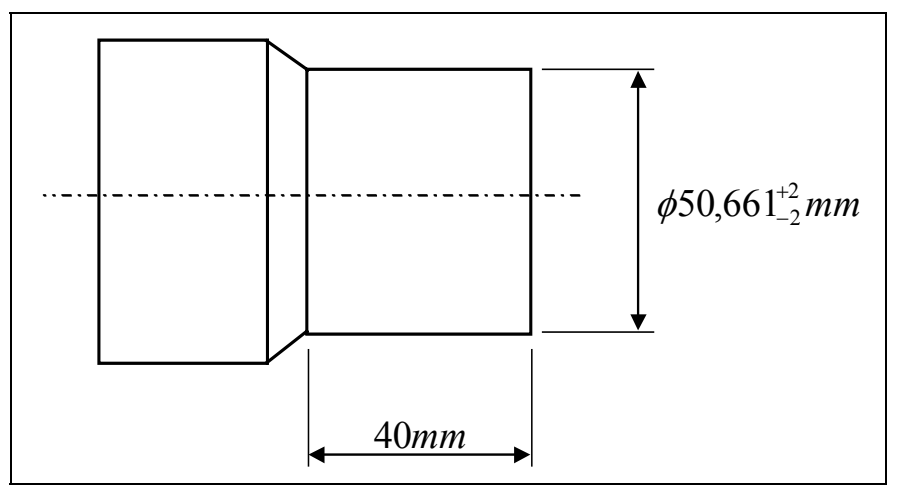

FIGURA 4.2 - Corpo de prova preparado para a primeira etapa

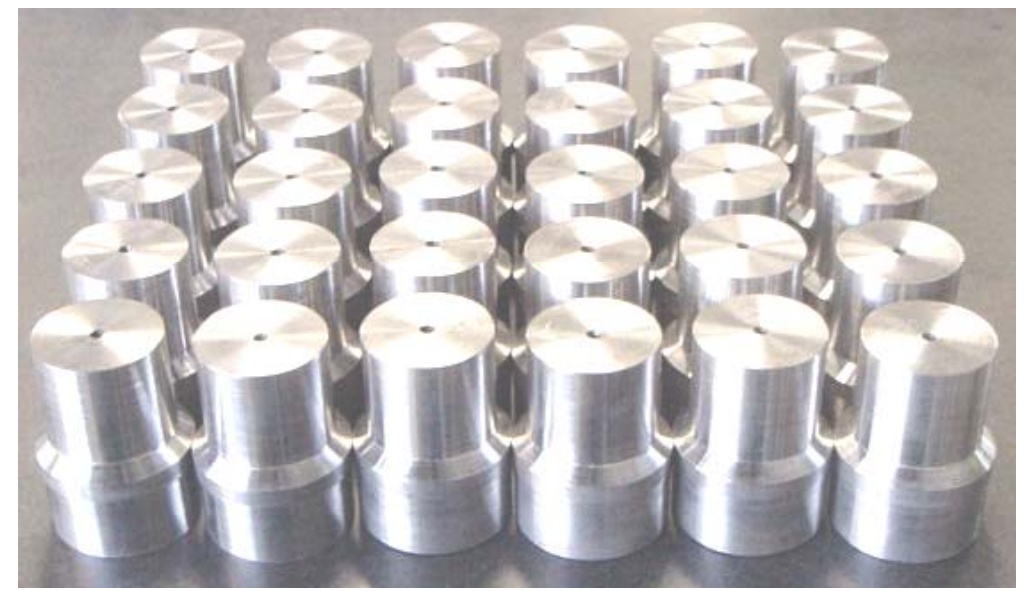

FIGURA 4.3 - Corpos de prova 


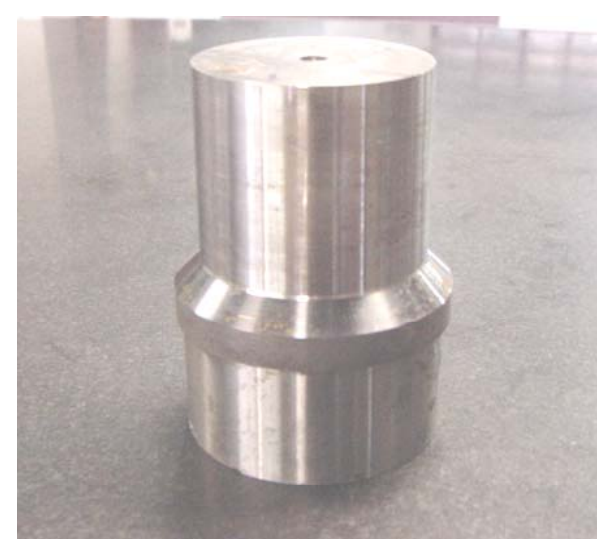

FIGURA 4.4 - Detalhe do corpo de prova

Para a segunda etapa, torneou-se novamente os mesmos 30 corpos de prova em condições de corte suaves, resultando agora em diâmetros de 48,240 mm $\pm 2 \mu \mathrm{m}$. Utilizou-se então, nesta segunda etapa, o sistema proposto e o mesmo procedimento de usinagem e medição dos diâmetros da primeira etapa. Assim, o objetivo dessa segunda etapa foi o de acompanhar os erros dimensionais das peças usinadas usandose o sistema de monitoramento, avaliando-se assim, o desempenho do mesmo. 


\section{Resultados e discussões}

Quanto à avaliação utilizando-se do simulador do processo de torneamento, notou-se perfeita coerência entre os dados gerados no simulador, para as diversas situações, e as informações apresentadas no sistema, tanto na estação SCADA/ WEB Server, quanto nas estações CLIENTES via Internet, através de páginas HTML.

Segundo o procedimento experimental descrito anteriormente, obtiveram-se os seguintes resultados (diâmetros dos 30 corpos de prova):

1. Primeira etapa (sem compensação de desgaste)

- $\mathrm{D}_{\text {inicial }}=50,661 \mathrm{~mm} \pm 2 \mu \mathrm{m}$

- $\mathrm{V}_{\mathrm{c}}=70 \mathrm{~m} / \mathrm{min}, \mathrm{f}=0,1 \mathrm{~mm} / \mathrm{r}, \mathrm{a}_{\mathrm{p}}=0,263 \mathrm{~mm} \mathrm{l}_{\mathrm{c}}=40 \mathrm{~mm}$

- $D_{\text {peça }}=50,136{ }^{+334} \mathrm{~mm}$

- $\mathrm{t}_{\mathrm{c}}($ tempo de corte $)=55 \mathrm{seg}$.

2. Segunda etapa (com compensação de desgaste - pelo sistema)

- $\mathrm{D}_{\text {inicial }}=48,240 \mathrm{~mm} \pm 2 \mu \mathrm{m}$

- $\mathrm{V}_{\mathrm{c}}=70 \mathrm{~m} / \mathrm{min}, \mathrm{f}=0,1 \mathrm{~mm} / \mathrm{r}, \mathrm{a}_{\mathrm{p}}=0,263 \mathrm{~mm} \mathrm{l}_{\mathrm{c}}=40 \mathrm{~mm}$

- $D_{\text {peça }}=47,715{ }^{+27} \mathrm{~mm}$

- $\mathrm{t}_{\mathrm{c}}($ tempo de corte $)=55 \mathrm{seg}$.

- $\mathrm{t}_{\text {comp. }}$ (tempo de compensação) $=3 \mathrm{seg}$.

Para a comparação das duas etapas, obteve-se, para cada corpo de prova usinado, o erro do diâmetro obtido no torneamento $\left(D_{\text {peça }}\right)$ em relação ao diâmetro de especificação $\left(D_{\text {especif }}=D_{\text {inicial }}-2 \cdot a_{p}\right)$. 
Assim, na figura 5.1 tem-se uma comparação entre a usinagem de peças sem a compensação do desgaste da ferramenta de corte $\left(1^{\circ}\right.$ etapa) com a usinagem de peças utilizando-se da compensação realizada pelo sistema proposto ( $2^{\circ}$ etapa), através desse erro (erro $\left.=D_{\text {peça }}-D_{\text {especif }}\right)$.

É possível notar, na curva sem compensação, a evolução do erro dimensional ao longo das peças usinadas, e na outra, com compensação, o "controle" do erro dimensional realizado pelo sistema. Particularmente, na peça 2 os erros dimensionais nas duas etapas são aproximadamente iguais, pois o sistema passa a compensar o desgaste somente à partir da peça 3, após calcular o primeiro PCDD, que no caso seria igual a :

$$
\text { erro }=D_{\text {peça }}-D_{\text {especif }}=D_{\text {peça 2 }}-D_{\text {peça } 1}
$$

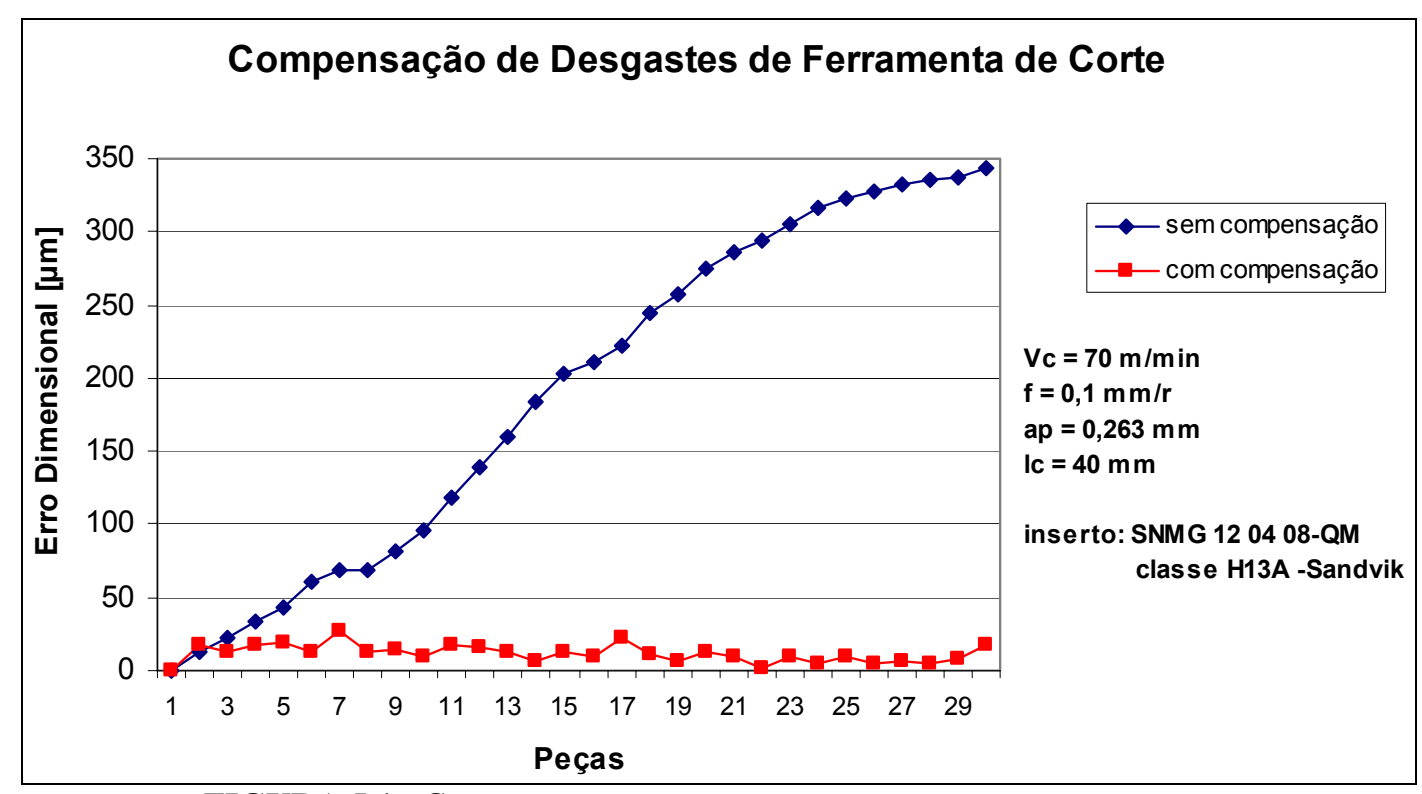

FIGURA 5.1 - Comparação entre torneamentos com compensação e sem.

Nota-se, diante dos resultados obtidos com esse experimento, uma melhora considerável da qualidade dimensional de peças obtida com o sistema proposto de compensação de desgastes de ferramentas de corte. Um lote de peças, cujas dimensões poderiam estar $100 \%$ dentro de qualidade IT13 $(+460 \mu \mathrm{m}$ para uma faixa de diâmetro de mais de 50 a $80 \mathrm{~mm}$, de acordo com a Associação Brasileira de Normas Técnicas), produzidas sem a compensação de desgastes ( $1^{\circ}$ etapa), passaram

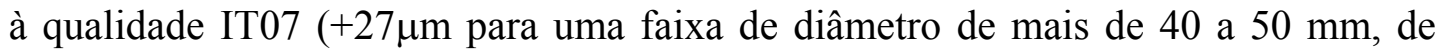
acordo com a ABNT) com a utilização da compensação ( $2^{\circ}$ etapa), usando-se o 
mesmo critério. Ou seja, o sistema foi capaz de produzir automaticamente, sem intervenção do operador, um lote de peças com 100\% delas dentro de qualidade dimensional ISO IT07, na qual sem o mesmo a qualidade seria ISO IT13.

Quanto à qualidade superficial, para não compromete-la, o sistema dependerá do conhecimento do operador na determinação da máxima compensação de desgaste da ferramenta a ser realizada.

Como auxílio na troca de ferramenta, o sistema permite o acompanhamento da compensação de desgaste da ferramenta, indicando o quanto já foi realizado, além de advertir o operador quando alcançada a máxima compensação de desgaste pré configurada. Este mesmo sistema poderia ser capacitado a realizar o controle estatístico de processo, já alimentando uma base de dados e montando, em tempo real, as cartas de controle dimensional de processo.

Nesse experimento, todas as peças do lote foram medidas devido à situação extrema em que a ferramenta foi submetida, que levou a altos desgastes. Assim, pôde-se acompanhar melhor o desgaste sofrido pela ferramenta de corte. Para situações cotidianas, as condições de corte podem ser mais brandas, diminuindo-se o desgaste. Deste modo, pode-se espaçar mais as medições, diluindo-se o tempo de medição em um número maior de peças, propiciando menores influências no tempo de produção. No experimento, realizando-se medições de todas as peça, o aumento de tempo foi de aproximadamente 5,5\% no corte de uma peça. 


\section{Conclusões}

O sistema permitiu que informações on-line do processo de torneamento, bem como informações tecnológicas do torno e de sua produção, pudessem ser acessadas de maneira confiável em uma rede local (via Intranet) e até mesmo em qualquer localidade (via Internet), bastando apenas de um navegador de páginas HTML.

O sistema se mostrou eficiente no monitoramento do estado da ferramenta de corte, tornando automática a compensação de desgastes. Ele foi capaz de produzir automaticamente, sem intervenção do operador, um lote de peças com 100\% delas dentro de qualidade dimensional ISO IT07, na qual sem o mesmo a qualidade seria ISO IT13.

E, finalmente, o sistema permitiu o acompanhamento da compensação de desgaste da ferramenta, realizada por ele mesmo, auxiliando na determinação do momento mais adequado para a troca da ferramenta, garantindo o seu máximo aproveitamento, além de peças produzidas dentro de suas especificações dimensionais e qualidades superficiais. 


\section{Sugestões para trabalhos futuros}

Como sugestões para trabalhos futuros, tem-se, a seguir, melhorias e complementações possíveis de serem realizadas no presente trabalho:

1. implementar, no sistema desenvolvido, a capacidade de realizar medições de diâmetros em mais de um colo.

2. desenvolver sistema automático de alimentação de base de dados e implementação de carta de controle estatístico de processo (CEP).

3. implementar a captação e disponibilização de imagens do processo, com atualizações de imagens automáticas. 


\section{ANEXO}

\section{Anexo A - Programa CN (utilizando um LVDT para medições)}

A seguir, tem-se o programa utilizado para o torneamento, tendo um LVDT como sensor de medição das peças usinadas.

MSG("Monitoramento por LVDT")
;diâmetro de especificação
N10 R1=50,00
;velocidade de avanço de setpoint [mm/r]
N20 R10=0,1
;velociade de corte de setpoint [m/min]
N30 R11=70,0
;diâmetro bruto da peça [mm]
N40 R12 $=50,263$
;comprimento de corte [mm]
N50 R15=40,00
;tolerancia + [mm $]$
N60 R16=0.050
;tolerancia - [mm $]$
N70 R17=0.050
;linha final do ciclo
N80 R20 $=19$

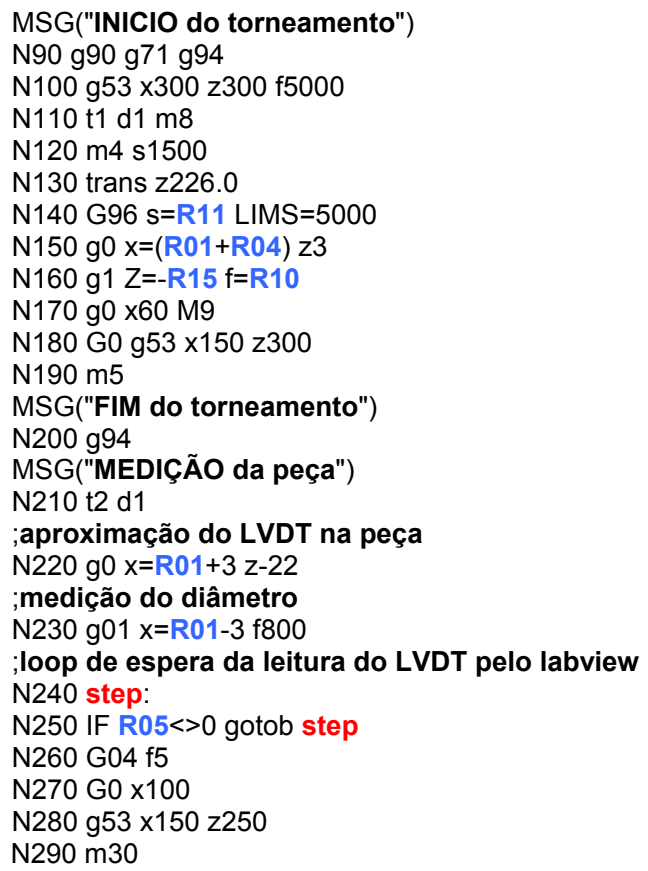




\section{REFERÊNCIAS BIBLIOGRÁFICAS}

\section{Referências Citadas}

AGOSTINHO, O. L. (1996). Integração Estrutural dos Sistemas de Manufatura como Pré Requisito de Competitividade. Campinas. 265p. Tese (Livre Docência) - Universidade Estadual de Campinas.

ALLIANCE for Converging Technologies (1999). Internet Enabled Supply Chain Management: Inter-enterprise Fusion.

ASSOCIAÇÃO BRASILEIRA DE NORMAS TÉCNICAS (1961). NB - 86 : Norma de Sistema de Tolerâncias e Ajustes. Rio de Janeiro.

AUTOMACAO.NET (2001). SCADA/ HMI. http://www.automacao.net/scada.htm (4 mar.)

BLUM, T.; SUZUKI, I.; INASAKI, I. (1988). Development of a Condition Monitoring System for Cutting Tools Using an Acoustic Emission Sensor. Bulletin of theJapan Society of Precision Engineering, v. 22, n.4, p.301-8.

BUZATTO, W. T., (1999). Open CNC. Controle \& Instrumentação, p.70-71, jan.

BYRNE, G. et al. (1995). Tool condition monitoring - the status of research and industrial application. Annals of the CIRP, v. 44, n.2, p.541-67.

CHEN, S. et al (1998). Error source diagnostic using a turning process simulator. Transactions ASME Journal of Manufacturing Science and Engineering, 120, p. 409-16.

COELHO, R. T.; BRAGHINI Jr., A.; MARTINS, R. O. (1999). Curso de programação e operação em máquinas-ferramentas CNC - nivel básico. São Carlos. 83p. Apostila Escola de Engenharia de São Carlos, Universidade de São Paulo.

COUNCIL of Logistics Management (2000). The Mission Section (on-line). http://www.clm1.org/mission.html (4 jul).

DANEELS, A.; SALTER, W. (1999). What is SCADA?. Internacional Conference on Accelerator and Large Experimental Physics Control Systems. p.339-43.

DEGARMO, E. P.; BLACK, J. T.; KOHSER, R. A. (1997). Materials and processes in Manufacturing. USA, Prentice-Hall.

DINIZ, A. E.; PIGARI, A. (1995). Monitoramento do processo de torneamento em desbaste via emissão acústica. Congresso Brasileiro de Engenharia Mecânica-COBEM. 
DINIZ, A. E.; MARCONDES, F. C.; COPPINI, N. L. (1999). Tecnologia da Usinagem dos Materiais. São Paulo, MM editora.

DU, R.; ELBESTAWI, M. A.; WU, S. M. (1995). Automated monitoring of manufacturing process, part 1: monitoring methods. ASME Journal of Engineering of Industry, v.117, n.2, p.121-32.

FERRARESI, D. (1990). Fundamentos da Usinagem dos Metais. $8^{\circ}$ reimpressão. São Paulo, Edgard Blücher.

GATES, B. (1999). A Empresa na Velocidade do Pensamento. Ed. Companhia das Letras.

GERMAIN, G. L.; CLARKE, T. W. (1998). A.R.T. of supervisory control and data acquisition. In: INTERNATIONAL PIPELINE CONFERENCE, Calgary, 1998. Proceedings, Fairfield, ASME, p 895-902.

GIFFORD, C.; DUENAS, M. (1998). Industrial Web. Industrial Computing, v. 17, Issue 4, p. 25-29, April.

GONÇALVES FILHO, E. V. (1994). Comando Numérico de Máquinas Ferramentas. São Carlos. 45p. Apostila - Escola de Engenharia de São Carlos, Universidade de São Paulo.

GONÇALVES FILHO, E. V. (1998). Introdução à Robótica Industrial. São Carlos. 47p. Apostila - Escola de Engenharia de São Carlos, Universidade de São Paulo.

GRAHAM, T. S. (1989). Monitoring the unmanned machining systems. FMS Magazine,v.3, n.7, p. 127-31.

HONEYWELL (2000). http://www.iac.honeywell.com-plantscape.com (4 mar).

IAS (2000). The International Society for Measurement and Control. http://www.iasnet.com.br (4 maio).

INTECH Brasil (2000). http://www.netsite.com.br/intechbrasil/capa.htm (4 maio).

INTECH Brasil (1998) Conai : especialistas apontam as tendências da automação e da tecnologia da informação. Revista InTech Brasil, ano 1, n ${ }^{\circ}$ 4, p. 38-41, maio.

INTERBUSCLUB (2001). http://interbusclub.com (4 jun).

INTERNACIONAL Journal of Electrical Power \& Energy Systems (2000). Wide area network performance study of a distribution management system. International Journal of Electrical Power \& Energy Systems, v. 22, Issue 1, p. 9-14, January.

ISA - The Instrumentation, Systems, and Automation Society (2000). Sensors Guide. http://www.isa.org ( 4 mar).

JEMIELNIAK, K. (1999). Comercial tool condition monitoring systems. The Internacional Journal of Advanced Manufacturing Technology, v.15 , n. , p.711-21. 
LI, X. (2001). Real-time prediction of workpiece errors for a CNC turning centre, part 1. measurement and indentification. The Internacional Journal of Advanced Manufacturing Technology, v.17, n. , p.649-53.

LIMA, E.(2000). Sistemas integrados na era do e-Business - Como ser competitivo no novo milênio dominado pela Internet. Revista InTech Brasil, p. 34-40, novembro.

MACHADO, A. R.; SILVA, M. B. (1999). Usinagem dos Metais. Uberlância 223p. Apostila - Laboratório de Ensino e Pesquisa em Usinagem/ Departamento de Engenharia Mecânica, Universidade Federal de Uberlândia.

MACIEL, C. D., RITTER, C. M., (1998), TCP/ IP Networking in process control plants. Elsevier Science Ltda, v.35, n. 3-4, p. 611-14.

MARINO, A. F., (2000). Controle baseado em PC: uma tecnologia inevitável. Revista InTech Brasil, p. 30-32, abril.

MATHEW, J.; DAN, L. (1990). Tool wear and failure monitoring techniques for turning: a review. Internacional Journal of Machine Tools Manufacturing, v.30, n.4, p.579-98.

MEIRELES, G. S. C. (2000). Desenvolvimento de sistema de aquisição de dados em operações de usinagem visando o monitoramento de linhas ou células de produção. São Carlos, 2000. 97p. Dissertação (Mestrado) - Escola de Engenharia de São Carlos, Universidade de São Paulo.

MODERN Metal Cutting - a practical handbook.

OPC Foundation (2001). OPC Techical Overview. http://www.opcfoundation.org (4 mar).

PIRES, S. R. I.; MUSETTI, M. A. (2000). Logística Integrada e Gestão da Cadeia de Suprimentos. Fábrica do Futuro, Ed. Banas, p. 65-76, dezembro.

ROCHA, I. R. (1998). Redes de comunicação industriais: solução ou opção ?. Revista InTech Brasil, ano 1, n. 4, p. 26-30, maio.

ROCKWELL (2000). http://www.software.rockwell.com (4mar).

SANTOCHI, M. et al. (1997). A sensor-integrated tool for cutting force monitoring. Annals of the CIRP, v. $46, \mathrm{n} .1, \mathrm{p} .49-52$.

SIEMENS (2000). http://www.siemens.com (4 mar).

SOUZA, A. J.(1999). Desenvolvimento e implementação de funções de automação inteligentes num torno CNC utilizando técnicas de monitoramento por emissão acústica. São Carlos,. 82. Tese (Mestrado) - Escola de Engenharia de São Carlos, Universidade de São Paulo.

TANENBAUM, A. S.(1997). Redes de computadores. Ed. Campus Ltda, Rio de Janeiro, Brasil.

TEK Soft Consulting (1999). SCADA Introduction. http://www.iinet.net.au/intro.html (25 aug). 
WOJCIK, M., RANGANATHAN, G.(2000). Ethernet and the Web gang up on process monitoring and control. InTech - The Internacional Journal for measurement and control, p. 48-51, September.

WONDERWARE (2000). http://www.microsoft.com/industry/man (4 mar).

ZAMPRONHA, R. S.(1998). Uso da intranet/ internet para supervisão e controle de processos. Revista InTech Brasil, p. 45-50, novembro.

\section{Referências Consultadas}

AB (2001). http://www.ab.com/catalogs/b113/comm/overview.html (4 jun).

DINIZ, A. E., Pigari, A. (1996). Monitoramento do desgaste da ferramenta no processo de torneamento usando emissão acústica. RBCM Journal of the Brazil Society Mechanical Sciences, v.XVIII, n.3, p. 227-38.

ELIPSE Softwares (2001). Sistema de Supervisão via Internet. http://www.elipse.com.br (4 abril).

FRANCO, E. F.(1999). As novas tecnologias para Gerenciamento de Energia Elétrica. Controle \& Instrumentação, p. 63-66, março.

INTELLUTION (2000). http://www.intellution.com (4 mar).

KLUFT, W. (1994). A monitoração dos processos reduz custos e desperdícios. Máquinas e Metais, Ed. Aranda, outubro, p. 60-80.

LINS e SILVA, C. K., Lima, R. (2000). Exemplo de um MES e porque o ERP não atende ao chão-de-fábrica (parte I). Revista InTech Brazil, p. 63-74, novembro.

MICROSOFT (2000). http://www.microsoft.com/industry/man (4 mar).

NATIONAL Instruments (2000). http://www.ni.com (4 mar).

NUMA (Núcleo de Manufatura Avançada) - EESC/USP (2000), http://www.numa.org.br/conhecimento/index.html (4 maio).

OLIVEIRA, J.F.G.; MEIRELES, G.S.C.; SOARES, D.D. (2000). Monitoramento e otimização no chão de fábrica via diagnóstico remoto. Máquinas e Metais, Ed. Aranda, p.72-87, setembro.

SMAR Catálogo - SYSTEM302 (2000). O Novo Paradigma de Gerenciamento e Controle. p. 4

STEIDINGER, M. ( 1999 ). Extend the plant with an MES. Industrial Computing, v.18, Issue 2, p. 32-34, February.

UNISOFT (2000). http://www.unisoft.com.br (4 mar). 
VARHOL, P. (1998) Linking the enterprise. Industrial Computing, v.17, Issue 4, p.30-32, April.

VELAZQUEZ, D. (1998). Data connection. Industrial Computing, v.17, Issue 4, p.38-39, April. 